\title{
Study on Surface Tension and Evaporation Rate of Human Saliva, Saline, and Water Droplets
}

\author{
Tian Zhang \\ West Virginia University
}

Follow this and additional works at: https://researchrepository.wvu.edu/etd

\section{Recommended Citation}

Zhang, Tian, "Study on Surface Tension and Evaporation Rate of Human Saliva, Saline, and Water Droplets" (2011). Graduate Theses, Dissertations, and Problem Reports. 2271.

https://researchrepository.wvu.edu/etd/2271

This Thesis is protected by copyright and/or related rights. It has been brought to you by the The Research Repository @ WVU with permission from the rights-holder(s). You are free to use this Thesis in any way that is permitted by the copyright and related rights legislation that applies to your use. For other uses you must obtain permission from the rights-holder(s) directly, unless additional rights are indicated by a Creative Commons license in the record and/ or on the work itself. This Thesis has been accepted for inclusion in WVU Graduate Theses, Dissertations, and Problem Reports collection by an authorized administrator of The Research Repository @ WVU. For more information, please contact researchrepository@mail.wvu.edu. 


\title{
Study on Surface Tension and Evaporation Rate of Human Saliva, Saline, and Water Droplets
}

\author{
Tian Zhang
}

Thesis submitted to the

College of Engineering and Mineral Resources

at

West Virginia University

In partial fulfillment of the requirements for the degree of

Master of Science

in

Mechanical Engineering

Ismail B. Celik, Ph.D., Chair

Alejandro Posada, Ph.D.

Hailin Li, Ph.D.

Jagannath Nanduri, Ph.D.

Mechanical and Aerospace Engineering Department

Morgantown, West Virginia

2011

Keywords: saliva, droplet, surface, evaporation 


\section{ABSTRACT \\ Study on Surface Tension and Evaporation Rate of Human Saliva, Saline, and Water Droplets}

\section{Tian Zhang}

Cough, sometimes shedding plenty of germs and virus, is the human body's way of cleaning the breathing passages. The virus and germs spread rapidly through ambient air among humans and may cause infection. To reduce ultimately the infections caused by the germs and virus contained in human saliva droplets, it is necessary to understand the vaporization process of human saliva and its role on virus transmission. Virus-laden droplets, shed by an infected person through coughing and sneezing, evaporate until becoming droplet nuclei which will remain airborne for a long time and can infect other people. In other words, evaporation rate is an important factor affecting the transmission of virus and germ contained in human saliva. Accordingly, the present research focuses the evaporation of human saliva droplets, the carriers of virus. Experiments and numerical methods are utilized in this research to study surface tension and evaporation rate. In order to determine which component influences the surface tension and evaporation rate of droplet, different solutions are evaluated. Capillary tubes and a high performance camera are used for measuring the surface tension of these solutions. Evaporation measurements were carried out by taking pictures of droplets hanging vertically from a thin needle or laying on a flat surface. These images were later postprocessed using an in-house developed Matlab code to obtain the evaporation rate. A more general evaporation equation was derived to determine numerically the evaporation rate of the different solutions and then used to analyze the evaporation process of multi-component droplets. Eventually, the numerical results compare 
reasonably well with the experimental measurements. These findings will help understand the role of temperature and relative humidity of ambient air in virus transmission. 


\section{Acknowledgements}

First and foremost, I would like to acknowledge and extend my most heartfelt gratitude to my advisor, Dr. Ismail B. Celik. He encouraged me vitally from the start to the end and has given me opulently inestimable trust and advice, without which I could not complete my research. I appreciate to Dr. Alejandro Posada, who was guiding me most of the time, without any impatience. I am grateful to my other committee members, Dr. Jagannath Nanduri and Dr. Hailin $\mathrm{Li}$, for all their constant reminds and contributions. I would like to broaden my appreciation to the other members of the CFD group of CEMR in WVU, for their help and inspiration in my life and study. Specially thank John, who I never met but gave me persistent help through email. I would also like to thank the help and support from my other friends, especially Lina in Civil Engineering Lab who gave me most useful tips of performing experiments. Lastly, I would like to thank my parents, for their patience and efforts of raising me all the past 24 years, and their incessantly self-giving and categorical love. 


\section{Table of Contents}

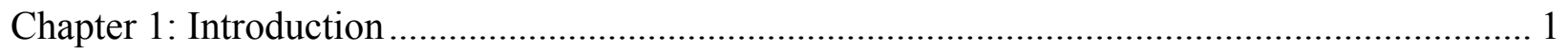

1.1 Importance of droplets on the transmission of infectious diseases ................................. 1

1.2 Effect of droplet properties on evaporation.............................................................. 2

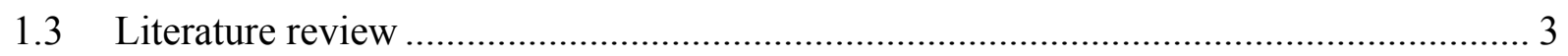

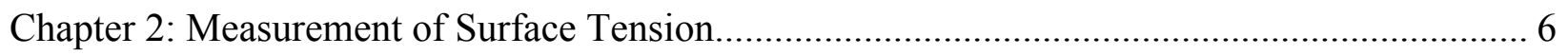

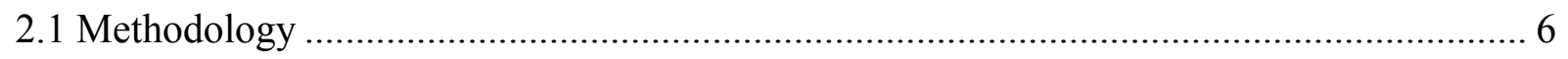

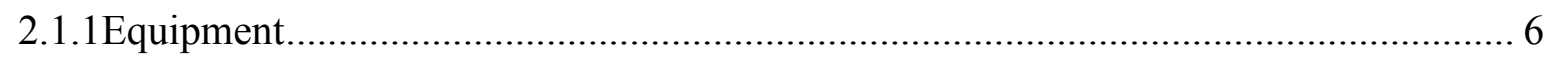

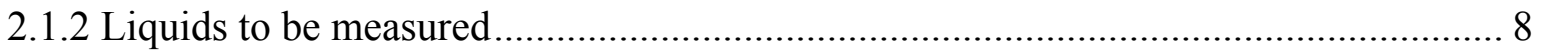

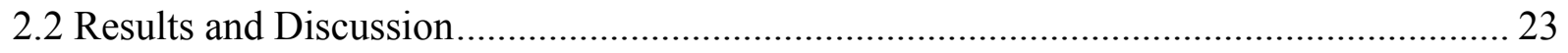

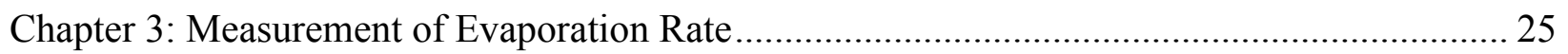

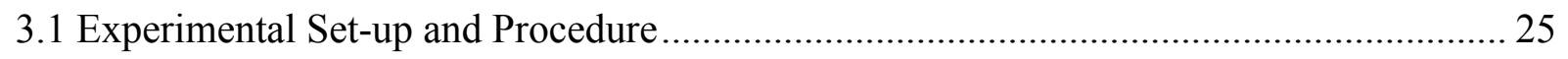

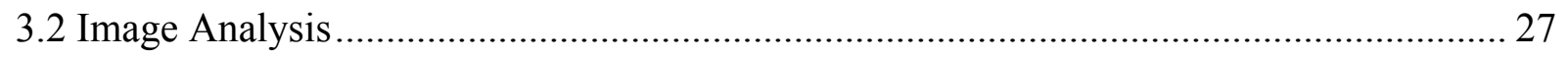

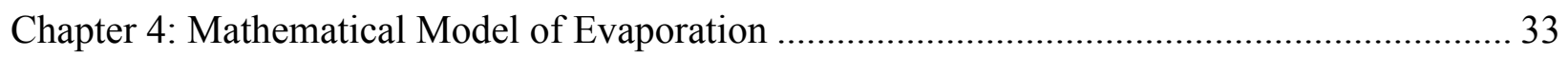

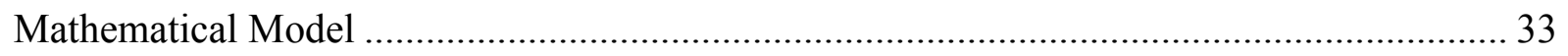

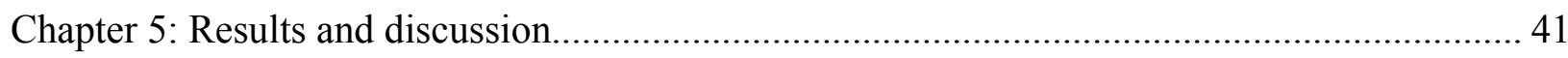

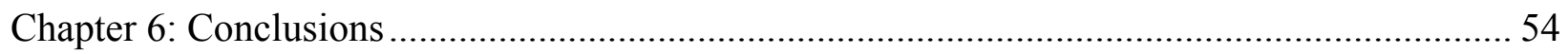

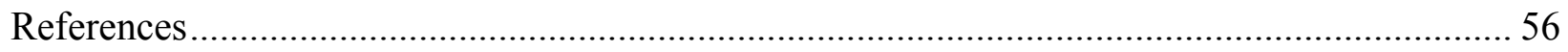

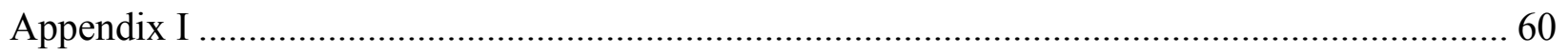

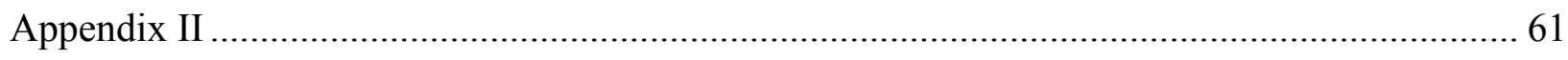

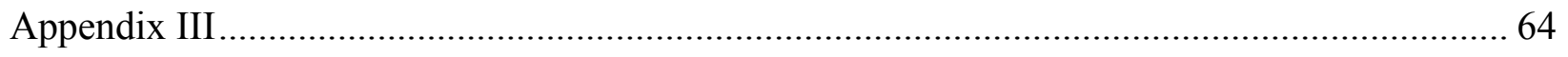




\section{List of Tables}

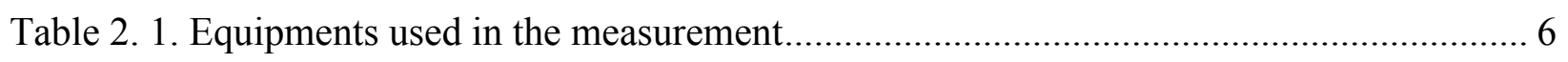

Table 2. 2 Measured mass of water and $\mathrm{NaCl}$ for three concentrations of $\mathrm{NaCl}$ water solutions .. 9

Table 2. 3 Measured data of mass of water and glucose for two concentrations of glucose water

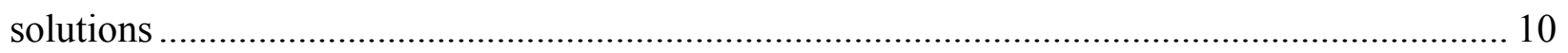

Table 2. 4 Measured data of mass of water and milk of the two concentrations of milk water

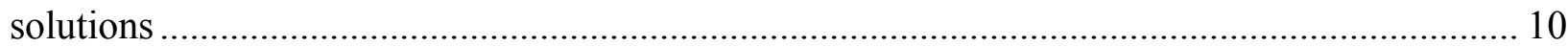

Table 2. 5 Measured mass data of three concentrations of $\mathrm{NaCl}$ solutions with fixed volume $2 \mathrm{~mL}$

Table 2. 6 Results of densities of $\mathrm{NaCl}$ solutions of the three methods ....................................... 13

Table 2. 7 Measured mass and calculated density of human saliva............................................... 13

Table 2. 8 Mass concentration of inorganic components of human saliva ................................... 14

Table 2. 9 Mole number in $1 \mathrm{~mL}$ and density information of salts in human saliva ..................... 15

Table 2. 10 Major components of proteins in human saliva........................................................ 16

Table 2. 11 Substances used in the calculation of density of $1 \mathrm{~mL}$ human saliva........................ 16

Table 2. 12 The measurement data and calculation of density of solid part of human saliva ...... 19

Table 2. 13 Calculation of density of human saliva................................................................... 20

Table 2. 14 Difference of human saliva density of the two methods .......................................... 20

Table 2. 15 Results of surface tension of each kind of liquid...................................................... 23

Table 4. 1 Composition of human saliva in the mathematical solution.........................40

Table 5. 1 Comparison of numerical results: Matlab vs. experiments........................................... 47

Table 5. 2 Evaporation rate of human saliva droplet: experiment vs. numerical results ............... 48

Table 5. 3 Evaporation rate of other kinds droplets: experiment vs. numerical results................. 48

Table 6. 1 The concentration of components of artificial human saliva........................55 


\section{List of Figure}

Figure 2. 1 Surface Tension Measurement: Red Tube I.D. $=1.12 \mathrm{~mm}$, O.D. $=1.47 \mathrm{~mm} \ldots \ldots \ldots \ldots . .7$

Figure 2. 2 Surface Tension Measurement: Yellow Tube I.D. $=0.96 \mathrm{~mm}$, O.D. $=1.38 \mathrm{~mm} \ldots \ldots \ldots .8$

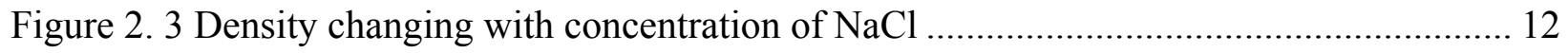

Figure 2. 4 Samples of the human saliva solid part on glasses............................................ 18

Figure 2. 5 The sample of image analysis of surface area of the solid part............................. 19

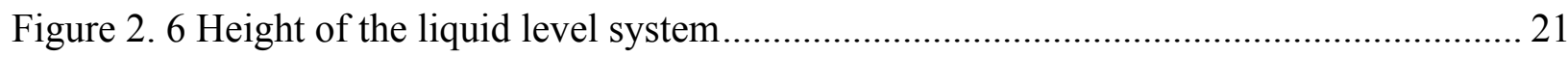

Figure 2. 7 Contact angle by Matlab: (a) Actual photo of the boundary, (b) Maniscus boundary

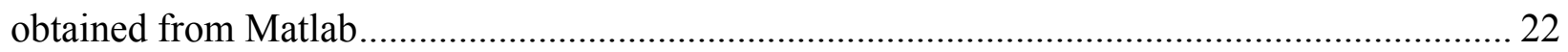

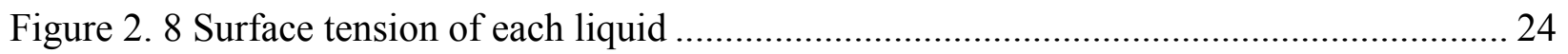

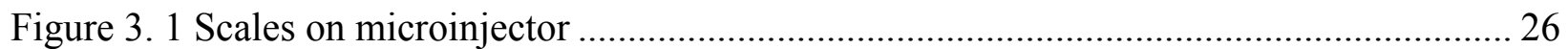

Figure 3. 2 Photo studio used in the experiment of evaporation rate ..................................... 27

Figure 3. 3 Pictures of droplet on the needle: (a) Photo of droplet on the needle, (b) Binary photo

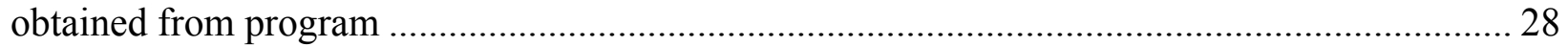

Figure 3. 4 Pictures of droplet on the surface: (a) Photo of droplet on the needle, (b) Binary photo

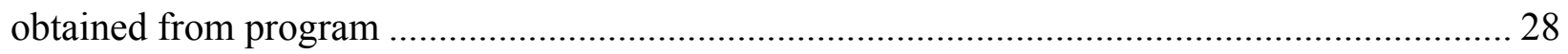

Figure 3. 5 The experimental result of evaporation rate distilled water droplet: Surface area vs.

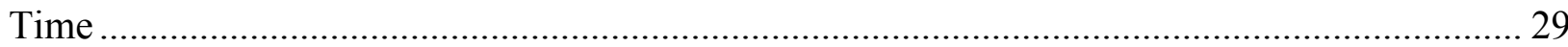

Figure 3. 6 Experimental results: saline water and human saliva droplets evaporation: Surface

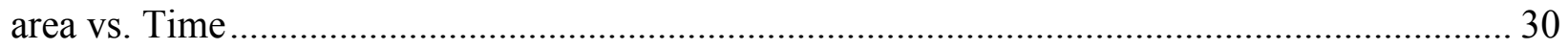

Figure 3. 7 The experimental result of evaporation of $\mathrm{NaCl}$ water solution droplets: Surface area

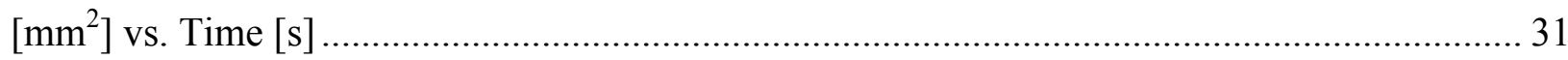

Figure 3. 8 The experimental result of evaporation of human saliva droplets: Surface area $\left[\mathrm{mm}^{2}\right]$

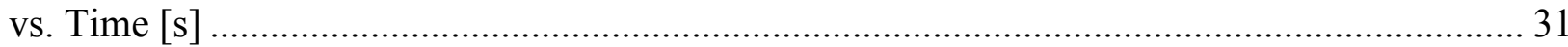

Figure 3. 9 Experimental results of semi-sphere Human saliva Droplets evaporation under different environmental temperature and relative humidity: Surface area $\left[\mathrm{mm}^{2}\right]$ vs. Time $[\mathrm{s}] \ldots . .32$ Figure 5. 1 Water droplet evaporation: Surface area vs. Time ............................................ 41

Figure $5.20 .3 \% \mathrm{NaCl}$ water droplet evaporation: Surface area $\left[\mathrm{mm}^{2}\right]$ vs. Time $[\mathrm{s}\} \ldots \ldots \ldots \ldots \ldots . . . . . .42$ Figure 5. 3 Results of Evaporation of different droplets under various environmental

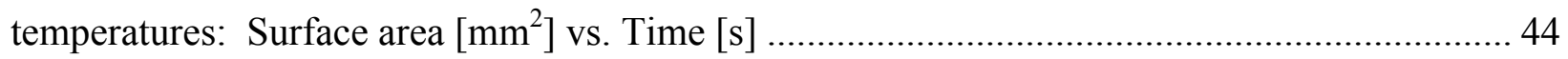


Figure 5. 4 The evaporation results of human saliva droplets at different temperature and relative

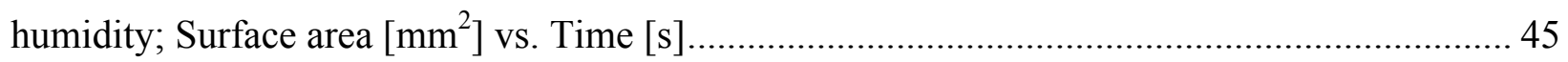
Figure 5. 5 Evaporation of human saliva droplets under different environmental temperature,

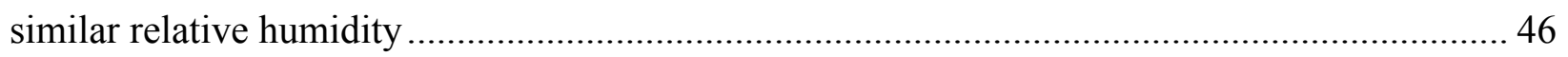
Figure 5. 6 Evaporation of coffee and $0.9 \% \mathrm{NaCl}$ water solution droplet: $\mathrm{Temp}=22^{\circ} \mathrm{C}, \mathrm{RH}=33 \%$ ……

Figure 5. 7 Numerical results of human saliva droplets under different temperature, same relative

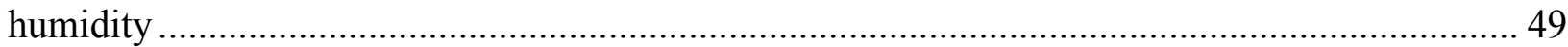

Figure 5. 8 Numerical results of human saliva droplets under different relative humidity, same

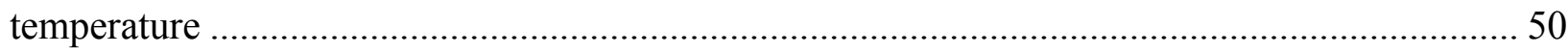

Figure 5. 9 Numerical results of evaporation of different droplets.............................................. 51 Figure 5. 10 Numerical solution of evaporation of artificial human saliva evaporation vs. Human

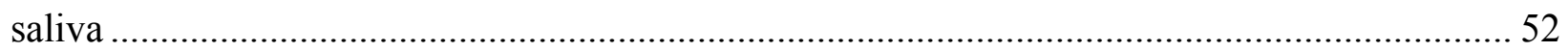

Figure 5. 11 Human saliva droplet evaporation: temperature $\left[{ }^{\circ} \mathrm{C}\right]$ vs. time $[\mathrm{s}] \ldots \ldots \ldots \ldots \ldots \ldots \ldots \ldots \ldots \ldots . . .52$ 


\section{Nomenclature}

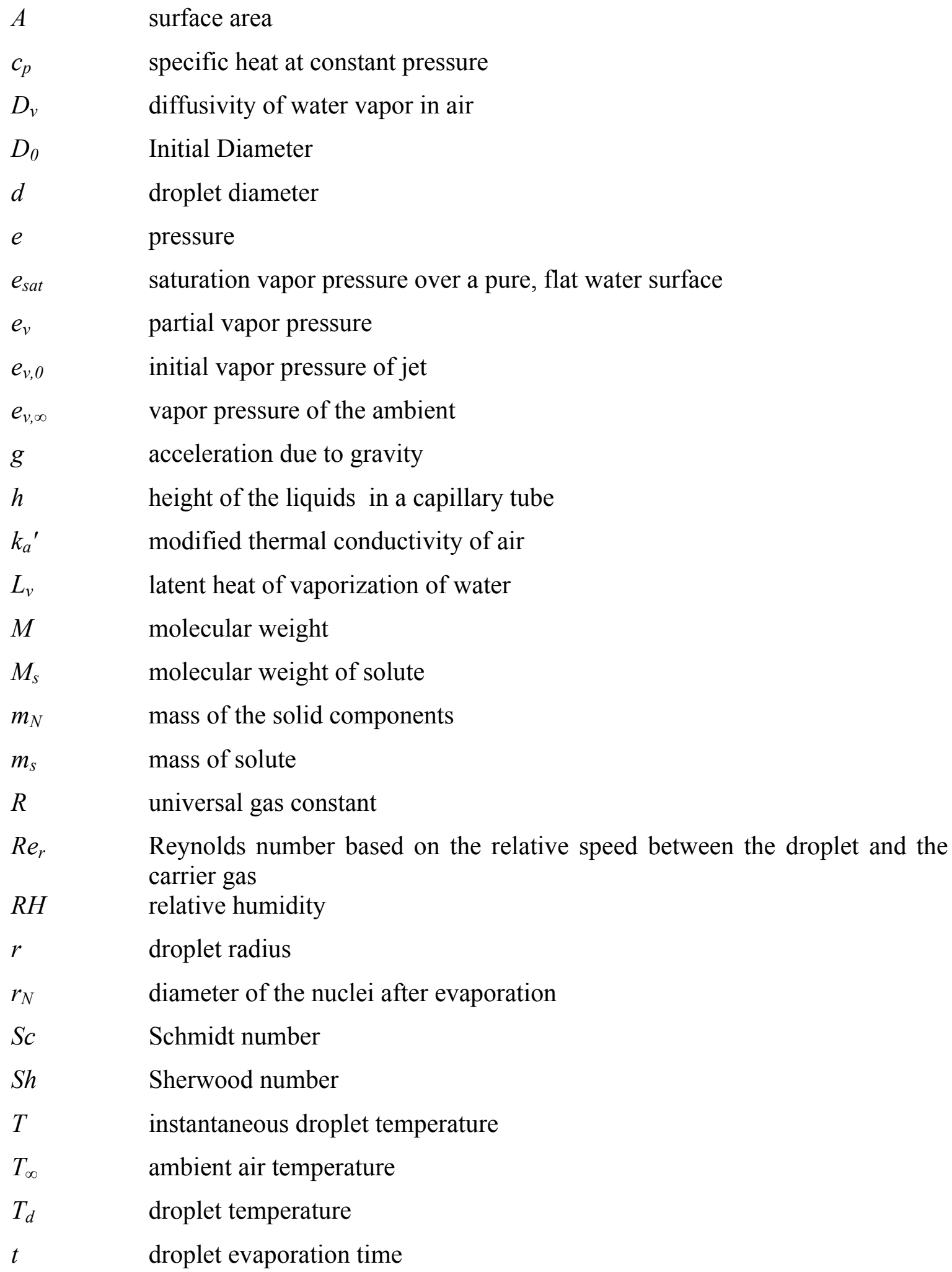




\title{
Greek Symbols
}

\author{
$\Phi_{s} \quad$ practical osmotic coefficient \\ $\theta \quad$ contact angle \\ $v \quad$ number of ions into which a salt molecule dissociates \\ $\rho \quad$ density of liquids \\ $\rho_{A} \quad$ density of specie A \\ $\rho_{s} \quad$ mixture density \\ $\rho_{w} \quad$ water density \\ $\sigma \quad$ surface tension \\ $\sigma_{w} \quad$ surface tension of water to the air \\ $\sigma_{s w} \quad$ surface tension of salt water solution to the air \\ $\omega_{A} \quad$ mass fraction of specie A \\ $\omega_{A, \infty} \quad$ mass fraction of specie $\mathrm{A}$ in the free stream \\ $\omega_{A, S} \quad$ mass fraction of specie $\mathrm{A}$ at the droplet surface
}




\section{Chapter 1: Introduction}

\subsection{Importance of droplets on the transmission of infectious diseases}

Influenza virus affects millions of people every year (The New York Times, 2009). According to the World Health Organization (WHO), more than 16,455 people died and millions of people were affected in 2009 from influenza H1N1 (Swine flu) (Centers for Disease Control and Prevention - CDC, 2009). More research should be done to avoid and restrain the spread of viruses and germs, and thereafter, less people will be affected and killed by influenza. According to the $\mathrm{CDC}$, avian influenza is contagious among birds (i.e., chickens, ducks, and turkeys) and can make some domesticated birds sick and die. Infected birds secrete influenza virus in their saliva, nasal secretions, and feces. Contacting with those contaminated secretions or excretions, some of susceptible birds might be infected (CDC, 2009). Although, typically these viruses do not affect human beings and there is no risk for us; there are increasing confirmed cases of human infection from several subtypes of avian influenza infection appeared increasingly (CDC, 2009). Therefore, the research on the control of the influenza virus is a matter of great urgency.

Among the paths of virus transmissions, the droplets generated by cough are important path. The breathing flow may transit the contagious secretion from the human body to the environment ( Weber \& Stilianakis, 2008). That is to say, the viruses and the germs from others might be transmitted into one's body by breathing and one can also expel viruses and germs to the environment. When people cough or sneeze, human saliva droplets will be sprayed; therefore, the human saliva is an important carrier of the influenza virus and should be studied. Additionally, there are millions of droplets included in a cough or sneeze (Duguid, 1946), and the transmission of the virus will happen when a cough or sneeze reaches another person. The 
temperature, salinity and the constituents of the droplet are the properties that determine the droplet characteristics (i.e., surface tension, evaporation rate) of the droplets. In order to significantly reduce the transmission of the infectious virus by airborne droplets, the droplet characteristics should be understood.

There are several ways of transmission of virus and germs: (1) Direct contact with infected individuals; (2) Indirect contact with contaminated objects; (3) Inhalation of virus-laden aerosols; (4) inhalation or contact with large droplets. Considering the point of indirect contact with contaminated objects, those droplets (Diameter $>5 \mu \mathrm{m}$ ) are the important source of infection, because they can travel and reach up to $2 \mathrm{~m}$ and fall on the objects and contaminate them. Hence, in this research, comparatively large droplets (diameter up to $1 \mathrm{~mm}$ ) are studied, while small droplets (diameter $<0.5 \mathrm{~mm}$ ) are not included in the research.

\subsection{Effect of droplet properties on evaporation}

Viruses are shed by an infected person through coughing and sneezing and the water in the droplets of the cough and sneeze starts to evaporate. In case the saliva evaporates speedily, the droplets will remain airborne and not fall down to the ground. Anyone passing by and inhaling these droplets may be infected. Evaporation is important because it reduces the droplet diameter, and therefore the time that the droplets remain airborne. A water droplet of $0.17 \mathrm{~mm}$ diameter, if it is generated by cough or sneeze in dry air (relative humidity $=0$ ), the droplet will fall $2 \mathrm{~m}$ in $3 \mathrm{~s}$, and if the surrounding air is not dry and the evaporation is slower, the droplet will settle slower (Wells, 1934). Furthermore, Nicas et al. (2005) also commented that evaporation process also affected the final size of the droplet. In this case, the evaporation is important, because it determines how fast the droplet settles and what the final size of the droplet is,. Therefore, the 
droplet evaporation is an important factor which can influence the influenza transmission, and it is considered the main topic in this research. Generally, the evaporation rate of droplet is affected significantly by the droplet properties (e.g., surface tension, latent heat, salinity), and surrounding environment conditions (e.g., temperature, relative humidity, and wind velocity). This study will focus on how the droplet constituents and the environmental conditions influence the evaporation rate of water, saline, and human saliva droplets.

\subsection{Literature review}

Extensive experiments of water droplet, salt water droplet, and human saliva droplet have been conducted during the last decades. Investigation of the evaporation (Ranz \& Marchall, 1952a) of distilled water droplet was examined based on the energy and mass transfer at low Reynolds numbers. Independent correlations of heat and mass transfer rates were obtained by measuring the drop temperatures measured with $0.127 \mathrm{~mm}$ thermocouples. The diameter of the drops ranged from 0.06 to $0.11 \mathrm{~cm}$. The experiment was performed in still dry air under the environmental temperature of $24.9^{\circ} \mathrm{C}$ and the temperature of the droplet was $9.11^{\circ} \mathrm{C}$. In the experiment, photomicrographs were taken when the droplet was held by a feed capillary with a $0.127 \mathrm{~mm}$ manganin-constantan thermo element junction at its center. According to their results, a $0.1 \mathrm{~cm}$ diameter water droplet would take about 780 seconds to evaporate under those environmental conditions. Also, the results show that the results predicted by their model agreed well with experimental data.

Moyle et al. (2006) investigated the evaporation of small diameter (from $36 \mu \mathrm{m}$ to $50 \mu \mathrm{m}$ ) water droplets. An electrodynamics particle trap was utilized to examine the evaporation of individual 
high-purity water droplets, diameter ranged from 15 to 50 microns. The properties of the gaseous environment were: temperature around $-43^{\circ} \mathrm{C}$, dew point temperature around $-33^{\circ} \mathrm{C}$ under the pressure around $59.2 \mathrm{kpa}$. In this study, according to the information provided in that table, the relative humidity the environment around each droplet was calculated by using Magnus-Tetens approximation ( Redmond, 2007) and it is $36 \%$. In the theoretical analysis, the mass rate of change of a water droplet in a steady state vapor field (Pruppacher \& Klett, 1978) was used to predict the diameter change with time. The results obtained from the experiments and the theoretical model show that the small water droplet evaporation can be predicted by using that numerical method.

Pyung et al. (1968) performed measurements of water droplet evaporation rates. In these experiments, water droplets were supported by two methods: a $0.18 \mathrm{~mm}$ diameter Fenwal thermistor and a $40-\mu \mathrm{m}$ diameter glass fiber with a beaded tip. A microscope was used for the photographic records. The results agreed with the quasi-stationary prediction from Maxwell's treatment (Fuks, 1959) that the rate of change of the evaporating droplet diameter should be inversely proportional to the droplet diameter (Equation 1):

$$
\frac{d m}{d t}=-4 \pi D_{v}\left(C_{0}-C_{\infty}\right)
$$

where $m$ is the mass of the droplet, $t$ is time, $r$ is the radius of the drop, $D_{v}$ is the diffusion coefficient of the water in air, $C_{0}$ is the saturated vapor concentration at the surface of the droplet, and $C_{\infty}$ is the ambient vapor concentration.

John Redrow (2009) developed a numerical model for the evaporation of human saliva droplets expelled by a cough or sneeze. Also, he developed a model to simulate the transport of a sputum 
droplet within a jet of air, representing a human cough. FLUENT was used to perform simulations of an experimental setup at the Morgantown NIOSH facility. A prediction of a human producing multiple, consecutive coughs within this room was simulated through the use of FLUENT, as well. In these simulations, small particles were injected into the room by the source of the cough, and their trajectories were tracked all the time. The calculated particle dispersion within the room was then compared to experimental results. In the experiment, the author is focusing more on the moving saliva droplet, and the droplet sizes ranged from 1.5 to $1500 \mu \mathrm{m}$. And then the droplet size should be very small (ranged from 1.5 to $1500 \mu \mathrm{m}$ ). In the first part of the study, it was proven by John Redrow to be quite accurate at predicting the properties of binary aqueous solution droplets containing either sodium chloride, glucose, or bovine serum albumin, but for ternary or higher order solutions, the result predicted does not match with experiment results. In the second part of the study, the transmission of the droplets generated by cough within a room was simulated. 


\section{Chapter 2: Measurement of Surface Tension}

In this chapter, the methodology of performing the measurement of surface tension is introduced, including the measured liquids, equipment, and procedure of measurement in the experiment. Afterwards, the results and discussion are provided.

\subsection{Methodology}

\subsubsection{Equipment}

Table 2.1 shows all the equipment used in these measurements. As showing in Table 2.1, electrical balance was used to measure the mass of water, salt, etc; Tencor Alpha-Step 200 was used to measure the thickness; Finnipipette II was used to measure the volume of liquid; Canon camera, with Tokina lense, was used to take images; capillaries were used in the measurement of surface tension.

Table 2. 1. Equipments used in the measurement

\begin{tabular}{|c|c|c|c|}
\hline Equipment & Range & Resolution & Manufacturer \\
\hline $\begin{array}{l}\text { Electrical balance - AdventurerTM } \\
\text { Pro AV264 }\end{array}$ & $0-100 \mathrm{~g}$ & $0.001 \mathrm{~g}$ & $\begin{array}{l}\text { OHAUS, Pine Brook, New } \\
\text { Jersey, USA }\end{array}$ \\
\hline $\begin{array}{l}\text { Electrical balance - AdventurerTM } \\
\text { Pro AV114C }\end{array}$ & $0-10 \mathrm{~g}$ & $0.001 \mathrm{~g}$ & $\begin{array}{l}\text { OHAUS, Pine Brook, New } \\
\text { Jersey, USA }\end{array}$ \\
\hline Tencor Alpha-Step 200 & $\pm 160 \mu \mathrm{m}$ & $0.015 \mu \mathrm{m}$ & $\begin{array}{l}\text { KLA-Tencor, } \\
\text { California, U.S.A. }\end{array}$ \\
\hline Finnipipette II & $1-5 \mathrm{~mL}$ & $0.01 \mathrm{~mL}$ & $\begin{array}{l}\text { Fisherbrand, Pittsburgh, } \\
\text { Pennsylvania, U.S. }\end{array}$ \\
\hline Canon EOS 450D camera & $\mathrm{N} / \mathrm{A}$ & $\mathrm{N} / \mathrm{A}$ & Canon, Ōta, Tokyo, Japan \\
\hline $\begin{array}{l}\text { Tokina AT-X } 100 \mathrm{~mm} \mathrm{f} / 2.8 \text { PRO D } \\
\text { Macro Lens }\end{array}$ & $\mathrm{N} / \mathrm{A}$ & N/A & Tokina, Tokyo, Japan \\
\hline Capillary & $\mathrm{N} / \mathrm{A}$ & N/A & $\begin{array}{l}\text { Fisherbrand, Pittsburgh, } \\
\text { Pennsylvania, U.S. }\end{array}$ \\
\hline
\end{tabular}


There are two kinds of capillaries in the experiment. The red marked tube has an inside diameter (I.D.) of $1.12 \mathrm{~mm}$ and an outside diameter (O.D.) of $1.47 \mathrm{~mm}$. The yellow marked tube has an inside diameter of $0.96 \mathrm{~mm}$ and an outside diameter of $1.38 \mathrm{~mm}$. All of them are made of glass. When the capillary is inserted into water, there will be an "up-hill" (against the force of gravity) liquid level, and which is called "Capillary Phenomenon" (Batchelor, 2000). Figure 2.1 and 2.2 show the capillary phenomenon. Capillary tube is inserted to the solution, and there is a liquid column rising up.

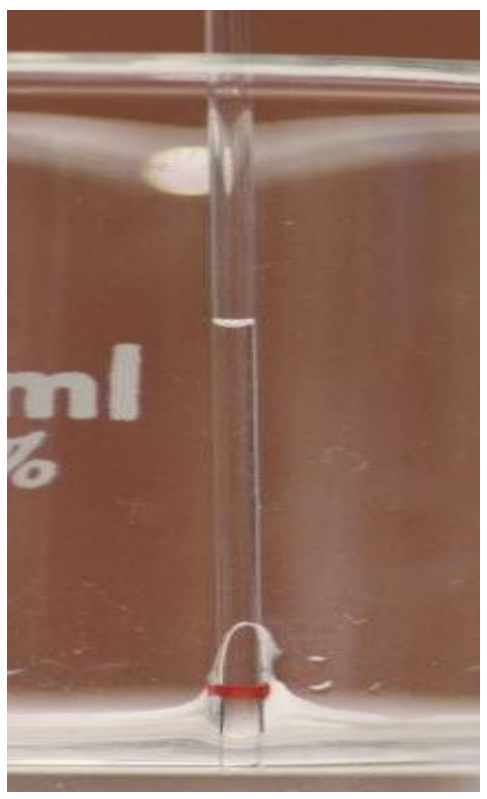

Figure 2. 1 Surface Tension Measurement: Red Tube I.D. $=1.12 \mathrm{~mm}$, O.D. $=1.47 \mathrm{~mm}$ 


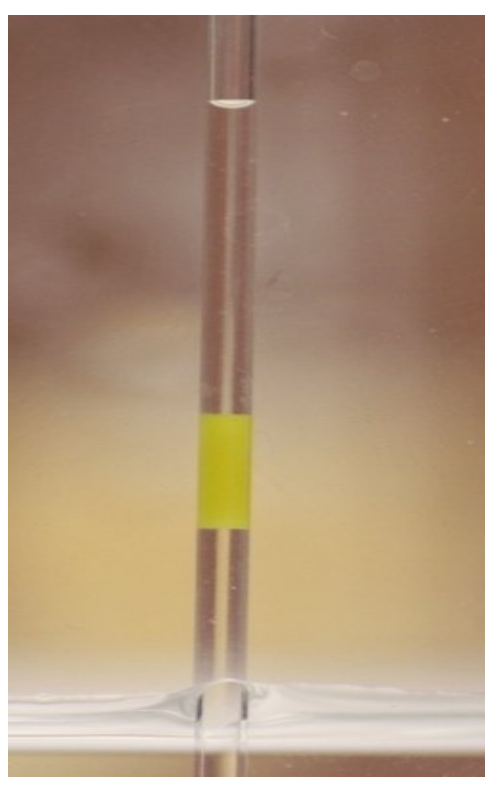

Figure 2. 2 Surface Tension Measurement: Yellow Tube I.D. $=0.96 \mathrm{~mm}$, O.D. $=1.38 \mathrm{~mm}$ Other devices were utilized during the measurements, such as beakers, iron supports, microinjector $(1-10 \mu L)$, etc.

\subsubsection{Liquids to be measured}

\subsubsection{Compound solutions}

Because of the surface tension is an important factor in droplet evaporation, as showing the equation 2.1, the surface tension of different liquids was measured. Inoder to have a more comprehensive research on surface tension influence on evaporation, many liquids were used in the measurement. These liquids included distilled water, tap water, $0.3 \% \mathrm{NaCl}$ water solution, $0.6 \% \mathrm{NaCl}$ water solution, $0.9 \% \mathrm{NaCl}$ water solution, $0.6 \%$ glucose water solution, $0.9 \%$ glucose water solution, $5 \%$ milk water solution, $10 \%$ milk water solution, brewed coffee, and human saliva. 


$$
\sigma=\frac{h \rho g \cdot r}{2 \cos \theta}
$$

where $\sigma$ is the surface tension in $[\mathrm{N} / \mathrm{m}], h$ is the height of the liquids in $[\mathrm{m}], \rho$ is density of liquids in $\left[\mathrm{kg} / \mathrm{m}^{3}\right], g$ is the acceleration of gravity in $\left[\mathrm{m} / \mathrm{s}^{2}\right]$, and $r$ is the inner radius of the tube in [m], and $\theta$ is the contact angle.

\subsubsection{Preparation of the liquids}

The three different concentrations of salt water solutions were obtained by measuring the masses of pure solid $\mathrm{NaCl}$ and distilled water. For instance, to compound $0.3 \% \mathrm{NaCl}$ solution, the procedure is as follows:

1. Calculate the mass of $\mathrm{NaCl}$ and distilled water (Table 2.2);

2. Put a piece of clean dry paper on the pallet of the electrical balance, set the balance to zero, and use the spatula to fill the calculated mass of salt on the paper, and put the salt into a beaker;

3. Lay a clean empty beaker on the pallet, set the balance to zero, and fill it with the calculated mass of distilled water,

4. Pour the water into the beaker which contains the salt, and mix the water and salt with glass rod gently, and

5. Repeat the same procedure to obtain the other two $\mathrm{NaCl}$ water solutions.

Table 2. 2 Measured mass of water and $\mathrm{NaCl}$ for three concentrations of $\mathrm{NaCl}$ water solutions

\begin{tabular}{|c|c|c|}
\hline Mass & $\mathrm{NaCl}[\mathrm{g}]$ & Distilled Water $[\mathrm{g}]$ \\
\hline $0.3 \% \mathrm{NaCl}$ Water Solution & 0.1501 & 49.8509 \\
\hline $0.6 \% \mathrm{NaCl}$ Water Solution & 0.3002 & 49.7009 \\
\hline $0.9 \% \mathrm{NaCl}$ Water Solution & 0.4502 & 49.5501 \\
\hline
\end{tabular}


The glucose water solutions are obtained with the same procedure used before but with different concentrations (Table 2.3).

Table 2. 3 Measured data of mass of water and glucose for two concentrations of glucose water solutions

\begin{tabular}{|c|c|c|}
\hline Mass & Glucose $[\mathrm{g}]$ & Distilled Water $[\mathrm{g}]$ \\
\hline $0.6 \%$ Glucose Water Solution & 0.3001 & 49.7008 \\
\hline $0.9 \%$ Glucose Water Solution & 0.4503 & 49.5505 \\
\hline
\end{tabular}

Milk water solutions were made from $0.02 \%$ fat milk. The procedure to obtain it is the same as the one used before, and the measured mass of milk is in Table 2.4.

Table 2. 4 Measured data of mass of water and milk of the two concentrations of milk water solutions

\begin{tabular}{|c|c|c|}
\hline Mass & $0.02 \%$ Fat Milk $[\mathrm{g}]$ & Distilled Water $[\mathrm{g}]$ \\
\hline $5 \%$ milk Water Solution & 2.5001 & 47.5003 \\
\hline $10 \%$ milk Water Solution & 5.0003 & 45.0009 \\
\hline
\end{tabular}

\subsubsection{Densities of solutions}

Density values would be used in the surface tension calculation. After collecting all the solutions, density of each liquid should be measured. The density of distilled water is assumed to be the same as the density of pure water under normal temperature and pressure $\left(20^{\circ} \mathrm{C}\right.$ and $1 \mathrm{~atm}$, respectively) ( Efunda, 2011). During the experiments, the temperature and pressure are kept well at $20-23^{\circ} \mathrm{C}$ and $1 \mathrm{~atm}$, respectively. 
The density of the tap water is obtained as the same temperature and pressure as the distilled water ( SImetric, 2010).

Three methods were used to obtain the densities of $\mathrm{NaCl}$ solutions. One method is by calculation. The second method is to measure the mass and volume of the three $\mathrm{NaCl}$ solutions by taking 10 times measurements, the density value can be calculated as an mean value density. In this method, $V$ is fixed and set to $2 \mathrm{~mL}$. The procedure is as follows:

1. Use Finnipipette II 1-5mL (Fisherbrand, Pittsburgh, Pennsylvania, U.S.) to measure $2 \mathrm{~mL}$ of liquids;

2. Lay a beaker onto the pallet of the electrical balance, set the balance to zero;

3. Put the liquid into the beaker, and read the mass

4. Repeat this process 10 times (Table 2.5);

5. Calculate the mean mass

Table 2. 5 Measured mass data of three concentrations of $\mathrm{NaCl}$ solutions with fixed volume $2 \mathrm{~mL}$

\begin{tabular}{|c|c|c|c|}
\hline Mass & $\begin{array}{c}0.3 \% \mathrm{NaCl} \\
\text { solution }[\mathrm{g}]\end{array}$ & $\begin{array}{c}0.6 \% \mathrm{NaCl} \\
\text { solution }[\mathrm{g}]\end{array}$ & $\begin{array}{c}0.9 \% \mathrm{NaCl} \\
\text { solution }[\mathrm{g}]\end{array}$ \\
\hline 1 & 2.0014 & 2.0095 & 2.0126 \\
\hline 2 & 2.0029 & 2.0074 & 2.0130 \\
\hline 3 & 2.0032 & 2.0063 & 2.0140 \\
\hline 4 & 2.0040 & 2.0079 & 2.0129 \\
\hline 5 & 2.0036 & 2.0069 & 2.0115 \\
\hline 6 & 2.0031 & 2.0075 & 2.0136 \\
\hline 7 & 2.0028 & 2.0085 & 2.0143 \\
\hline 8 & 2.0042 & 2.0090 & 2.0150 \\
\hline 9 & 2.0036 & 2.0080 & 2.0127 \\
\hline 10 & 2.0035 & 2.0096 & 2.0131 \\
\hline Mean & 2.0032 & 2.0081 & 2.0133 \\
\hline
\end{tabular}


The final method is from "The Engineering Toolbox". It offers a relationship between the concentration of $\mathrm{NaCl}$ solutions and their densities (Fig. 2.3) (EngineeringToolBox, 2009)

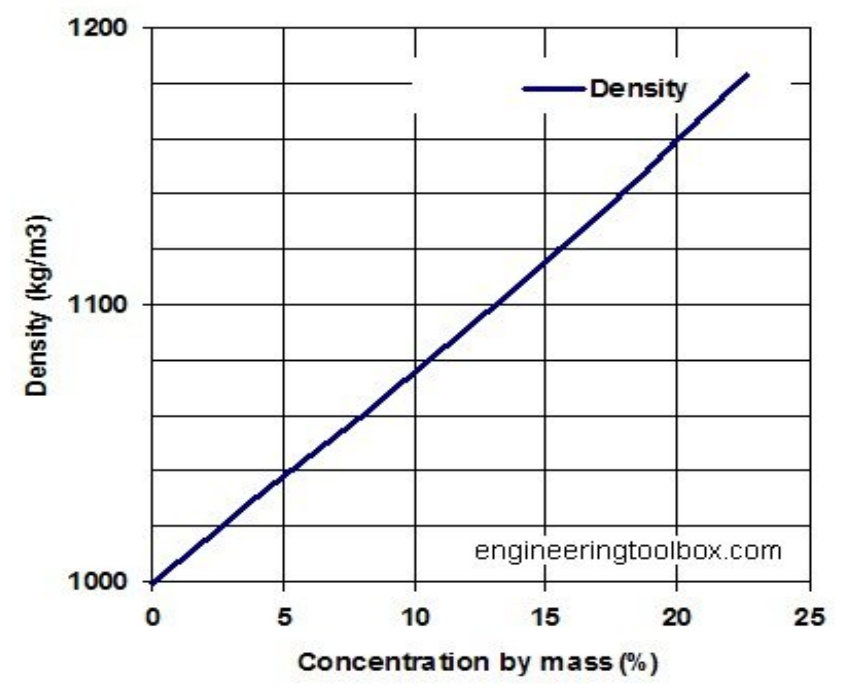

Figure 2. 3 Density changing with concentration of $\mathrm{NaCl}$

A function of density and concentration is calculated, which is:

$$
\rho=7.84 c+1000
$$

Where $c$ is the concentration and $\rho$ is the density of the $\mathrm{NaCl}$ solution. Then the density of any $\mathrm{NaCl}$ solution can be obtained as long as the concentration is known.

The other reference is a calculator developed by CSGNetwork (CSG Method), University of Michigan, and NOAA (NOAA, 2010). The calculator can compute the $\mathrm{NaCl}$ solution density if the value of temperature and concentration are given (NOAA, 2010)

Table 2.6 shows the results of the three methods. 
Table 2. 6 Results of densities of $\mathrm{NaCl}$ solutions of the three methods

\begin{tabular}{|c|c|c|c|c|}
\hline Density $\left[\mathrm{kg} / \mathrm{m}^{3}\right]$ & $\begin{array}{c}\text { Method 1 } \\
\text { (Calculation) }\end{array}$ & $\begin{array}{c}\text { Method 2 } \\
\text { (Measurement) }\end{array}$ & $\begin{array}{c}\text { Method 3 } \\
\text { (Function) }\end{array}$ & $\begin{array}{c}\text { Method 4 (CSG } \\
\text { Method) }\end{array}$ \\
\hline $0.3 \% \mathrm{NaCl}$ solution & 1001.20 & 1001.6 & 1002.35 & 999.85 \\
\hline $0.6 \% \mathrm{NaCl}$ solution & 1004.23 & 1004.0 & 1004.70 & 1002.11 \\
\hline $0.9 \% \mathrm{NaCl}$ solution & 1007.27 & 1006.6 & 1007.06 & 1004.37 \\
\hline
\end{tabular}

From Table 2.6, the difference of density values of each method is small; since the result of method 2 was obtained by measurement, it was used in this thesis.

The densities of glucose water solutions are obtained by measurement, and the method is the same as used in the $\mathrm{NaCl}$ water solutions.

The densities of $0.02 \%$ fat milk water solutions were obtained by using equation:

$$
\rho_{\text {mixture }}=\sum_{i=1}^{n} \rho_{i} \omega_{i}
$$

where $\rho_{\text {mixture }}$ is the density of milk water solution; $\rho_{i}$ is the density of each component in the solution, including $0.02 \%$ fat milk and distilled water; and $\omega_{i}$ is the mass fraction of each component. The density of $0.02 \%$ fat milk is $1,033 \mathrm{~kg} / \mathrm{m}^{3}$ at $20{ }^{\circ} \mathrm{C}$ (Jones, 2002).

The density of brewed coffee was measured by the same procedure before, but the fixed volume was set to $5 \mathrm{~mL}$.

Two methods were used to obtain the density of human saliva. One is measurement, and the other one is calculation. The measured human saliva is collected between 9:00 AM to 11:00 AM as unstimulated whole saliva (Chiappin et al., 2007). The procedure is still the same as before. The measured data is shown in Table 2.7.

Table 2. 7 Measured mass and calculated density of human saliva

\begin{tabular}{|c|c|}
\hline Mass [g] & Density $\left[\mathrm{g} / \mathrm{cm}^{3}\right]$ \\
\hline 2.0032 & 1.00160 \\
\hline
\end{tabular}




\begin{tabular}{|l|l|}
\hline 1.9998 & 0.99990 \\
\hline 2.0039 & 1.00195 \\
\hline 2.0045 & 1.00225 \\
\hline 2.0089 & 1.00445 \\
\hline 2.0061 & 1.00305 \\
\hline 2.0045 & 1.00225 \\
\hline 1.9993 & 0.99965 \\
\hline 2.0034 & 1.00170 \\
\hline 2.0012 & 1.00060 \\
\hline
\end{tabular}

From Table 2.7, the average value of density of human saliva can be calculated, which is $1001.73 \mathrm{~kg} / \mathrm{m}^{3}$.

Human saliva contains many substances, including the major component water, inorganic salt components, organic components, etc. The mass fraction and density of each component have been obtained by some scientists before. These mass fractions are $99.5 \%$ water, $0.3 \%$ proteins, and $0.2 \%$ inorganic and trace substances (Schipper et al., 2007). These data were used in the calculation of human saliva density.

Some assumptions were made in this method. First, because trace substances constitute a very small part in human saliva, less than $1 / 10000$, they were neglected in the calculation. Then, there are many kinds of inorganic ions in human saliva listed (Table 2.8) (Chiappin et al., 2007).

Table 2. 8 Mass concentration of inorganic components of human saliva

\begin{tabular}{|c|c|c|c|}
\hline $\begin{array}{c}\text { Inorganic } \\
\text { components }\end{array}$ & $\begin{array}{c}\text { Mole } \\
{[\mathrm{mmol} / \mathrm{L}]}\end{array}$ & $\begin{array}{c}\text { Concentration } \\
{[\mathrm{mg} / \mathrm{L}]}\end{array}$ & $\begin{array}{c}\text { Molecular } \\
\text { weight }[\mathrm{g} / \mathrm{mol}]\end{array}$ \\
\hline $\mathrm{Na}^{+}$ & 5 & 115 & 23 \\
\hline $\mathrm{K}^{+}$ & 22 & 860.2 & 39.1 \\
\hline $\mathrm{Cl}^{-}$ & 15 & 532.5 & 35.5 \\
\hline $\mathrm{Ca}_{2}{ }^{+}$ & 2.5 & 100 & 40 \\
\hline $\mathrm{HCO}_{3}{ }^{-}$ & 5 & 305 & 61 \\
\hline $\mathrm{Mg}_{2}{ }^{+}$ & 0.2 & 4.8 & 24 \\
\hline
\end{tabular}




\begin{tabular}{|c|c|c|c|}
\hline $\mathrm{NH}_{3}{ }^{+}$ & 6 & 108 & 18 \\
\hline
\end{tabular}

In order to calculate the density of human saliva, the density of each component should be known. Table 2.8 shows the amount of solvent of each substance, and according to those data, some solid substances were assumed when water evaporates completely. In Table 2.9, the amount of $\mathrm{NaCl}, \mathrm{KCl}, \mathrm{MgCl}_{2}$, and $\mathrm{NH}_{4} \mathrm{HCO}_{3}$ are listed by combining the ions in Table 2.8 in 1 $\mathrm{mL}$ human saliva. For instance, $5 \mathrm{~mol}$ of $\mathrm{Na}^{+}$was considered combined with $5 \mathrm{~mol} \mathrm{Cl}$, and then 5 mol sodium chloride was created.

Table 2.9 Mole number in $1 \mathrm{~mL}$ and density information of salts in human saliva

\begin{tabular}{|c|c|c|}
\hline & Mole $[\mathrm{mmol}]$ & Density $\left[\mathrm{kg} / \mathrm{m}^{3}\right]$ \\
\hline $\mathrm{NaCl}$ & 5 & 2165 \\
\hline $\mathrm{KCl}$ & 10 & 1984 \\
\hline $\mathrm{MgCl}_{2}$ & 0.2 & 2320 \\
\hline $\mathrm{NH}_{4} \mathrm{HCO}_{3}$ & 5 & 1586 \\
\hline
\end{tabular}

After combining the anions with cations, there are still some cations remained. As for there are no more anions can be used to create substance, the rest of cations (i.e. $12 \mathrm{mmol} / \mathrm{L}$ of $\mathrm{K}^{+}$, $2.5 \mathrm{mmol} / \mathrm{L}$ of $\mathrm{Ca}^{2+}$, etc.) were neglected.

Secondly, protein was another important substance in human saliva, taking up to $0.3 \%$ in human saliva (Chiappin et al., 2007). There were plenty of kinds of proteins in human saliva (Chiappin et al., 2007), but most of them had a very small amount and they were ignored here. The major components were shown in Table 2.10. 
Table 2. 10 Major components of proteins in human saliva

\begin{tabular}{|c|c|c|c|c|}
\hline & $\begin{array}{c}\text { Concentration } \\
{[\mathrm{mg} / \mathrm{ml}]}\end{array}$ & $\begin{array}{c}\text { Mass in } 1 \mathrm{~mL} \\
{[\mathrm{mg}]}\end{array}$ & $\begin{array}{c}\text { Molecular } \\
\text { Weight }[\mathrm{g} / \mathrm{mol}]\end{array}$ & Density $\left[\mathrm{g} / \mathrm{cm}^{3}\right]$ \\
\hline$\alpha$-amylase & 0.476 & 0.476 & $51000^{[1]}$ & $1.25^{[2]}$ \\
\hline Albumin & 0.2 & 0.2 & $66438^{[3]}$ & $1.202^{[4]}$ \\
\hline Secretory-IgA & 0.2298 & 0.2298 & $70000^{[5]}$ & $1.145^{[6]}$ \\
\hline Hystatin & 1.19 & 1.19 & $926.09^{[7]}$ & $1.26^{[8]}$ \\
\hline Statherin & 36 & 36 & $5379.59^{[9]}$ & Not Found \\
\hline PRPs & 0.621 & 0.621 & $35500^{[10]}$ & Not Found \\
\hline Transferrin & 58 & 58 & $80000^{[11]}$ & Not Found \\
\hline
\end{tabular}

[1] (WBC, 2010), [2] (Makkar et al., 2007), [3-4] (Bull, 1941), [5-6] (Tartakoff, 1982), [7] (Rxlist, 2008), [8] (Esser et al., 1979), [9] (Gururaja \& Levine, 1996), [10] ( Hegde et al., 2010), [11] ( Roberts et al., 1966)

The density information of last three kinds of proteins was not found, and they were neglected in the calculation. Thus, all the substances which were used in the calculation had been introduced (Table 2.11).

Table 2. 11 Substances used in the calculation of density of $1 \mathrm{~mL}$ human saliva

\begin{tabular}{|c|c|c|c|c|c|}
\hline & $\begin{array}{c}\text { Density } \\
{\left[\mathrm{kg} / \mathrm{m}^{3}\right]}\end{array}$ & $\begin{array}{c}\text { Mole } \\
{[\mathrm{mmol}]}\end{array}$ & $\begin{array}{c}\text { Molecular } \\
\text { Weight }[\mathrm{g} / \mathrm{mol}]\end{array}$ & $\begin{array}{c}\text { Mass } \\
{[\mathrm{kg}]}\end{array}$ & $\begin{array}{c}\text { Volume } \\
{\left[\mathrm{m}^{3}\right]}\end{array}$ \\
\hline $\mathrm{NaCl}$ & 2165 & 5 & 58.5 & 0.000293 & $1.35 \mathrm{E}-07$ \\
\hline $\mathrm{KCl}$ & 1984 & 10 & 74.6 & 0.000746 & $3.76 \mathrm{E}-07$ \\
\hline $\mathrm{MgCl}_{2}$ & 2320 & 0.2 & 95 & 0.000019 & $8.19 \mathrm{E}-09$ \\
\hline $\mathrm{NH}_{4} \mathrm{HCO}_{3}$ & 1586 & 5 & 79 & 0.000395 & $2.49 \mathrm{E}-07$ \\
\hline$\alpha$-amylase & 1250 & 0.0078 & 51000 & 0.0003978 & $3.18 \mathrm{E}-07$ \\
\hline Albumin & 1202 & 0.003 & 66438 & 0.0002 & $1.66 \mathrm{E}-07$ \\
\hline Secretory-IgA & 1145 & 0.0033 & 70000 & 0.00023 & $2.01 \mathrm{E}-07$ \\
\hline Hystatin & 1260 & 1.285 & 926.09 & 0.00119 & $9.44 \mathrm{E}-07$ \\
\hline
\end{tabular}

Table 2.11 shows the densities, mole number and molecular weight of each component in $1 \mathrm{~mL}$ of human saliva. The mass of each component can be calculated by the relationship: 


$$
m=n \cdot M
$$

where $m$ is the mass of each component, $n$ is the mole number, and $M$ is the molecular weight, which are all shown in Table 2.11.

After obtaining the volume and mass of each component in Table 2.11, the total volume of the inorganic components is $2.398 \mathrm{E}-06 \mathrm{~m}^{3}$ and mass of the inorganic components of proteins $0.00347 \mathrm{~kg}$; therefore, the density is $1446.99 \mathrm{~kg} / \mathrm{m}^{3}$. The total volume is the summation of the volume of all the solid components in Table 2.11. Similarly, the total mass is the summation of the mass of all the solid components in Table 2.11 .

In order to validate the assumption and calculation of the solid part of density of human saliva, an experiment was performed. The procedure of the experiment was:

- Mark five pieces of glass; weigh these glasses by using Adventurer Pro AV114C (OHAUS, Pine Brook, New Jersey, USA)

- Inject human saliva droplet on the glass

- Warm up $\left(50 \sim 60^{\circ} \mathrm{C}\right)$ the glass to let water in saliva evaporate more rapidly (less than 1 minute). Figure 2.4 shows the samples of human saliva solid part after the water evaporated. 


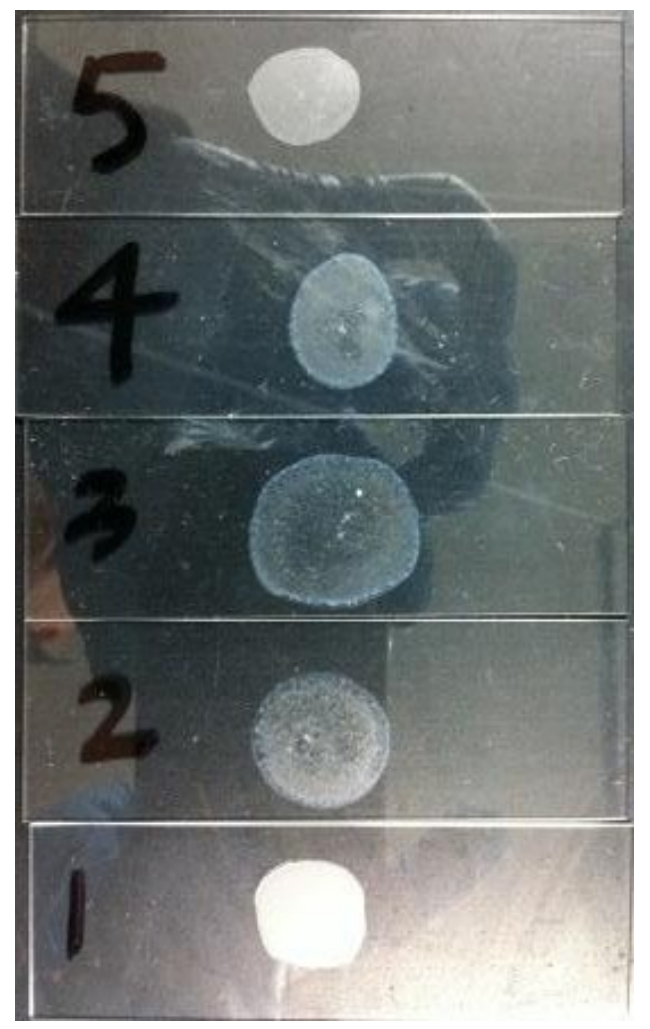

Figure 2. 4 Samples of the human saliva solid part on glasses

- Weigh the mass of each again, then by subtracting the glass mass, the mass of solid part of humans saliva on each glass can be obtained;

- Then use Tencor Alpha-Step $200( \pm 160 \mu \mathrm{m}$ height range) to measure the height of the solid part of saliva on the glass

- Afterward, take pictures for each of the sample individually, and use Matlab program to analyze it and calculate the surface area. 


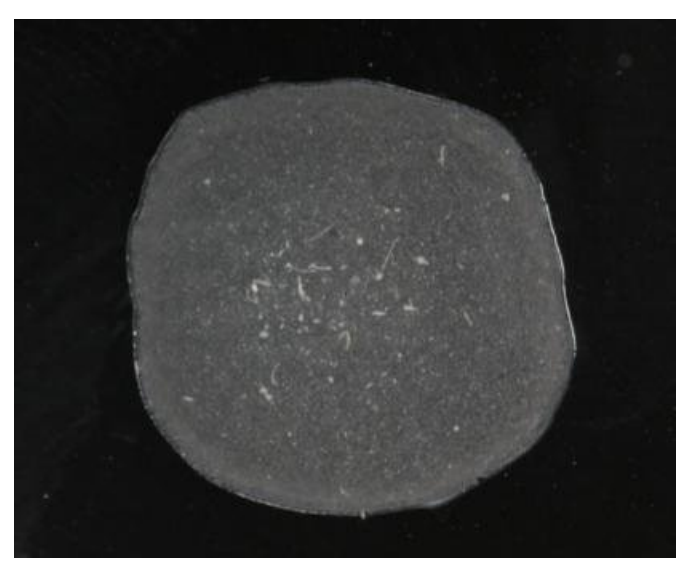

Figure 2. 5 The sample of image analysis of surface area of the solid part

- By this time, the density of saliva solid part can be obtained, by knowing both mass and volume. Table 2.12 shows the calculation and results.

Table 2. 12 The measurement data and calculation of density of solid part of human saliva

\begin{tabular}{|c|c|c|c|c|c|}
\hline Group* & $\begin{array}{c}\text { Total Area } \\
{\left[\mathrm{m}^{2}\right]}\end{array}$ & Height $[\mathrm{m}]$ & Weight $[\mathrm{kg}]$ & Volume $\left[\mathrm{m}^{3}\right]$ & $\begin{array}{c}\text { Density } \\
{\left[\mathrm{kg} / \mathrm{m}^{3}\right]}\end{array}$ \\
\hline 2 & $4.01 \mathrm{E}-04$ & $3.00 \mathrm{E}-06$ & $1.50 \mathrm{E}-06$ & $1.20 \mathrm{E}-09$ & 1246.35 \\
\hline 3 & $6.17 \mathrm{E}-04$ & $1.35 \mathrm{E}-06$ & $1.20 \mathrm{E}-06$ & $8.31 \mathrm{E}-10$ & 1443.74 \\
\hline 4 & $3.32 \mathrm{E}-04$ & $1.86 \mathrm{E}-06$ & $1.00 \mathrm{E}-06$ & $6.17 \mathrm{E}-10$ & 1621.24 \\
\hline 5 & $2.02 \mathrm{E}-04$ & $4.58 \mathrm{E}-06$ & $1.20 \mathrm{E}-06$ & $9.26 \mathrm{E}-10$ & 1296.22 \\
\hline
\end{tabular}

* Group 1 seemed like an outlier and was deleted in the calculation

Take average value of the density in Table 2.12 , the density of solid part in human saliva by measurement is $1401.88 \mathrm{~kg} / \mathrm{m}^{3}$; compared to the result of calculation $1446.99 \mathrm{~kg} / \mathrm{m}^{3}$, the difference is $3.12 \%$ which is not a high error.

After obtaining the density of the solid part of human saliva, water was taken into account and the total density of human saliva was calculated (Table 2.13). 
Table 2. 13 Calculation of density of human saliva

\begin{tabular}{|c|c|c|c|c|c|c|}
\hline & $\begin{array}{c}\text { Mass } \\
\text { fraction }\end{array}$ & $\begin{array}{c}\text { Mass } \\
{[\mathrm{kg}]}\end{array}$ & $\begin{array}{c}\text { Density } \\
{\left[\mathrm{kg} / \mathrm{m}^{3}\right]}\end{array}$ & $\begin{array}{c}\text { Volume } \\
{\left[\mathrm{m}^{3}\right]}\end{array}$ & $\begin{array}{c}\text { Total } \\
\text { Volume } \\
{\left[\mathrm{m}^{3}\right]}\end{array}$ & $\begin{array}{c}\text { Final } \\
\text { Density } \\
{\left[\mathrm{kg} / \mathrm{m}^{3}\right]}\end{array}$ \\
\cline { 1 - 5 } Solids & 0.005 & 0.00347 & 1446.99 & Neglected & 0.000692 & 1003.22 \\
\cline { 1 - 4 } Water & 0.995 & 0.691 & 998.2 & 0.000692 & & \\
\hline
\end{tabular}

Table 2.14 Difference of human saliva density of the two methods

\begin{tabular}{|c|c|c|}
\hline & Density $\left[\mathrm{kg} / \mathrm{m}^{3}\right]$ & Error \\
\hline Calculation & 1003.22 & \\
\hline Measurement & 1001.73 & $0.15 \%$ \\
\hline
\end{tabular}

The measurement density is mentioned in Table 2.7. From table 2.14, it can be observed that the error between the measurement and the calculation is small, so the measurement result of the density of human saliva was used in this study.

\subsubsection{Procedure for measuring surface tension}

The surface tension of the solutions was measured by placing the capillary tubes into those prepared liquids contained in the beakers. The capillary tubes was held by the iron support. After a while, due to the capillary effect, a rising liquid level inside of the capillary tubes can be observed. The height of the rising liquid $h$ inside of the tube and the contact angle between the top liquid level and the inner tube wall $\theta$ can be obtained. High resolution pictures were taken for the whole system after the liquid level stabilized. Figures 2.6 was the sample of the measurement sets. 


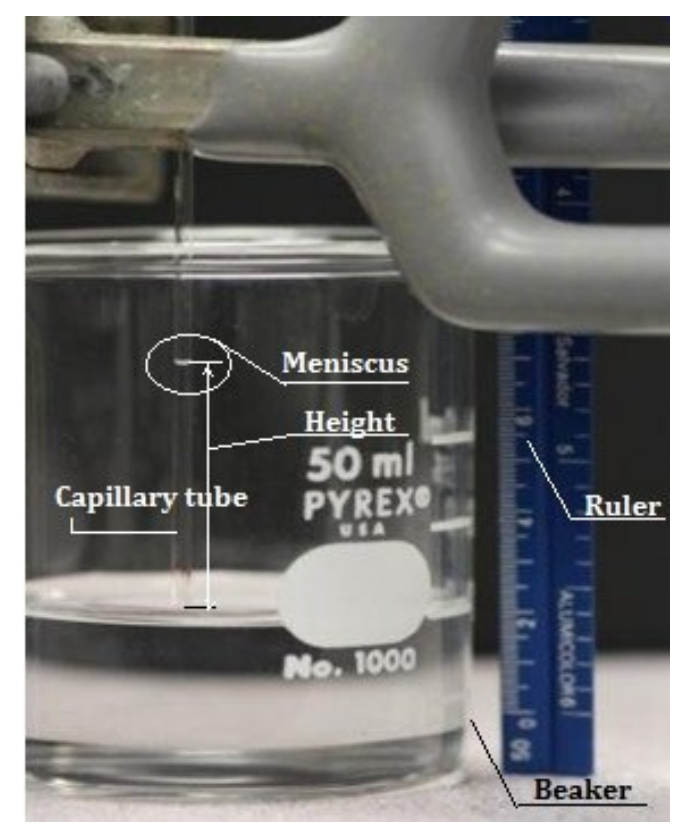

Figure 2. 6 Height of the liquid level system

After taking pictures, all of them are processed to provide $h$ and $\theta$ for the calculation of surface tension.

\subsubsection{Height in the tube}

In order to guarantee the accuracy of the values of the height inside of the capillary tubes, Photoshop (Adobe Systems, Inc. San Jose, CA) was used to measure the pixel length of the inner diameter $d_{\text {inside_pixel }}$, outside diameter $d_{\text {outside_pixel }}$, and the height between the higher liquid level and the lower liquid level $h_{\text {pixel }}$. The actual outside diameter $d_{\text {outside }}$ has been obtained by the slide caliper, and Equation 2.4 was used to compute the height $h$ and the inner diameter $d_{\text {inside }}$ :

$$
\frac{d_{\text {inside }}}{d_{\text {inside_pixel }}}=\frac{d_{\text {outside }}}{d_{\text {outside_pixel }}}=\frac{h}{h_{\text {pixel }}}
$$




\subsubsection{Contact angle}

The contact angle is the angle at which a liquid or vapor interface meets a solid surface ( Muson et al., 1994). Two methods were used to measure the contact angle. One is using Matlab code to obtain the boundary of the meniscus, and using the boundary, the contact angle can be calculated; the other one is to measure it by using ruler The purpose to measure the contact angle by two ways is to have a comparison of the values obtained from each method to ensure the accuracy.

A Matlab code was written to obtain the meniscus edge of the fluid. Then, it can capture a boundary of the picture. An example (Figure 2.7) of attaining the boundary of one picture is as follows:

(a)

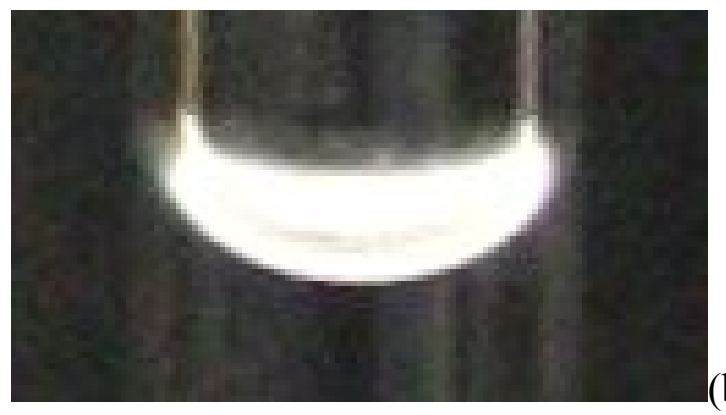

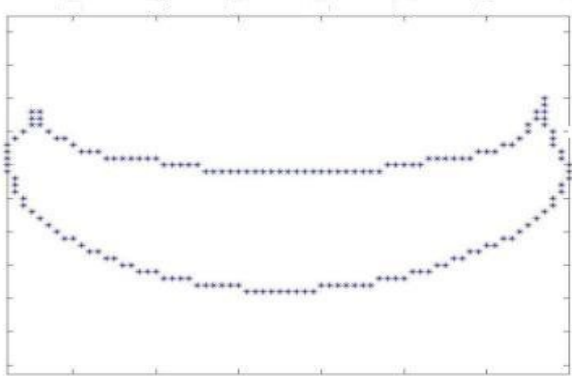

(b) Maniscus boundary obtained from Matlab

After capturing the boundary of the meniscus, two points at the boundary, either right or left side, were chosen, and the slope of the line between the two points can be calculated by using their coordinate value obtained by Matlab,. The slope is equal to $\tan (90-\theta)$, and the contact angle $\theta$ is calculated.

The measurements for distilled water, salt solutions, and human saliva have been repeated more than 5 times. 
The second method is to measure the contact angle by hand. The contact angle boundary pictures were printed, and a ruler was used to get the slope of the meniscus near the wall. The slope is also equal to $\tan (90-\theta)$, and the contact angle $\theta$ is calculated.

\subsubsection{Data Processing}

The surface tension of each liquid can be calculated using the Equation 2.1.

\subsection{Results and Discussion}

Collecting all the values needed in Equation 2.1, the surface tension of each liquid can be calculated (Table 2.15).

Table 2. 15 Results of surface tension of each kind of liquid

\begin{tabular}{|c|c|}
\hline Solutions & $\sigma[\mathrm{N} / \mathrm{m}]$ \\
\hline Distilled water & 0.0692 \\
\hline $0.3 \%$ Glucose $\left(\mathrm{C}_{6} \mathrm{H}_{12} \mathrm{O}_{6}\right)$ & 0.0680 \\
\hline $0.6 \%$ Glucose & 0.0650 \\
\hline $5 \%$ milk & 0.0576 \\
\hline $10 \%$ milk & 0.0540 \\
\hline Brewed Coffee & 0.0561 \\
\hline Tap water & 0.0659 \\
\hline Saliva & 0.0657 \\
\hline $0.3 \% \mathrm{NaCl}$ & 0.0782 \\
\hline $0.6 \% \mathrm{NaCl}$ & 0.0806 \\
\hline $0.9 \% \mathrm{NaCl}$ & 0.0845 \\
\hline
\end{tabular}

Figure 2.8 shows the surface tension of all the solutions measured. Some trends can be observed. As shown in Figure 2.8 the surface tension of the $\mathrm{NaCl}$ solution was found to increase with the $\mathrm{NaCl}$ concentration. This agreed with the result reported by (Lloyd Trefethen, 1969) which said that when some inorganic salts dissolved in water, the surface tension of the solution would increase. In addition, considering the sugar water solution, as the concentration increases, the surface tension will decrease. It has an opposite relationship between the concentration and surface tension with inorganic salts. It is also in agreement with the result published that when 
some organic substances dissolved in water, the surface tension of water will decrease (Lindfore, 1924; Weissenborn, 2006). Furthermore, the more milk dissolved in water, the lower surface tension obtained. The surface tension of human saliva is comparable to that of tap water.

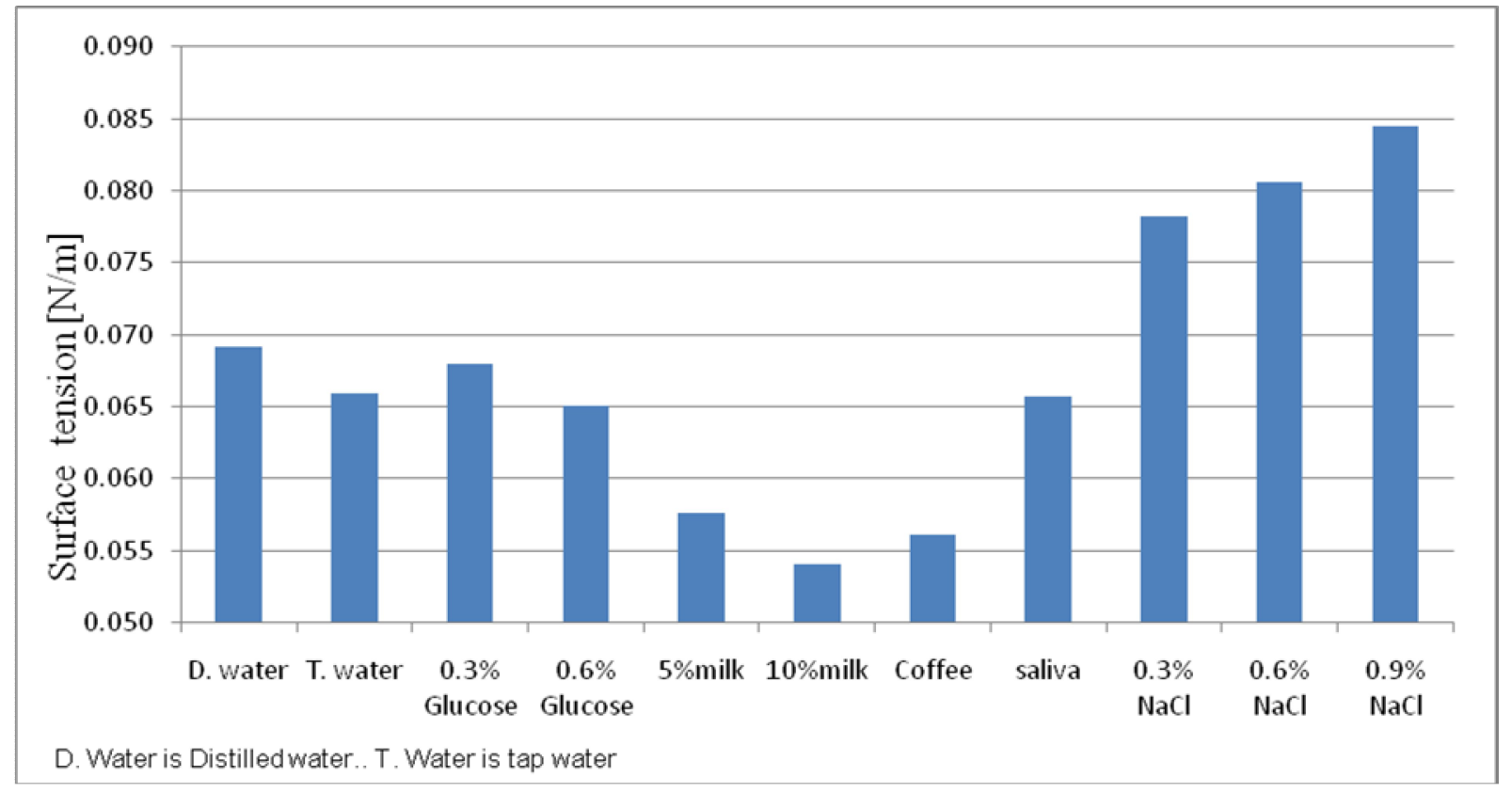

Figure 2. 8 Surface tension of each liquid 


\section{Chapter 3: Measurement of Evaporation Rate}

\subsection{Experimental Set-up and Procedure}

Experiments were performed to acquire the characteristics of droplet evaporation. The solutions measured included distilled water, tap water, $\mathrm{NaCl}$ with different concentrations, and human saliva.

The $\mathrm{NaCl}$ water droplets were attained from three different concentrations of $\mathrm{NaCl}$ water solutions, $0.3 \% \mathrm{NaCl}$ water solution, $0.6 \% \mathrm{NaCl}$ water solution, $0.9 \% \mathrm{NaCl}$ water solution, which are made by the same method as the solutions used in the surface tension measurements. The human saliva droplet is from unstimulated human saliva (Chiappin et al., 2007).

The procedure for the measurement of the evaporation rate of distilled water droplets is explained in the following lines. The water sample has to be placed in the experimental environment for more than 30 minutes, in order to obtain the same temperature of the environment. A calculation (Appendix I) has been done to prove that 30 minutes is long enough to ensure the temperatures are the same. Temperature and relative humidity of the surrounding environment are monitored by the hygrometer (Meade Instruments Corp., Irvine, CA, USA) during the entire measurement. Wind velocity has a significant effect on the evaporation rate, and it is measured by a hot wire thermo-anemometer (Extech Instruments Corporation, Waltham, MA, USA). Thereafter,

1. The temperature, relative humidity and the wind velocity were recorded at the beginning of the experiment, and the solutions to be studied would be placed in the experimental environmental for more than half an hour, sometimes, with a cover on top of the beakers; 
2. The microinjector $(1-10 \mu L)$ (Figure 3.1) is used to ingest some water;

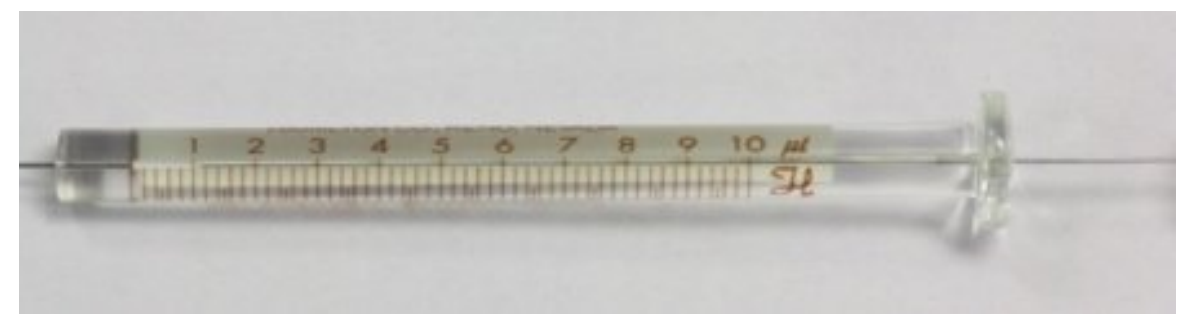

Figure 3. 1 Scales on microinjector

3. Inject $1 \mu L$ water approximately by subtracting the scales on the microinjector;

4. Move the water droplet down to the middle of the needle on the microinjector by slightly shaking, or inject a droplet and lie it on a flat plate;

5. If the droplet is held by the needle, hold it with the iron support vertically;

6. Taking pictures of the droplet every 30 seconds during the whole evaporation process;

7. Record the temperature, relative humidity and wind velocity at the end of the experiment, and if the difference between the initial and final droplet is small then the conditions can be considered as constants;

The $4^{\mathrm{d}}$ and $5^{\text {th }}$ step should be done as soon as possible to decrease the amount of water lost by evaporation. In order to obtain high quality pictures of the evaporation process, the illumination condition can easily influence the result; there will be a fluctuation of the illumination intensity shown in the pictures even a person just passing by, and afterward the results obtained from Matlab would be influenced. Therefore, the illumination intensity should be exactly the same during the entire process. In this research, in order to reduce the influence of the fluctuation of illumination intensity, a photo studio (Merax, City of Industry, CA, USA) was used to cover the droplet. 
Repeat the same procedure to all the other liquids to obtain the pictures. Figure 3.2 shows how the experiment is designed.

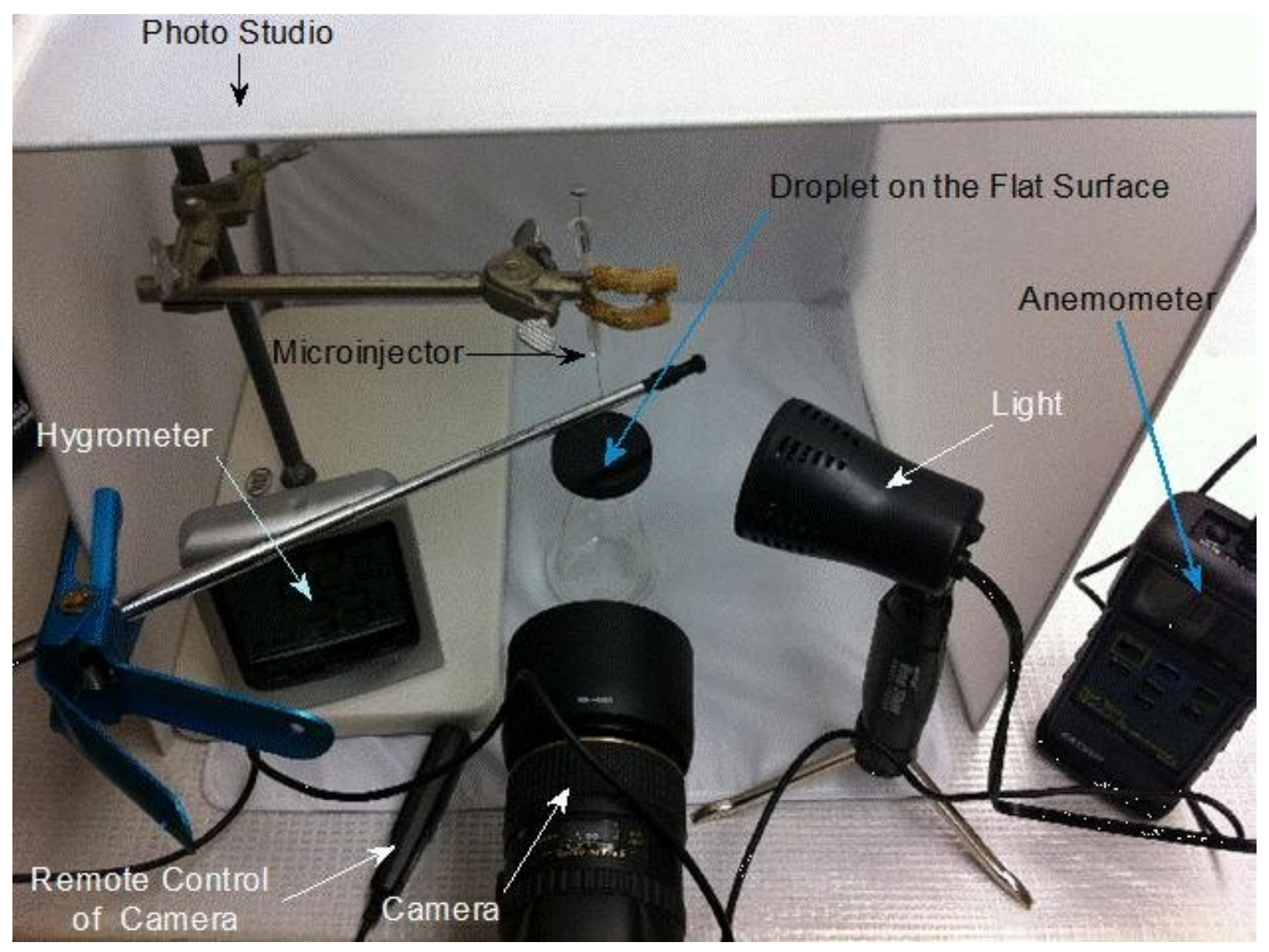

Figure 3. 2 Photo studio used in the experiment of evaporation rate

\subsection{Image Analysis}

A Matlab code is programmed to analyze the pictures of the evaporation attained previously, computing the volume and surface area of the droplet changing with time. The Matlab program zoomed in the droplet on the photos continuously and changed the photos to binary form (Figures 3.3 and 3.4), only containing black and white. 


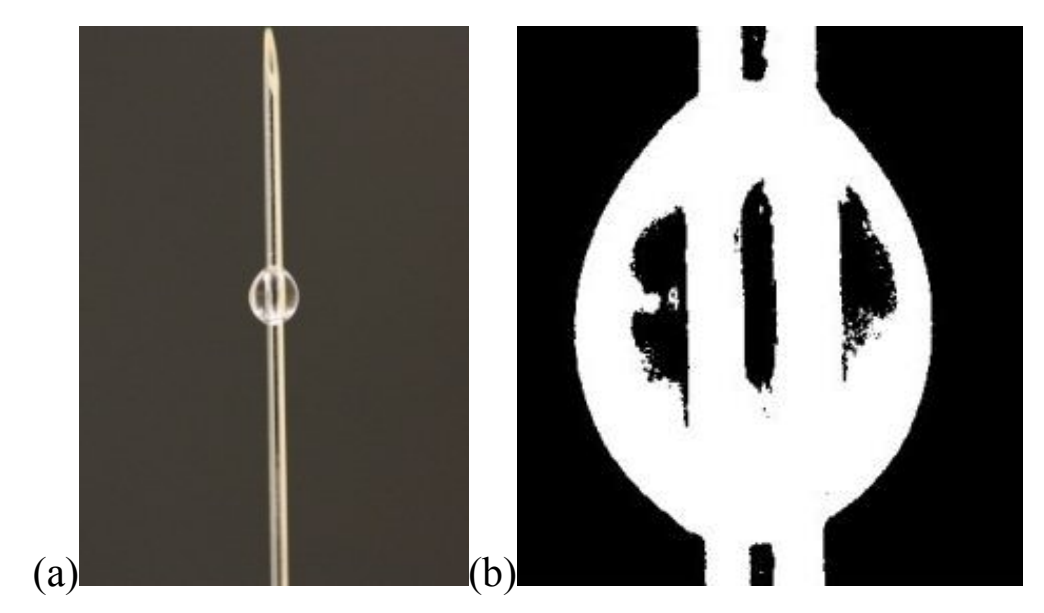

Figure 3. 3 Pictures of droplet on the needle: (a) Photo of droplet on the needle, (b) Binary photo obtained from program

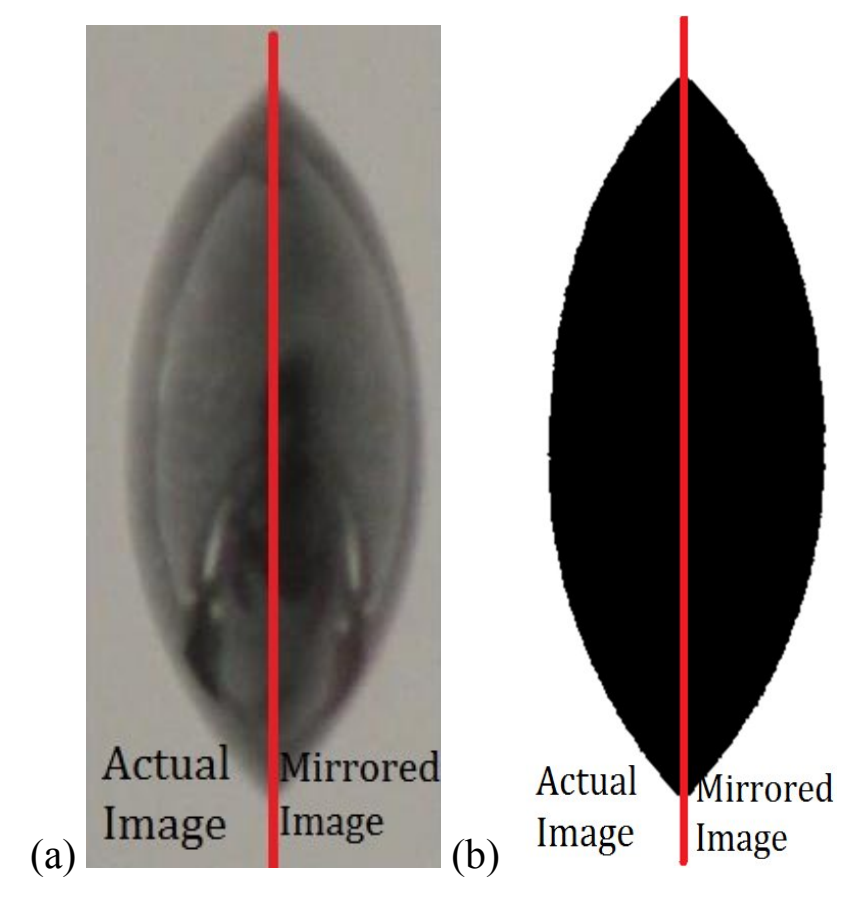

Figure 3. 4 Pictures of droplet on the surface: (a) Photo of droplet on the needle, (b) Binary photo obtained from program

In the binary photo, the boundary of the droplet can be captured. Considering the droplet on the needle is symmetric approximately by the centerline of the needle, the left part is used in the calculation of its volume and surface area.

The surface area of a sphere is shown in Equation 3.1: 


$$
A=4 \pi r^{2}=\pi d^{2}
$$

and for a semi-sphere, the surface area is shown in Equation 3.2:

$$
A=2 \pi r^{2}=\frac{1}{2} \pi d^{2}
$$

where $A$ stands for the surface area and $d$ is the diameter of the droplet.

The program performed this calculation procedure for all the pictures and showed the evaporation of a single droplet. A video showing the entire evaporation process of the droplet was then created. Eventually, the evaporation rate can be calculated. For example, Figure 3.5 shows the experimental result of evaporation rate of distilled water droplet measured at ambient temperature of $22.6^{\circ} \mathrm{C}$ and relative humidity of $48 \%$. It is showing that the evaporation rate is almost a straight line.

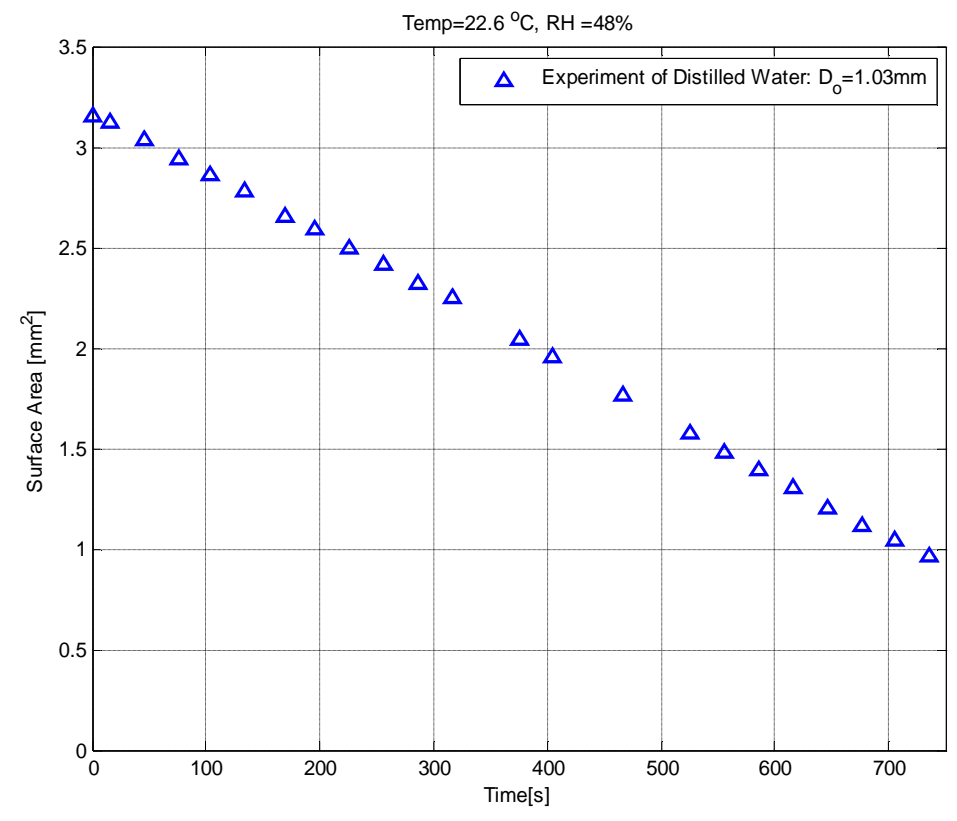

Figure 3. 5 The experimental result of evaporation rate distilled water droplet: Surface area vs. Time 
Figure 3.6 shows the Experimental results of $0.3 \% \mathrm{NaCl}$ water solution droplet, $0.6 \% \mathrm{NaCl}$ water solution droplet, $0.9 \% \mathrm{NaCl}$ water solution droplet, and human saliva droplet evaporation under $13.5^{\circ} \mathrm{C}$ and relative humidity of $33 \%$;

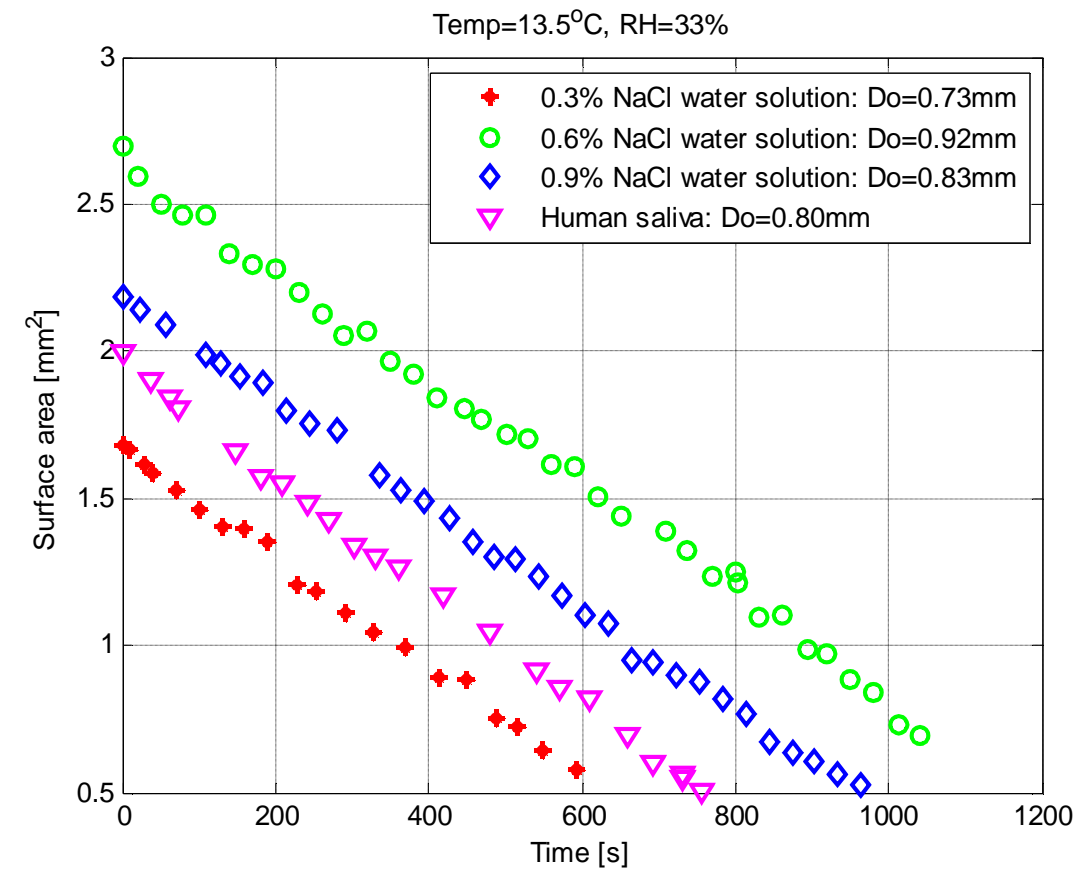

Figure 3. 6 Experimental results: saline water and human saliva droplets evaporation: Surface area vs. Time

In order to ensure the experiment is reliable, there are several groups of evaporation performed for each liquid. Figure 3.10 shows the experimental result of evaporation of $\mathrm{NaCl}$ water solution droplets under temperature around $34.5^{\circ} \mathrm{C}$ and relative humidity around $26 \%$.

Considering Figure 3.5 to Figure 3.6, there are some small fluctuations throughout the experimental result of evaporation. However, generally, it can be observed that the surface area of droplet is changing linearly with time.

Figure 3.7 shows the experimental evaporation results of droplets of different $\mathrm{NaCl}$ water solutions. The $0.3 \% \mathrm{NaCl}$ water solution droplet evaporates slightly faster than the $0.6 \%$ and $0.9 \% \mathrm{NaCl}$ water solution droplets. 


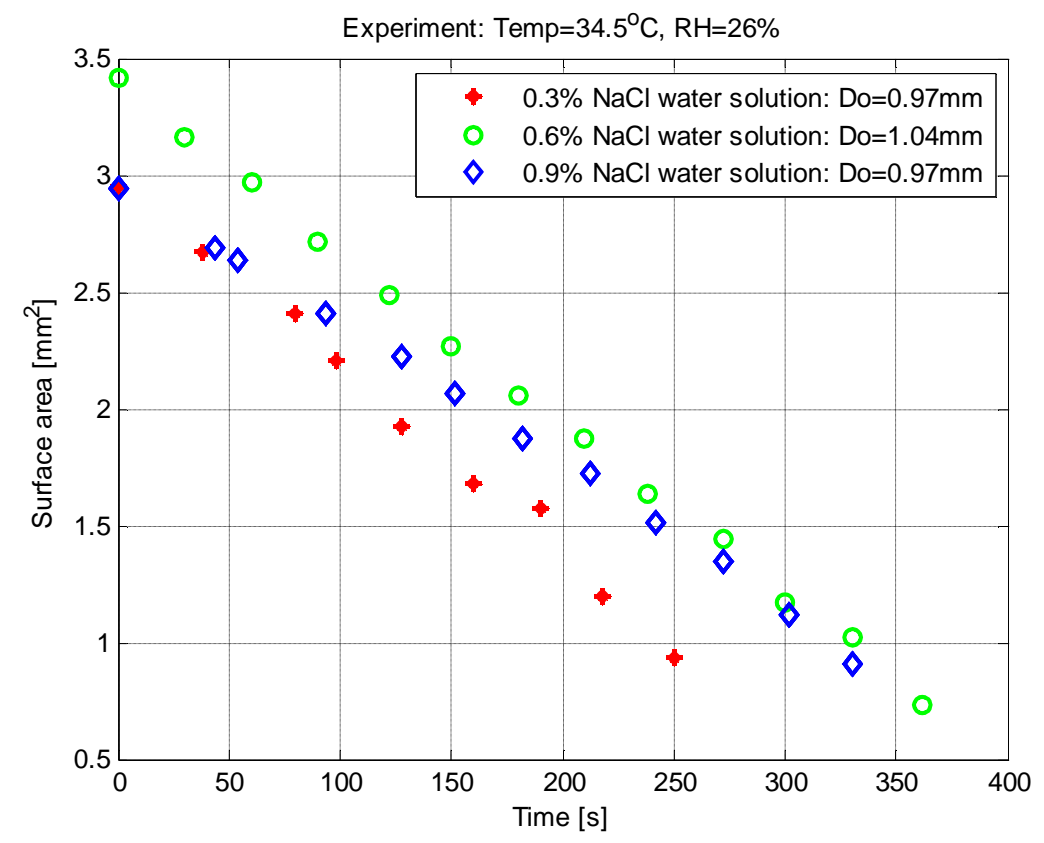

Figure 3. 7 The experimental result of evaporation of $\mathrm{NaCl}$ water solution droplets: Surface area $\left[\mathrm{mm}^{2}\right]$ vs. Time $[\mathrm{s}]$

Figure 3.8 shows the experimental result of evaporation of human saliva droplets under temperature around $23^{\circ} \mathrm{C}$ and relative humidity around $30 \%$.

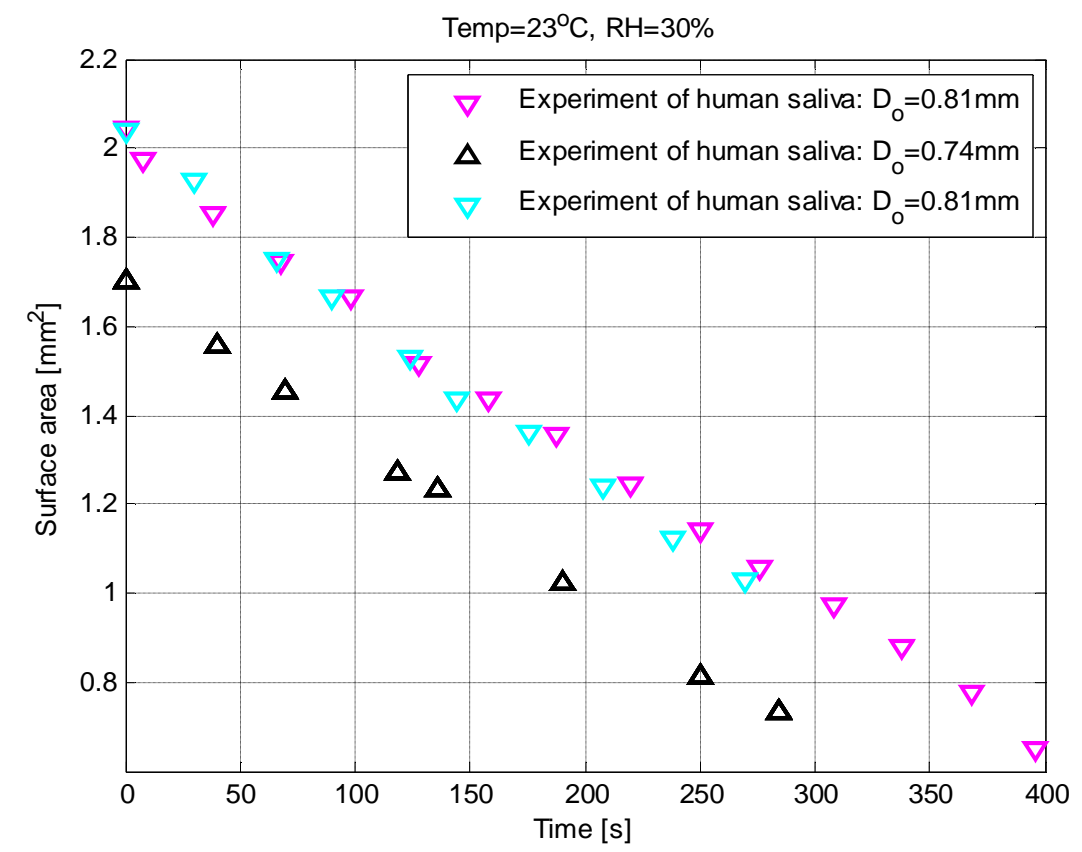

Figure 3. 8 The experimental result of evaporation of human saliva droplets: Surface area $\left[\mathrm{mm}^{2}\right]$ vs. Time $[\mathrm{s}]$ 
From Figure 3.7 and 3.8, the evaporation rates of various solutions are different. Besides, from Figure 3.11, under same environmental conditions, it can be observed that the evaporation of different human saliva droplets have the same evaporation rate.

Figure 3.9 shows the experimental results of evaporation of human saliva droplets under different environmental temperature and relative humidity. It shows that when temperature increases, the evaporation rate will increase, as shown, and when relative humidity decreases, the evaporation rate will increase.

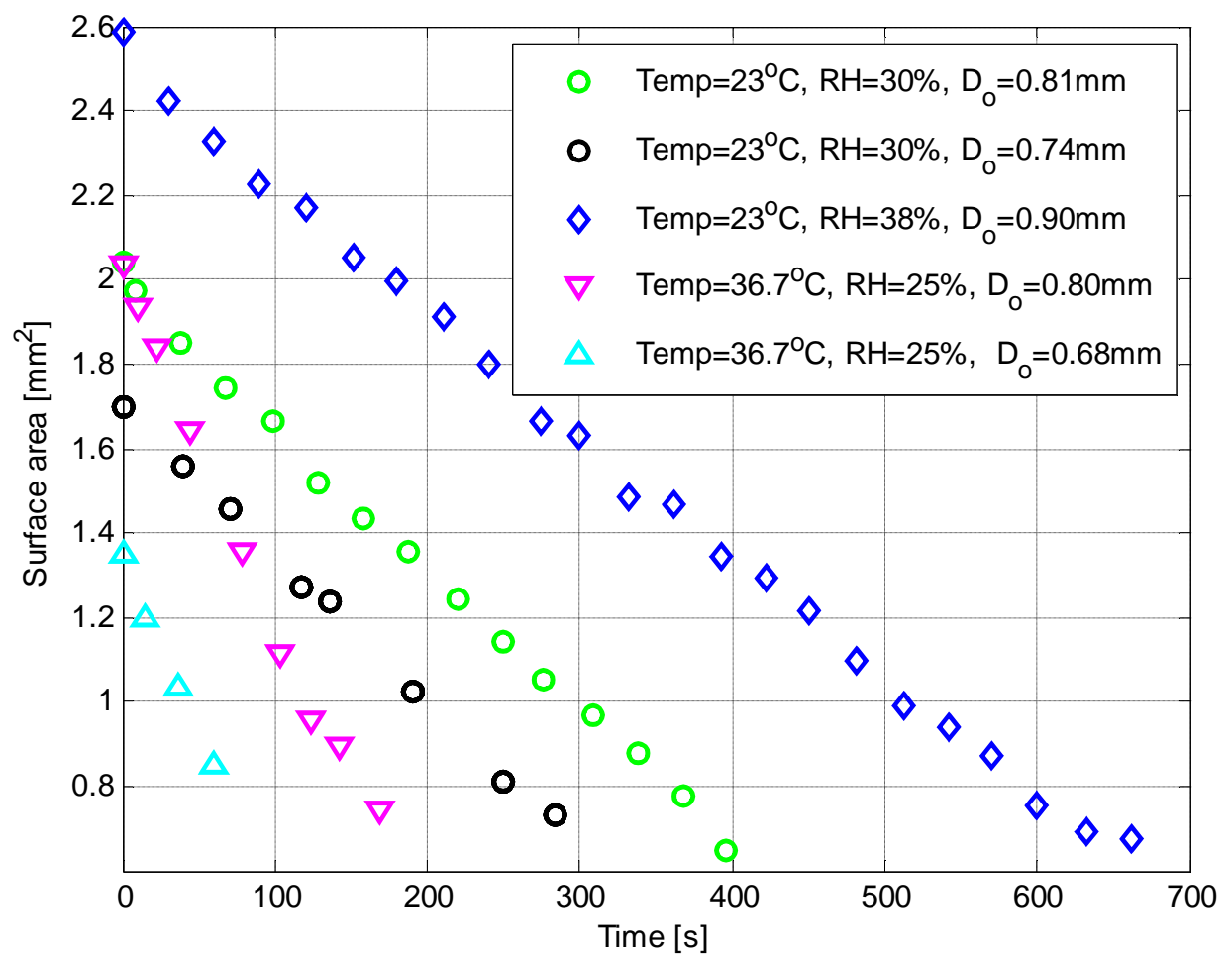

Figure 3.9 Experimental results of semi-sphere Human saliva Droplets evaporation under different environmental temperature and relative humidity: Surface area $\left[\mathrm{mm}^{2}\right]$ vs. Time [s] 


\section{Chapter 4: Mathematical Model of Evaporation}

\section{Mathematical Model}

According to Fick's law, the mass flux at the surface of an evaporating or condensing droplet in a binary mixture is:

$$
\rho_{s} \omega=-D_{v} \frac{\partial \rho_{A}}{\partial n}
$$

where $n$ is the coordinate normal to and away from the surface, $\rho_{A}$ is the mass density of species A, $\rho_{s}$ is the mixture density, $D_{v}$ is the diffusion coefficient (Crowe et al., 1997). Then,

$$
\rho_{s} \omega=-\rho_{s} D_{v} \frac{\partial\left(\rho_{A} / \rho_{s}\right)}{\partial n}=-\rho_{s} D_{v} \frac{\partial \omega_{A}}{\partial n}
$$

where $\omega_{A}$ is the mass fraction of species A in the mixture (Crowe et al., 1997).

For a droplet of diameter $d$ the gradient of mass fraction must be proportional to the mass fraction difference between the surface and the free stream and inversely proportional to the droplet diameter:

$$
\rho_{s} \omega=-\rho_{s} D_{v} \frac{\partial \omega_{A}}{\partial n} \propto \rho_{c} D_{v} \frac{\omega_{A, s}-\omega_{A, \infty}}{d}
$$

where $\omega_{A, S}$ is the mass fraction of species A at the droplet surface and $\omega_{A, \infty}$ in the free stream. The density $\rho_{c}$ is the representative density and may be the average density between the surface and the free stream (Crowe et al., 1997).

The droplet continuity equation states that the rate of change of droplet mass is the negative value of the mass efflux through the droplet surface, 


$$
\frac{d m}{d t}=-\rho_{s} \omega A
$$

where $A$ is the area of the droplet surface (Crowe et al., 1997).

Thus the rate of change of droplet mass should be proportional to

$$
\frac{d m}{d t} \propto \pi d^{2} \rho_{c} D_{v} \frac{\omega_{A, \infty}-\omega_{A, s}}{d}
$$

The constant of proportionality is the Sherwood number so the equation becomes (Crowe et al., 1997).

$$
\frac{d m}{d t}=\operatorname{Sh} \pi d \rho_{c} D_{v}\left(\omega_{A, \infty}-\omega_{A, s}\right)
$$

where $S h$ is Sherwood number (Crowe et al., 1997):

$$
S h=2.0+0.6 \operatorname{Re}_{r}^{0.5} \mathrm{Sc}^{0.33}
$$

where $\operatorname{Re}_{r}$ is the Reynolds number based on the relative speed between the droplet and the carrier gas,

$$
\operatorname{Re}_{r}=\frac{d|\mathbf{u}-\mathbf{v}|}{v}
$$

Where $\mathbf{u}$ and $\mathbf{v}$ are the velocity of the continuous and dispersed phases, respectively, $v$ is the kinetic viscosity.

Sc is the Schmidt number defined by

$$
\mathrm{Sc}=\frac{v}{D_{v}}
$$


The mass fraction terms:

$$
\omega_{A, \infty}-\omega_{A, s}=\frac{\rho_{A, \infty}-\rho_{A, s}}{\rho_{c}}
$$

where $\rho_{A, \infty}$ is the vapor density in free stream and $\rho_{A, s}$ is the density at droplet surface.

Then, equation (4.6) turns to:

$$
\frac{d m}{d t}=2 \operatorname{Sh} \pi r D_{\nu}\left(\rho_{A, \infty}-\rho_{A, s}\right)
$$

The mass changing with time can be represented by:

$$
\frac{d m}{d t}=\frac{d}{d t}\left(\rho_{d} \frac{\pi d^{3}}{6}\right)=\frac{\pi}{2} \rho_{d} d^{2} \frac{d d}{d t}
$$

Thus

$$
\frac{\pi}{2} \rho_{d} d^{2} \frac{d d}{d t}=2 \operatorname{Sh} \pi r D_{v}\left(\rho_{A, \infty}-\rho_{A, s}\right)
$$

where $\rho_{d}$ is the droplet density. (Pruppacher \& Klett, 1978)

From ideal gas law

$$
\rho=\frac{e M}{R T}
$$

where $R$ is the universal gas constant, $e$ is the atmosphere pressure.

Equation (4.11) becomes 


$$
\frac{d m}{d t}=\frac{2 S h \pi r D_{v} M_{\omega}}{R}\left(\frac{e_{\infty}}{T_{\infty}}-\frac{e_{d}}{T_{d}}\right)
$$

where $e_{\infty}$ is the vapor pressure in the free stream, $e_{d}$ is the vapor pressure at droplet location, $T_{\infty}$ is the temperature in the free stream and $T_{d}$ is the droplet temperature.

Then,

$$
r \frac{d r}{d t}=\frac{S h D_{v} M_{\omega}}{2 R \rho_{d}}\left(\frac{e_{\infty}}{T_{\infty}}-\frac{e_{d}}{T_{d}}\right)
$$

An expression for the temperature $T_{d}$ at the droplet surface can be obtained by considering the coupling of the rates of change of heat and mass through heat release (Pruppacher \& Klett, 1978):

$$
T_{d}=T_{\infty}+\frac{L_{v} \rho_{d}}{k_{a}^{\prime}} r \frac{d r}{d t}
$$

where $L_{v}$ is the latent heat of evaporation, $k_{a}^{\prime}$ is the modified thermal conductivity (Crowe et al., 1997):

Let

$$
\delta=\frac{L_{e} \rho_{d}}{T_{\infty} k_{a}^{\prime}} r \frac{d r}{d t}
$$

Then

$$
\frac{T_{d}}{T_{\infty}}=1+\delta
$$

Rewrite equation (4.16) 


$$
r \frac{d r}{d t}=\frac{S h D_{v} M_{\omega}}{2 R \rho_{d}} \frac{e_{s a t, w}\left(T_{\infty}\right)}{T_{\infty}}\left(\frac{e_{\infty}}{e_{s a t, w}\left(T_{\infty}\right)}-\frac{e_{d}}{e_{s a t, w}\left(T_{\infty}\right)} \frac{T_{\infty}}{T_{a}}\right)
$$

where $e_{s a t, w}\left(T_{\infty}\right)$ is the saturated vapor pressure at temperature $T_{\infty}$.

Relative humidity is defined as:

$$
R H=\frac{e_{\infty}}{e_{s a t, w}\left(T_{\infty}\right)}
$$

and

$$
\frac{e_{d}}{e_{s a t, w}\left(T_{\infty}\right)}=\frac{e_{d}}{e_{s a t, w}\left(T_{d}\right)} \cdot \frac{e_{s a t, w}\left(T_{d}\right)}{e_{s a t, w}\left(T_{\infty}\right)}=\exp \left[\frac{L_{e} M_{w}}{R T_{\infty}}\left(\frac{\delta}{1+\delta}\right)+\frac{2 M_{w} \sigma_{s / a}}{R T_{\infty}(1+\delta) \rho_{w} a}-\frac{v \Phi_{s} M_{w} / M_{s}}{\left(4 \pi a^{3} \rho_{d} / 3\right)-m_{s}}\right]
$$

where $\sigma_{s / a}$ is the surface tension, $\rho_{w}$ is the water density, $v$ is number of ions into which a salt molecule dissociates, $\Phi_{s}$ is the practical osmotic coefficient, $M_{s}$ is the molecular weight of salt and $m_{s}$ is the mass of salt in the droplet (Pruppacher \& Klett, 1978). Then, the general equation becomes:

$$
r \frac{d r}{d t}=\frac{S h D_{v} M_{\omega}}{2 R \rho_{d}} \frac{e_{s a t, w}\left(T_{\infty}\right)}{T_{\infty}}\left\{R H-\frac{1}{1+\delta} \exp \left[\frac{L_{e} M_{w}}{R T_{\infty}}\left(\frac{\delta}{1+\delta}\right)+\frac{2 M_{w} \sigma_{s / a}}{R T_{\infty}(1+\delta) \rho_{w} r}-\frac{v \Phi_{s} M_{w} / M_{s}}{\left(4 \pi r^{3} \rho_{d} / 3\right)-m_{s}}\right]\right\}
$$

Equation 4.22 is an equation which can solve binary solutions, but for the purposes we need a more general model that can solve for multiple component solutions. To modify equation (4.22), using an aqueous solution drop containing a solid insoluble substance (Pruppacher \& Klett, 1978) 


$$
\frac{e_{d}}{e_{s a t, w}}=\exp \left[\frac{2 M_{w} \sigma_{s / a}}{R T \rho_{w} r}-\frac{\nu \Phi_{s} \varepsilon_{m} M_{w} \rho_{N} r_{N}^{3}}{M_{s} \rho_{w}\left(r^{3}-r_{N}^{3}\right)}\right]
$$

where $\varepsilon_{m} \equiv m_{s} / m_{N}, m_{N}$ is the mass of the solid components, $r_{N}$ is the diameter of the nuclei after evaporation.

Replacing the term shown in equation (4.22) in equation (4.23):

$$
r \frac{d r}{d t}=\underbrace{\frac{S h D_{v} M_{\omega}}{2 R \rho_{d}} \frac{e_{s a t, w}\left(T_{\infty}\right)}{T_{\infty}}}_{\text {Diffusion Term }}\left\{R H-\frac{1}{1+\delta} \exp [\underbrace{\frac{L_{e} M_{w}}{R T_{\infty}}\left(\frac{\delta}{1+\delta}\right)}_{\text {Latent Heat Term }}+\underbrace{\frac{2 M_{w} \sigma_{s / a}}{R T_{\infty}(1+\delta) \rho_{w} r}}_{\text {Surface Tension Influence }}-\underbrace{\frac{M_{w} \rho_{N} r_{N}^{3}}{\rho_{d}\left(r^{3}-r_{N}^{3}\right)} \sum_{y} \frac{v_{y} \Phi_{y} \varepsilon_{y}}{M_{y}}}_{\text {Solute Influence }}]\right\}
$$

A Matlab program was developed by using the mathematical model of equation (4.25).

To solve Equation 4.23, the valuables in the equation should be specified.

$D_{v, \text { original }}=0.211\left(\frac{T_{d}}{T_{0}}\right)^{1.94}\left(\frac{P_{0}}{P}\right) ;($ Pruppacher \& Klett, 1978$)$

The original equation is only valid for the distances greater than the 'vapor jump' length $\Delta_{v}(\Delta v$ $\approx \lambda$ mean free path) which is the average distance covered by a moving particle between successive impacts) from the drop surface. For the region $r \leq r_{i} \leq r+\Delta_{v}$, we need to consider the gas kinetic expressions and the original equation needs to be modified. $D_{v}=\frac{D_{v, \text { original }}}{\left[\frac{r}{r+5 e-8}+\frac{D_{v, \text { original }}}{r^{*} 0.002}\left(\frac{2 \pi}{R T_{d}}\right)^{0.5}\right]}$ (Pruppacher \& Klett, 1978); this equation is used to calculate in the Matlab code; 
$e_{s a t, w}=6.1121\left(1.0007+3.46 \times 10^{-6} P\right) \exp \left(\frac{17.502 T_{d}}{240.97+T_{d}}\right)$ (Andreas, 2005), and it is used in the Matlab code;

$c_{p}=1005.60+0.017211 T_{d}+0.000392 T_{d}$ (Andreas, 2005)

$L_{v}=\left(25.00-0.02274 * T_{C}\right) * 10^{5}($ Andreas, 2005);

$K_{a, \text { original }}=0.02411\left(1+3.309 e-3 T_{d}-1.441 e-6 \times T_{d}^{2}\right)($ Andreas, 2005$)$

$K_{a}=\frac{K_{a, \text { original }}}{\left[\frac{r}{r+2.16 e-7}+\frac{K_{a, \text { original }}}{r \times 0.7^{*} \rho \times c_{p}}\left(\frac{2 \pi M_{a}}{R T_{a}}\right)^{0.5}\right]}$ (Pruppacher \& Klett, 1978);

The number of ions into which a salt molecule dissociates: $v=2$;

$\Phi_{s}=0.0055\left(\frac{m_{\text {salt }}}{M_{s}}\right)^{2}+0.028\left(\frac{m_{\text {salt }}}{M_{s}}\right)+0.9128$ (Pruppacher \& Klett, 1978);

$\sigma_{w}=0.2358\left(\frac{374-T_{d}}{647.15}\right)^{1.256}\left(1-0.625\left(\frac{374-T_{d}}{647.15}\right)\right)($ Andreas, 2005);

$\sigma_{s w} \cong \sigma_{w}$

\section{Liquids used with the model}

Pure water, $0.3 \% \mathrm{NaCl}$ water solution, $0.6 \% \mathrm{NaCl}$ water solution, $0.9 \% \mathrm{NaCl}$ water solution and human saliva are modeled in the numerical solution. The constituents of human saliva used in the numerical solution are shown in Table 4.2 (Redrow, 2009). 
Table 4. 1 Composition of human saliva in the mathematical solution

\begin{tabular}{|l|r|}
\hline Composition of human saliva & Composition [mg/mL] \\
\hline $\mathrm{NaCl}$ & 9 \\
\hline Protein & 12.100 \\
\hline Lipid & 10.600 \\
\hline Carbohydrate & 9.200 \\
\hline DNA & 0.008 \\
\hline
\end{tabular}




\section{Chapter 5: Results and discussion}

Figure 5.1 shows the experimental result is highly fit to the numerical result. The small hump in the end of the experimental result might be due to the reflection and refraction of the light when the photos were taken. In the distilled water droplet evaporation experiment, the temperature is $23^{\circ} \mathrm{C}$; the relative humidity is $50 \%$ and the wind velocity is zero.

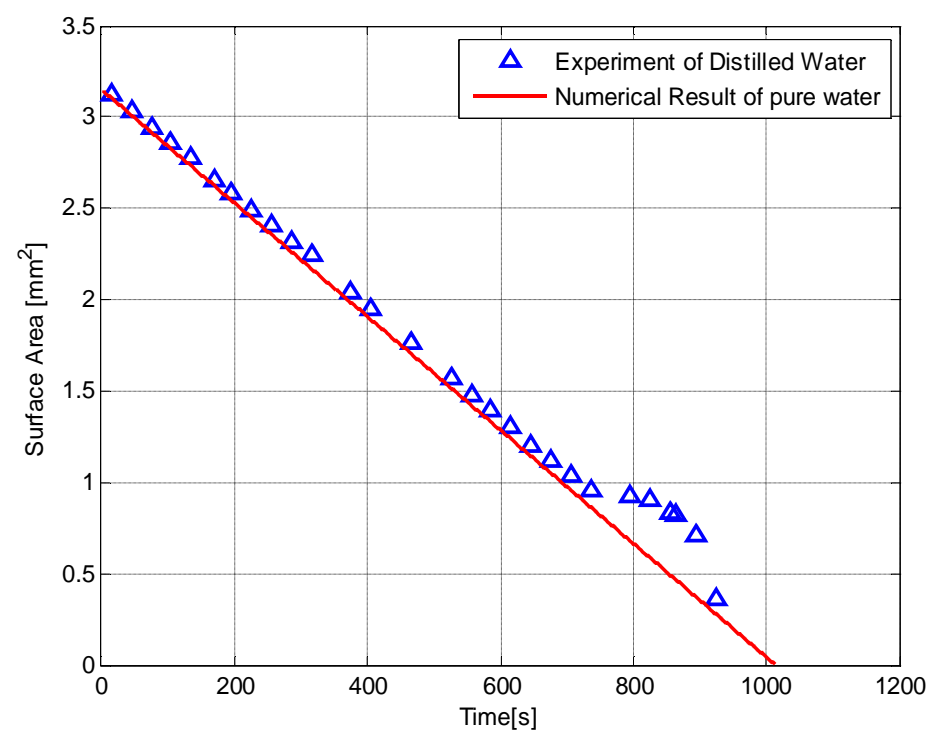

Figure 5. 1 Water droplet evaporation: Surface area vs. Time

The results of three different concentrations of $\mathrm{NaCl}$ water solution droplets and human saliva droplet are illustrated in Figure 5.2. The environmental temperature is $13.5^{\circ} \mathrm{C}$ and relative humidity is $33 \%$. 


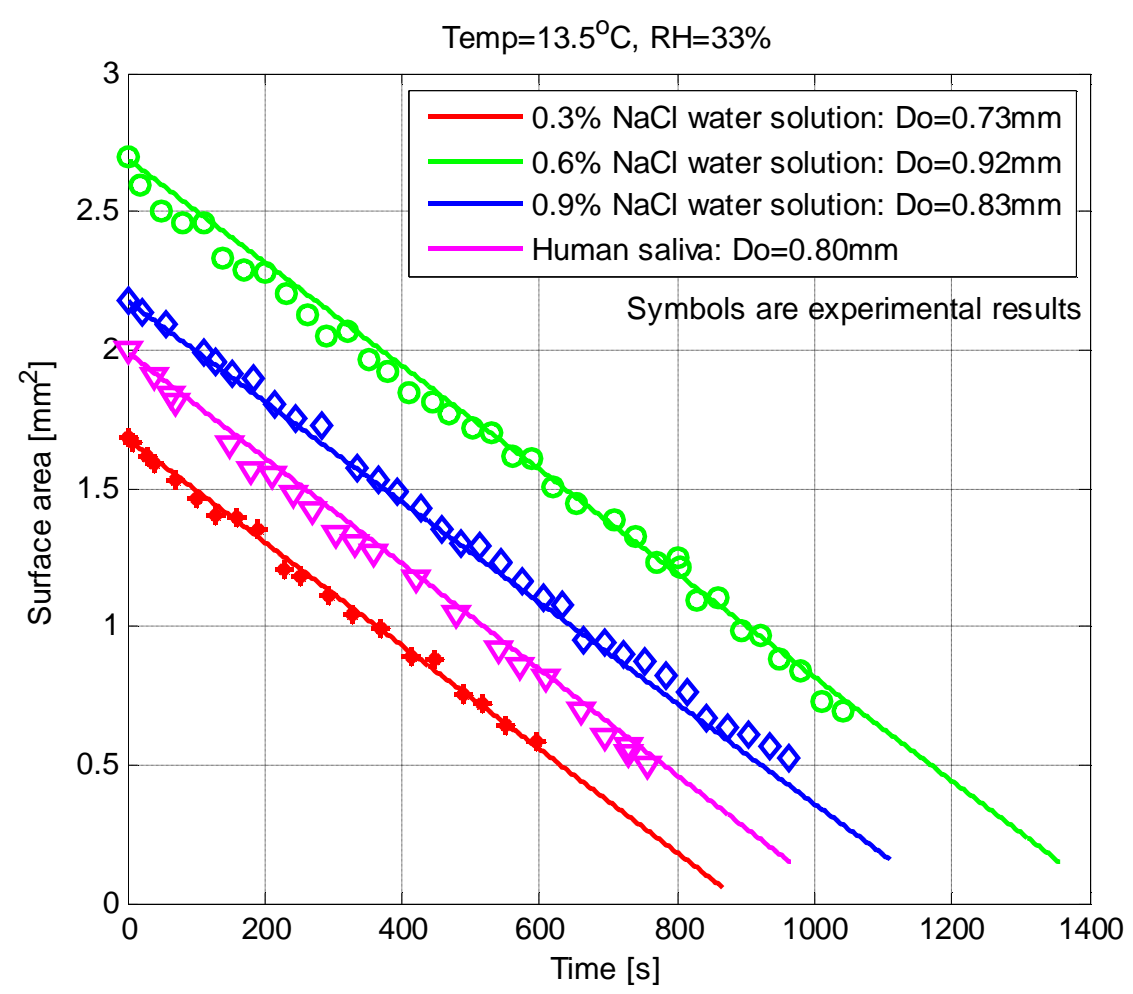

Figure 5. 2 0.3\% NaCl water droplet evaporation: Surface area $\left[\mathrm{mm}^{2}\right]$ vs. Time $[s\}$

Some noise points in the end of the evaporation process of the three experiments were cancelled and they were caused by the salt crystallized after the water evaporated. Ideally, the salt would crystallize as a semi-sphere finally, however, when the water evaporated, the salt was left in the flat plane randomly rather than like an exact semi-sphere. From Figure 5.2, it can be observed that the numerical results and the experimental results are matched well to each other. The evaporation rates of the droplet of the salt solutions are smaller than the rate of the water droplet evaporation. Additionally, Figure 5.2 also shows the evaporation of human saliva droplet. Numerical result is good enough to predict the experimental process. The evaporation rate of the human saliva droplet is also a little bit slower than that of the pure water droplet.

Figure 5.3 shows the evaporation of different kinds of droplets at different environmental temperature and relative humidity. In Figure 5.6, "N" means numerical result; "E" means 
experimental result; $0.3 \%$ means $0.3 \% \mathrm{NaCl}$ water solution droplet, similarly to $0.6 \%$ and $0.9 \%$; HS stands for human saliva; $\mathrm{T}$ is the environmental temperature. Under the environmental condition that temperature around $34.2^{\circ} \mathrm{C}$ and relative humidity around $26 \%$, the droplets include $0.3 \% \mathrm{NaCl}$ water solution droplet, $0.6 \% \mathrm{NaCl}$ water solution droplet, $0.9 \% \mathrm{NaCl}$ water solution droplet; under the environmental condition that temperature around $23^{\circ} \mathrm{C}$ and relative humidity around $30 \%$, there are three groups of human saliva droplets evaporation. From Figure 5.2.8, it can be observed that the experimental results fit well with the numerical results. The three groups of human saliva droplets evaporation can provide us the reliability of the numerical solution. 


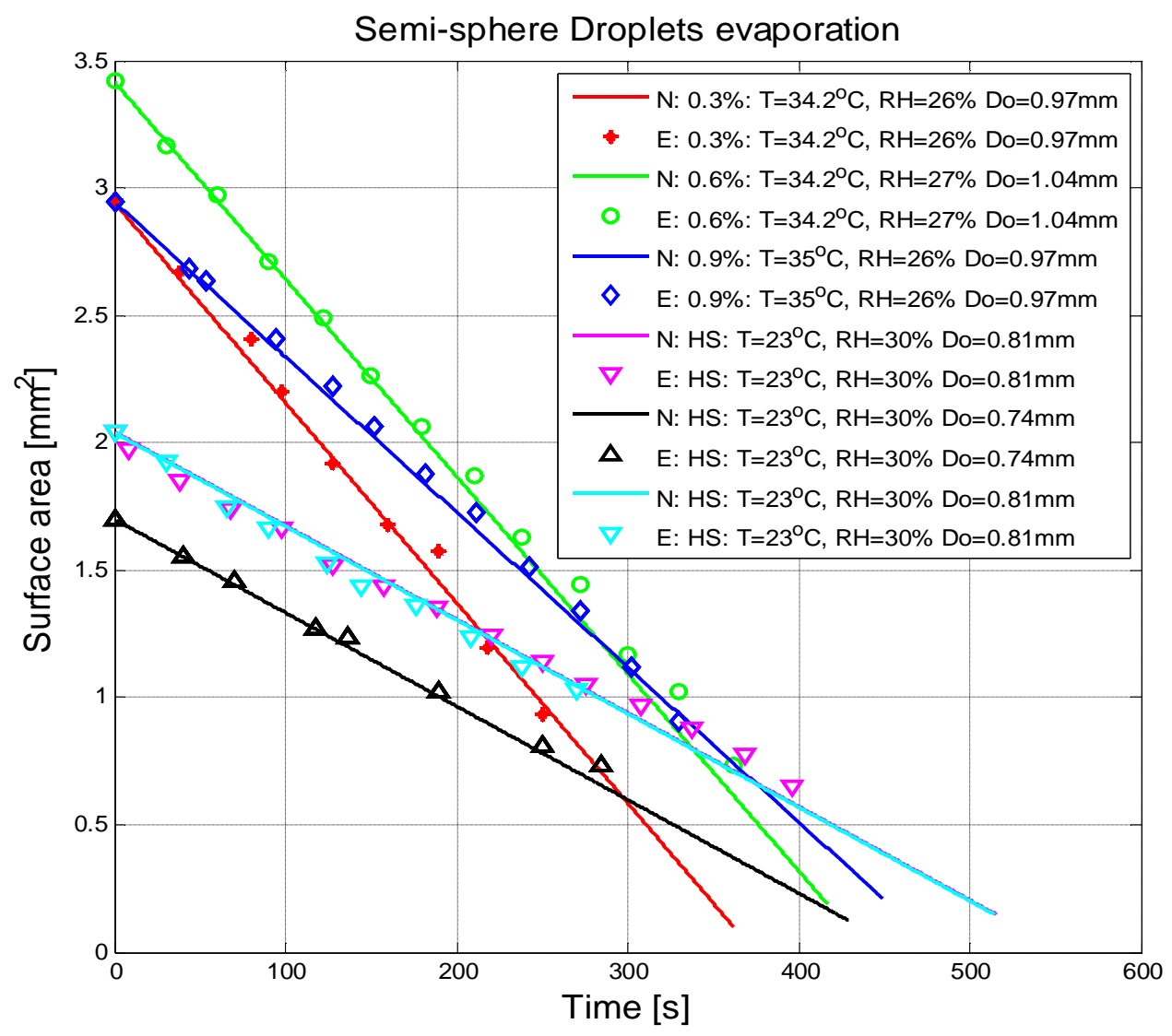

\section{Figure 5. 3 Results of Evaporation of different droplets under various environmental temperatures:}

Surface area $\left[\mathrm{mm}^{2}\right]$ vs. Time $[\mathrm{s}]$

Figure 5.4 shows all the groups of the human saliva droplet evaporation that have performed under high environmental temperature $\left(36.7^{\circ} \mathrm{C}\right)$ and relative humidity $(25 \%)$, medium temperature $\left(23^{\circ} \mathrm{C}\right)$ and relative humidity $(30 \%$ and $38 \%)$, and low temperature $\left(13^{\circ} \mathrm{C}, 2^{\circ} \mathrm{C}\right)$ and relative humidity (33\%). In Figure 5.7, "N" means numerical result; "E" means experimental result; $\mathrm{T}$ is the environmental temperature. 


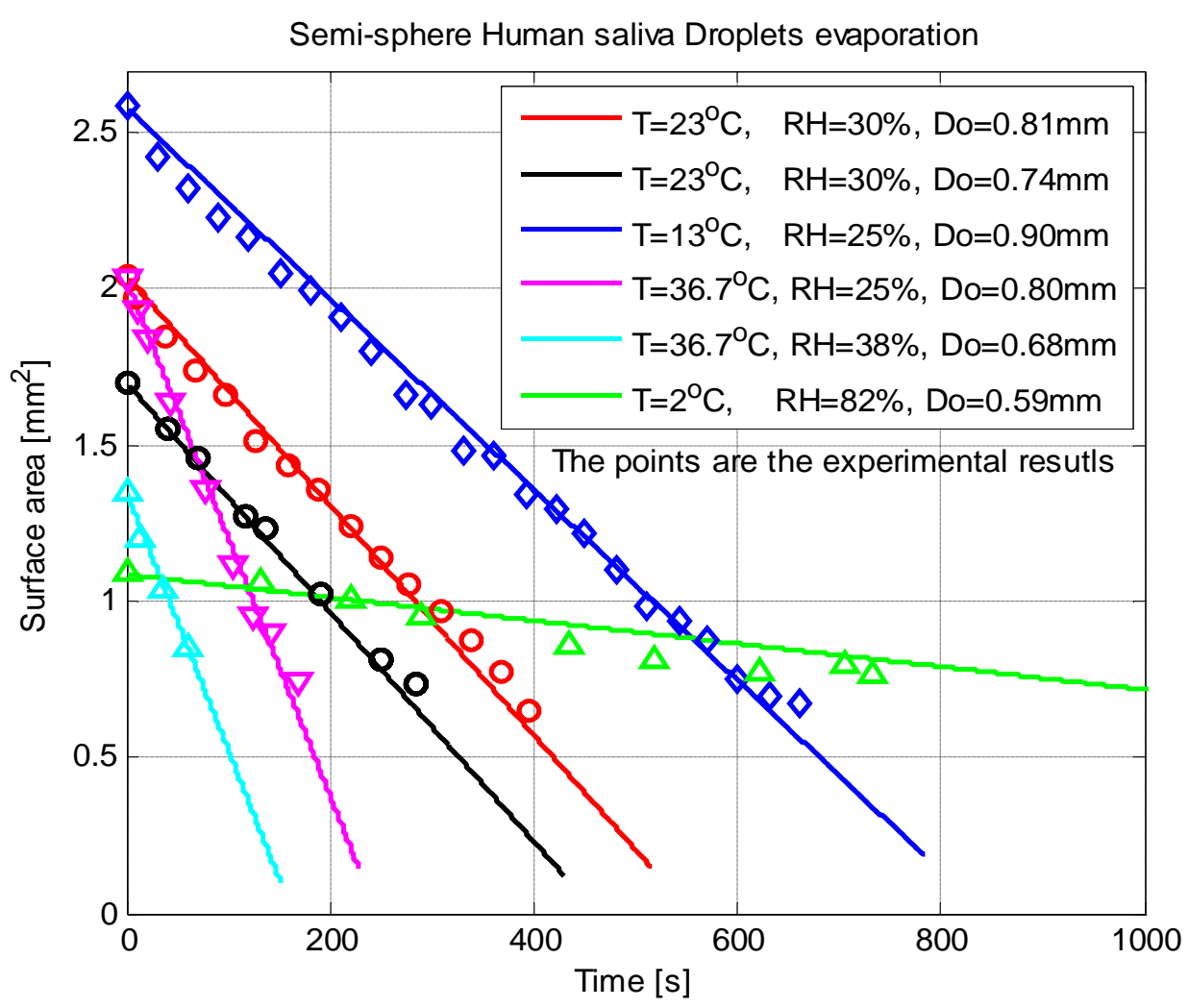

Figure 5. 4 The evaporation results of human saliva droplets at different temperature and relative humidity; Surface area $\left[\mathrm{mm}^{2}\right]$ vs. Time $[\mathrm{s}]$

Figure 5.5 shows that if the environment temperature increases, the evaporation will be faster, and keeping the temperature constantly, if the relative humidity increases, the evaporation rate will be slower. It can be concluded that at different temperature and relative humidity, the evaporation changes with environmental temperature and relative humidity. The numerical results are matched well with the experimental results. 


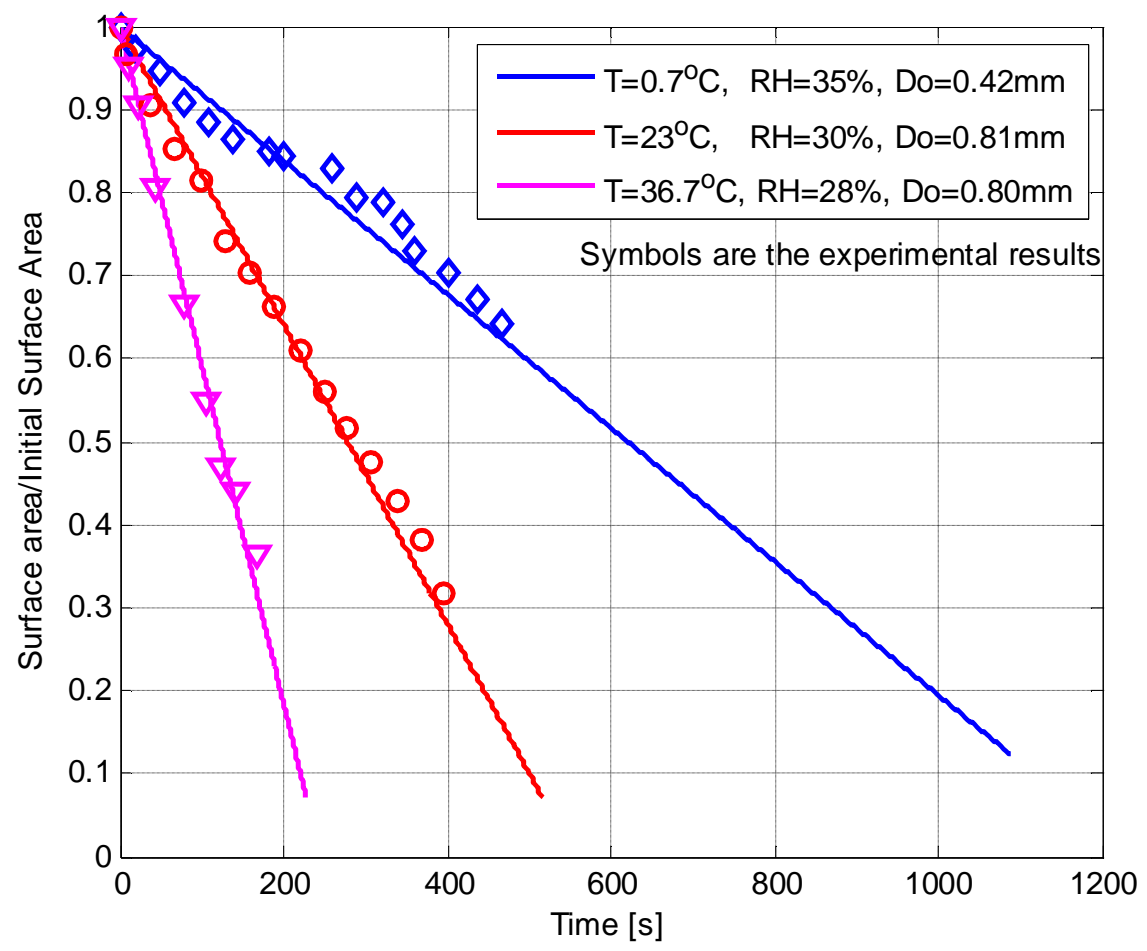

Figure 5. 5 Evaporation of human saliva droplets under different environmental temperature, similar relative humidity 
Figure 5.6 illustrates the experimental results and numerical results of $0.9 \% \mathrm{NaCl}$ water solution droplets and brewed coffee droplet evaporation.

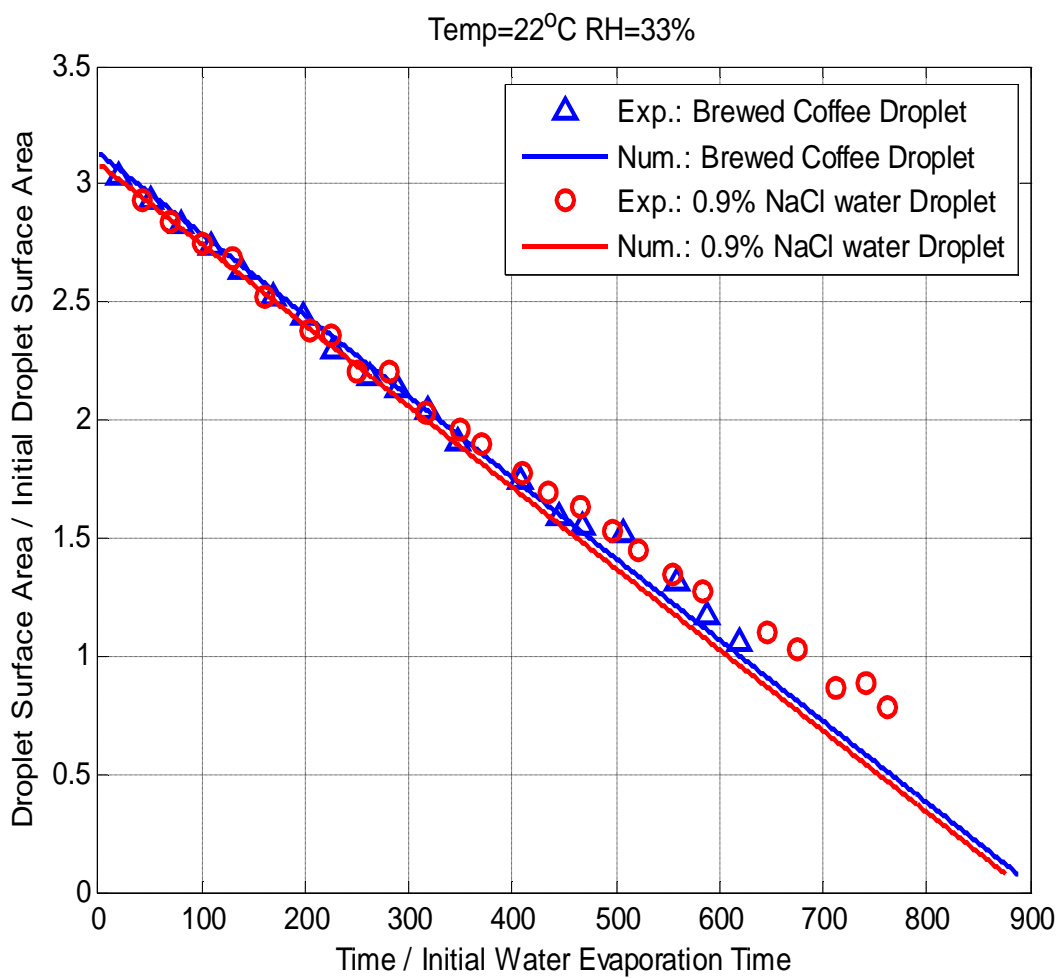

Figure 5. 6 Evaporation of coffee and $0.9 \% \mathrm{NaCl}$ water solution droplet: $\mathrm{Temp}=22^{\circ} \mathrm{C}$, $\mathbf{R H}=\mathbf{3 3 \%}$

Table 5.1 is showing the comparison of numerical results from the Matlab program and experimental results from other authors.

Table 5. 1 Comparison of numerical results: Matlab vs. experiments

\begin{tabular}{|c|c|c|c|c|c|c|c|c|}
\hline \multirow[b]{2}{*}{ Author } & \multirow[b]{2}{*}{ Solution } & \multicolumn{2}{|c|}{$\begin{array}{c}\text { Temperature } \\
{\left[{ }^{\circ} \mathrm{C}\right]}\end{array}$} & \multirow[b]{2}{*}{ RH } & \multirow{2}{*}{$\begin{array}{c}\text { Initial } \\
\text { diameter } \\
{[\mathrm{mm}]}\end{array}$} & \multicolumn{3}{|c|}{ Evaporation Rate $\left[\mathrm{mm}^{2} / \mathrm{s}\right]$} \\
\hline & & $\mathrm{Td}$ & Tatm & & & Experiment & $\begin{array}{c}\text { Numerical Result } \\
\text { [Zhang, 2011] }\end{array}$ & Error \\
\hline Smolik et al. & \multirow{7}{*}{$\begin{array}{l}\text { pure } \\
\text { water }\end{array}$} & 14.85 & 24 & $35 \%$ & 1.2 & -0.0064 & -0.0061 & $4.69 \%$ \\
\hline Ranz \& Marshall & & 9.11 & 24.9 & 0 & 1.05 & -0.003 & -0.0031 & $3.33 \%$ \\
\hline \multirow{5}{*}{$\begin{array}{l}\text { Molye et al.* } \\
\text { (Environmental } \\
\text { Pressure is } \\
\text { 596hpa) }\end{array}$} & & -33.5 & -33.5 & $36 \%$ & $5.00 \mathrm{E}-02$ & $-1.29 \mathrm{E}-04$ & $-1.24 \mathrm{E}-04$ & $4.11 \%$ \\
\hline & & -33.5 & -33.5 & $36 \%$ & $4.72 \mathrm{E}-02$ & $-1.32 \mathrm{E}-04$ & $-1.25 \mathrm{E}-04$ & $5.41 \%$ \\
\hline & & -33.5 & -33.5 & $36 \%$ & $4.46 \mathrm{E}-02$ & $-1.33 \mathrm{E}-04$ & $-1.24 \mathrm{E}-04$ & $6.26 \%$ \\
\hline & & -33.5 & -33.5 & $36 \%$ & $4.20 \mathrm{E}-02$ & $-1.25 \mathrm{E}-04$ & & $5.88 \%$ \\
\hline & & -33.5 & -33.5 & $36 \%$ & $3.70 \mathrm{E}-02$ & $-1.36 \mathrm{E}-04$ & $-1.26 \mathrm{E}-04$ & $7.70 \%$ \\
\hline
\end{tabular}


Table 5.2 shows the experimental results of human saliva droplets evaporation performed in this study and the numerical results under the same experimental conditions.

Table 5. 2 Evaporation rate of human saliva droplet: experiment vs. numerical results

\begin{tabular}{|c|c|c|c|c|c|c|c|}
\hline \multirow[b]{2}{*}{ Solution } & \multicolumn{2}{|c|}{ Temperature $\left[{ }^{\circ} \mathrm{C}\right]$} & \multirow[b]{2}{*}{$\mathrm{RH}$} & \multirow{2}{*}{$\begin{array}{c}\text { Initial } \\
\text { diameter } \\
{[\mathrm{mm}]}\end{array}$} & \multicolumn{3}{|c|}{ Evaporation Rate $\left[\mathrm{mm}^{2} / \mathrm{s}\right]$} \\
\hline & $\mathrm{Td}$ & Tatm & & & Experiment & $\begin{array}{c}\text { Numerical } \\
\text { Result }\end{array}$ & Error \\
\hline \multirow{10}{*}{$\begin{array}{l}\text { human } \\
\text { saliva }\end{array}$} & 23 & 23 & $30 \%$ & 0.81 & -0.0037 & -0.0035 & $5.41 \%$ \\
\hline & 23 & 23 & $30 \%$ & 0.74 & -0.0037 & -0.0035 & $5.41 \%$ \\
\hline & 13 & 13 & $25 \%$ & 0.90 & -0.0031 & -0.0031 & $0.00 \%$ \\
\hline & 36.7 & 36.7 & $25 \%$ & 0.80 & -0.0083 & -0.0086 & $3.61 \%$ \\
\hline & 36.7 & 36.7 & $38 \%$ & 0.68 & -0.0083 & -0.0086 & $3.61 \%$ \\
\hline & 2 & 2 & $82 \%$ & 0.59 & $-3.69 \mathrm{E}-04$ & $-3.62 \mathrm{E}-04$ & $1.90 \%$ \\
\hline & 23 & 23 & $30 \%$ & 0.74 & -0.0037 & -0.0036 & $2.70 \%$ \\
\hline & 23 & 23 & $30 \%$ & 0.81 & -0.0036 & -0.0036 & $0.00 \%$ \\
\hline & 23 & 23 & $30 \%$ & 0.81 & -0.0037 & -0.0036 & $2.70 \%$ \\
\hline & 0.7 & 0.7 & $35 \%$ & 0.42 & -0.0004 & -0.0005 & $7.77 \%$ \\
\hline
\end{tabular}

Table 5.3 shows the experimental results of $\mathrm{NaCl}$ water solution droplets and other droplet evaporation performed in this study and the numerical results under the same experimental conditions.

Table 5. 3 Evaporation rate of other kinds droplets: experiment vs. numerical results

\begin{tabular}{|c|c|c|c|c|c|c|c|}
\hline \multirow[b]{2}{*}{ Solution } & \multicolumn{2}{|c|}{ Temperature $\left[{ }^{\circ} \mathrm{C}\right]$} & \multirow[b]{2}{*}{$\mathrm{RH}$} & \multirow{2}{*}{$\begin{array}{c}\text { Initial } \\
\text { diameter } \\
{[\mathrm{mm}]}\end{array}$} & \multicolumn{3}{|c|}{ Evaporation Rate $\left[\mathrm{mm}^{2} / \mathrm{s}\right]$} \\
\hline & $\mathrm{Td}$ & Tatm & & & Experiment & $\begin{array}{c}\text { Numerical } \\
\text { Result }\end{array}$ & Error \\
\hline \multirow{3}{*}{$0.3 \% \mathrm{NaCl}$ water solution } & 13.5 & 13.5 & $33 \%$ & 0.73 & -0.0019 & -0.0019 & $0.00 \%$ \\
\hline & 34.2 & 34.2 & $26 \%$ & 0.97 & -0.0079 & -0.0080 & $1.27 \%$ \\
\hline & 34.2 & 34.2 & $26 \%$ & 0.97 & -0.0079 & -0.0080 & $1.27 \%$ \\
\hline \multirow{2}{*}{$0.6 \% \mathrm{NaCl}$ water solution } & 13.5 & 13.5 & $33 \%$ & 0.92 & -0.0019 & -0.0019 & $0.00 \%$ \\
\hline & 34.2 & 34.2 & $27 \%$ & 1.04 & -0.0076 & -0.0075 & $1.32 \%$ \\
\hline \multirow{3}{*}{$0.9 \% \mathrm{NaCl}$ water solution } & 35 & 35 & $26 \%$ & 0.97 & -0.0065 & -0.0067 & $3.08 \%$ \\
\hline & 13.5 & 13.5 & $33 \%$ & 0.83 & -0.0018 & -0.0018 & $0.00 \%$ \\
\hline & 22 & 22 & $33 \%$ & 1.00 & -0.0030 & -0.0030 & $0.00 \%$ \\
\hline brewed coffee & 22 & 22 & $33 \%$ & 1.00 & -0.0030 & -0.0029 & $3.33 \%$ \\
\hline
\end{tabular}


In Figure 5.7, under various temperature and constant relative humidity, the evaporation rate varies. When the temperature is increasing, the evaporation rate will increase, and contrarily, the evaporation rate will decrease.

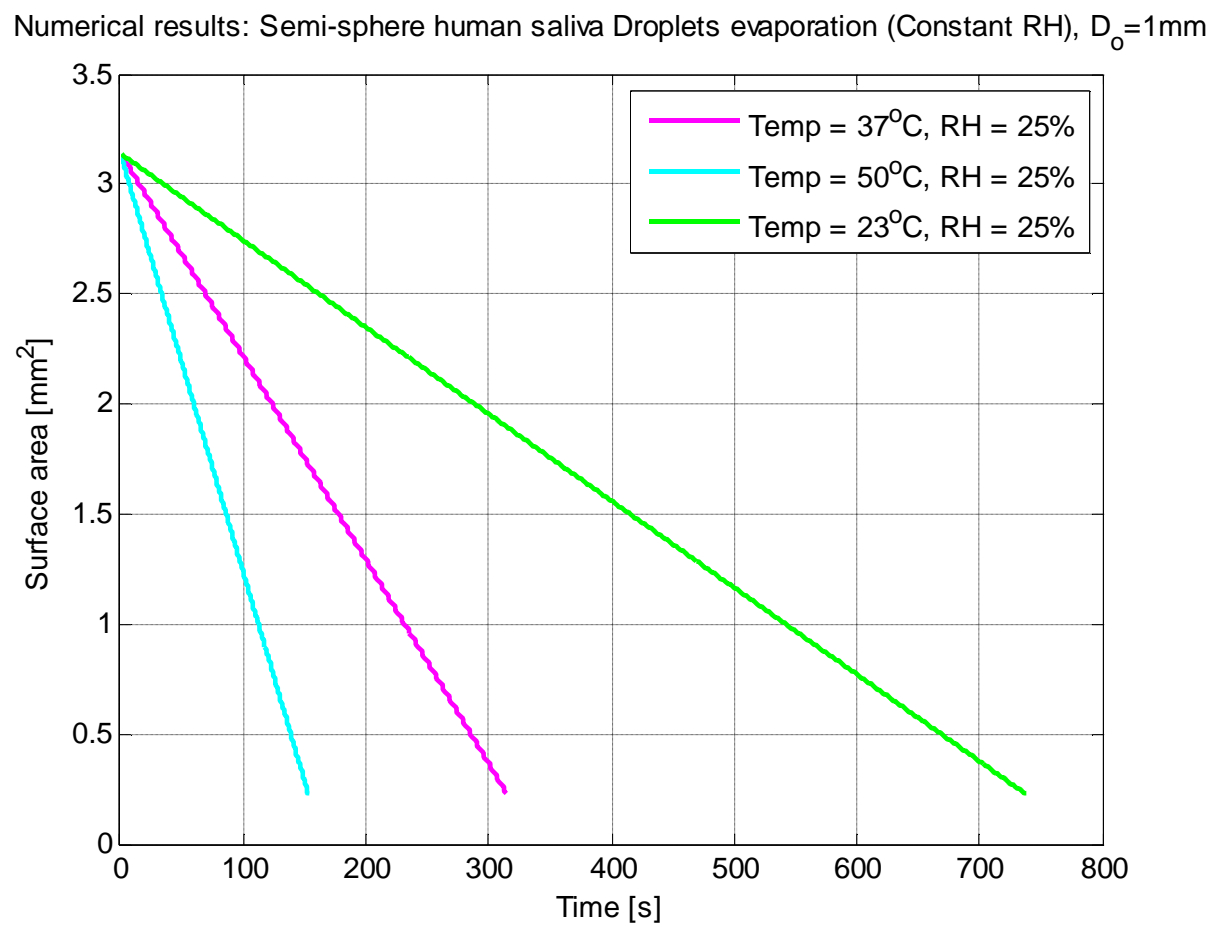

\section{Figure 5. 7 Numerical results of human saliva droplets under different temperature, same relative humidity}

On the other hand, as showing in Figure 5.8, under constant temperature and various relative humidity, the evaporation rate also varies. When the relative humidity of the ambient environment is increasing, the evaporation rate will decrease, and when it is decreasing, the evaporation rate will increase. 
Numerical results: Semi-sphere human saliva Droplets evaporation (Constant Temp.), $D_{0}=1 \mathrm{~mm}$

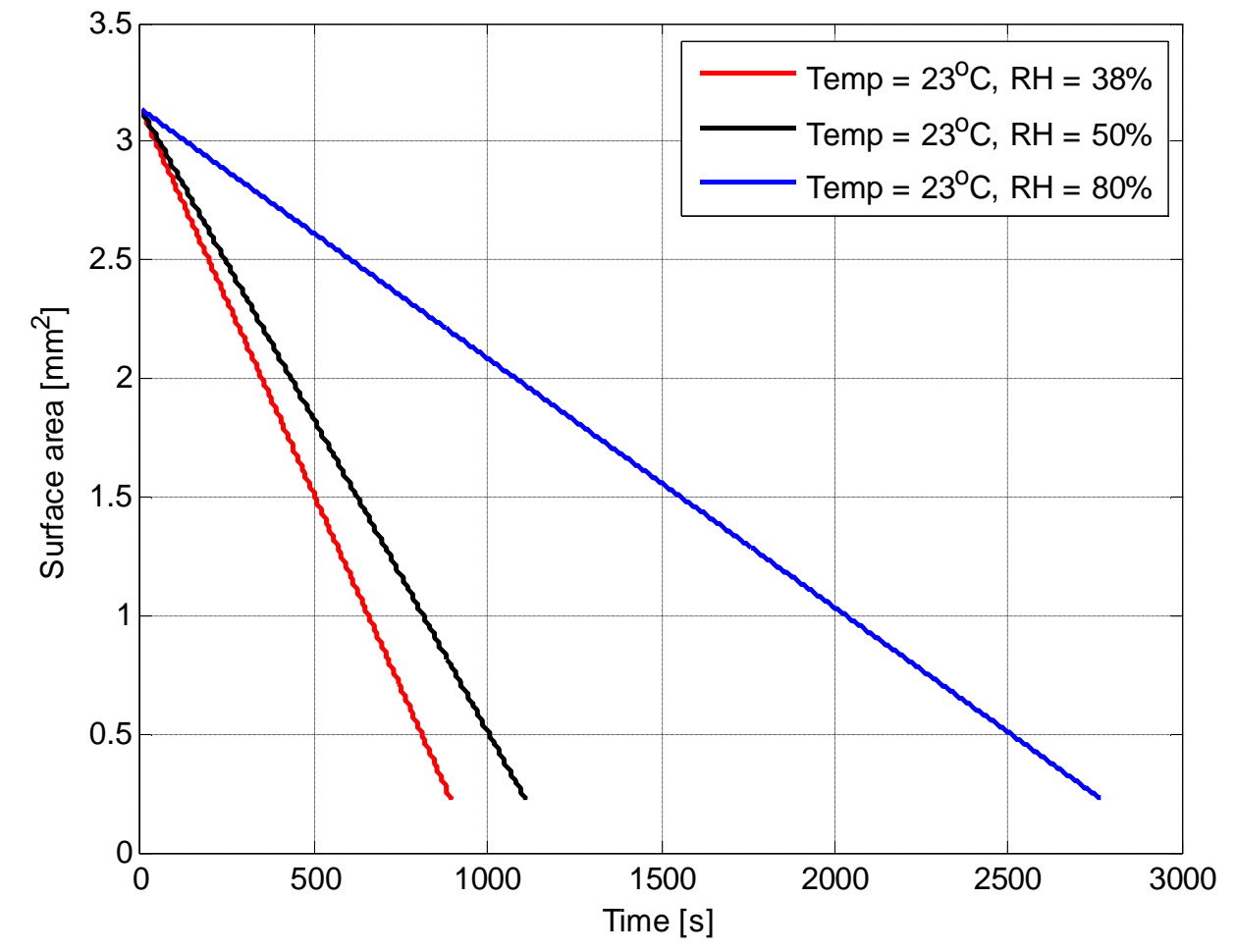

Figure 5. 8 Numerical results of human saliva droplets under different relative humidity, same temperature

In order to obtain a droplet with the same evaporation rate of human saliva droplet, Figure 5.9 was provided by showing the numerical results, including all kinds of droplets which have the same initial diameter $(1 \mathrm{~mm})$ in the study at the same temperature and relative humidity. Figure 5.9 tells that when the salinity increases, the evaporation rate will decrease, that is to say the water droplet has the largest evaporation rate among these kinds of droplets, and $1.2 \% \mathrm{NaCl}$ water droplet has the slowest evaporation rate. 


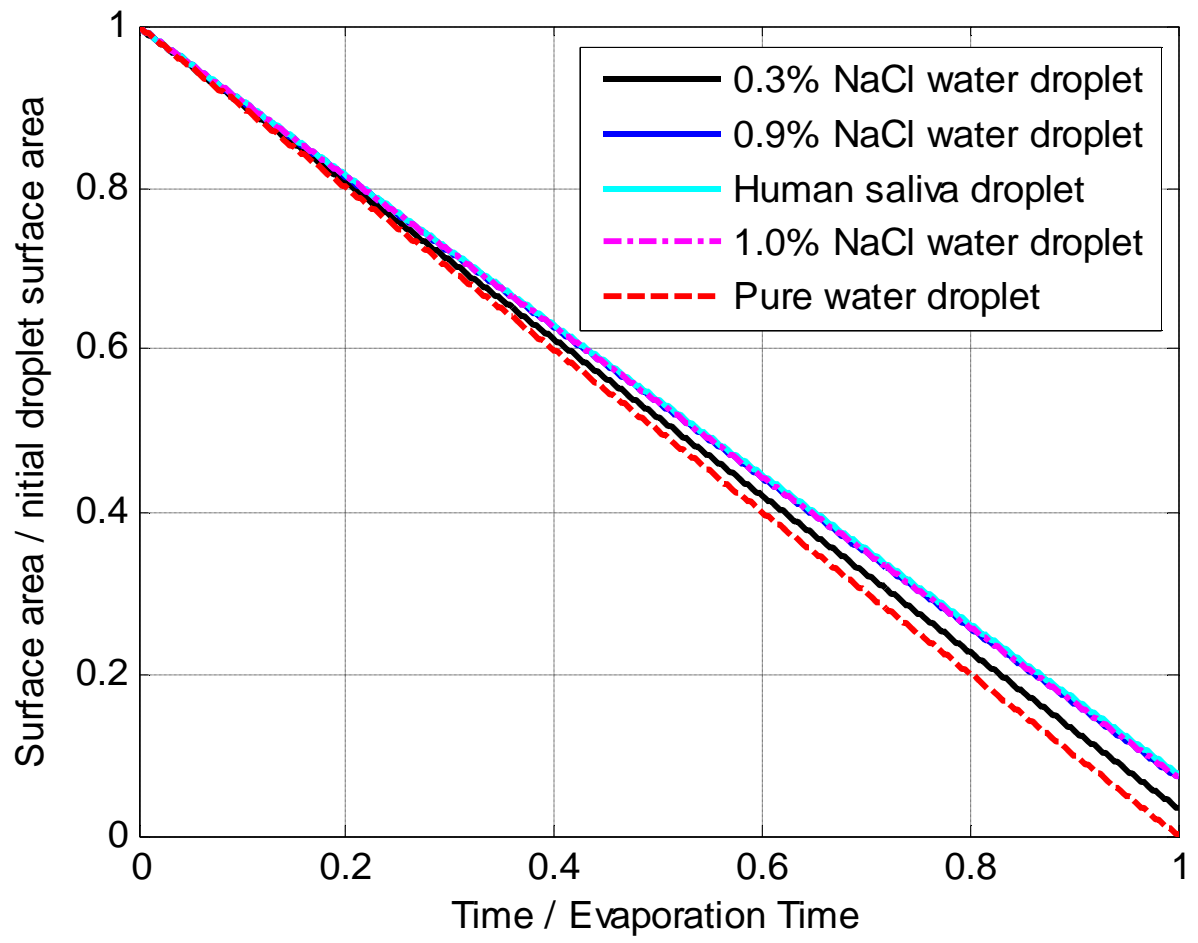

Figure 5. 9 Numerical results of evaporation of different droplets

Figure 5.10 shows the evaporation process of an artificial human saliva and human saliva droplet under same environmental conditions $\left(23^{\circ} \mathrm{C}\right.$ and $38 \%$ relative humidity) and same initial diameter $1 \mathrm{~mm}$. In order to make an artificial human saliva, run the numerical solution code of $1 \mathrm{~mm}$ diameter human saliva droplet at $23^{\circ} \mathrm{C}, 30 \%$ to obtain the result of time that the droplet evaporates completely, and then make the lipid and DNA concentration equal to zero, and try to run the code with the other three components concentration: salt, protein and carbohydrate to obtain the closest result with human saliva. 


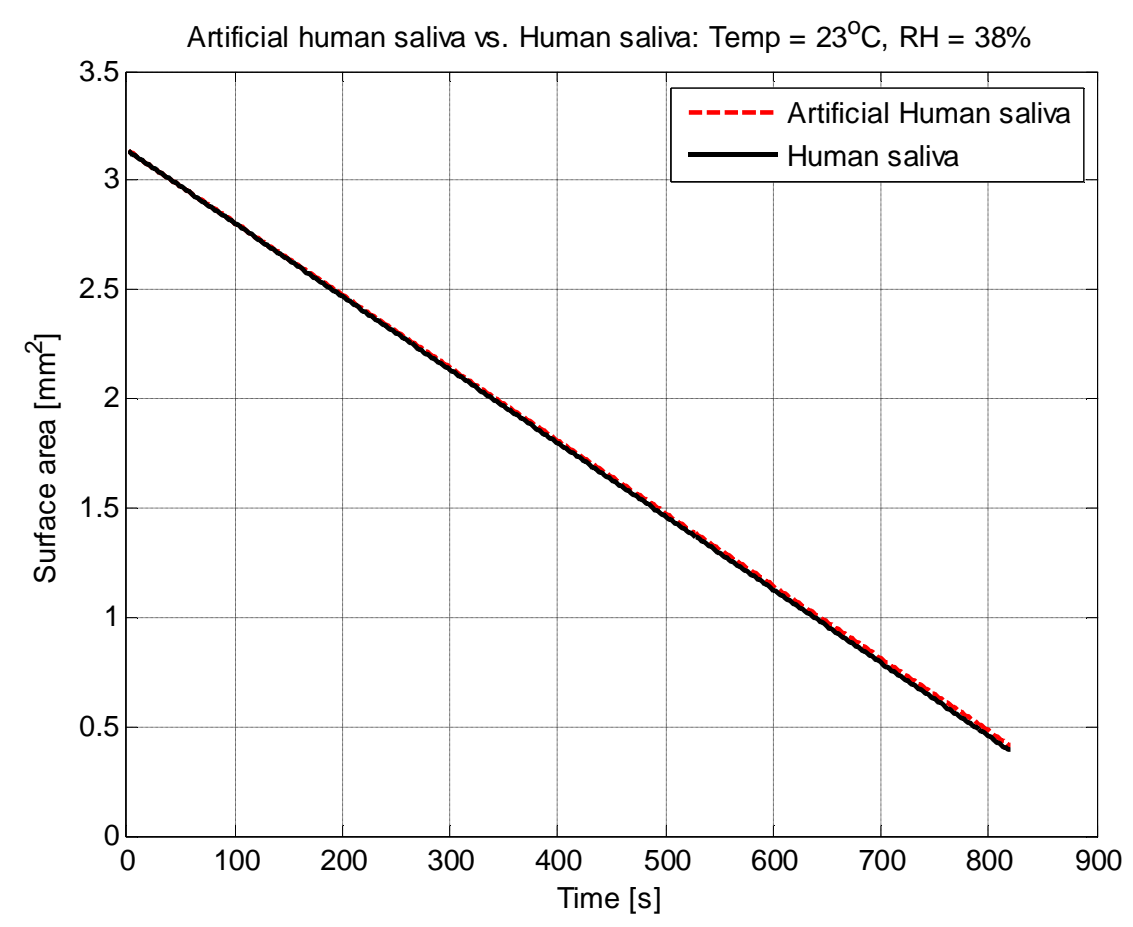

Figure 5. 10 Numerical solution of evaporation of artificial human saliva evaporation vs. Human saliva

In Figure 5.11, the temperature changed during the evaporation process.

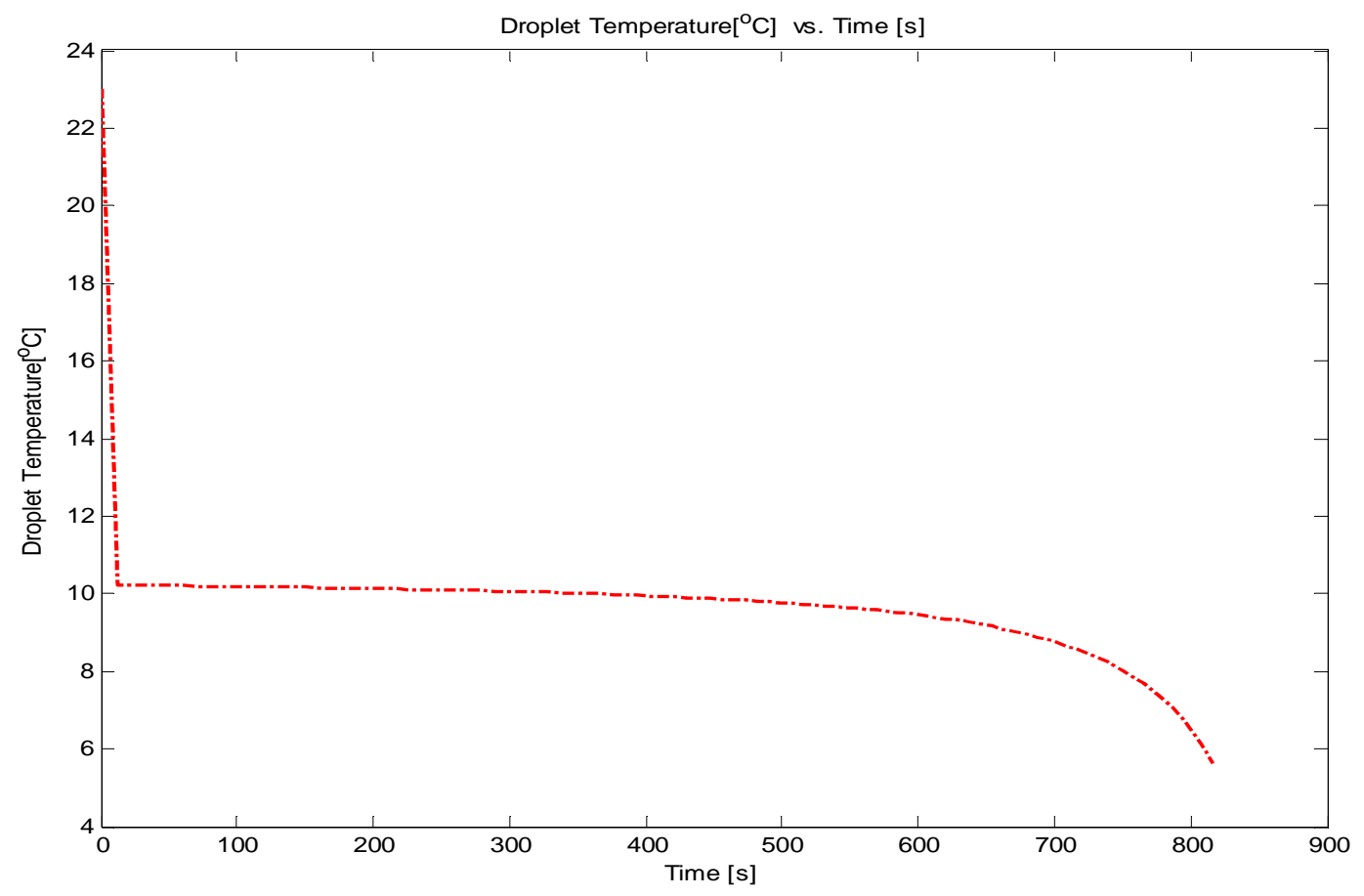

Figure 5. 11 Human saliva droplet evaporation: temperature $\left[{ }^{\circ} \mathrm{C}\right]$ vs. time $[\mathrm{s}]$ 
It can be observed that the temperature falls dramatically at the initial evaporation process to $10^{\circ} \mathrm{C}$, and then almost remains constant. The sharp decrease in temperature at the beginning is due to the latent heat of evaporation. At the end of the evaporation process, the temperature decrease again, this is due to the change of density of the liquid (see Equation 4.17). 


\section{Chapter 6: Conclusions}

The surface tension and evaporation rate of different droplets has been measured and analyzed in this study. Employing Matlab techniques and software, the surface tension and evaporation rate of different kinds of droplet have been calculated or simulated. It can be calculated that for water, if the temperature increases $20^{\circ} \mathrm{C}$, the surface tension of water will decrease $4.33 \%$.

When the salt concentration increases, the surface tension of the water solution will increase; contrarily, when the glucose concentration increases, the surface tension of the water solution will decrease.

Furthermore, salt decreases the evaporation rate of water droplet. It is reasonable that the intermolecular forces of atoms and molecules may repel or attract all elements. In the case of a soluble salt when dissolved into water it forms hydrogen bonds with the water through the dipole ends of the water molecule and the salt. These bonds make it necessary to apply more kinetic energy to create enough movement to break the bonds and the attraction between water molecules to change of state, in this case liquid to gas. If the temperature increases, the evaporation rate will be faster, and if the relative humidity increases, the evaporation rate will be slower, which can be concluded that when the temperature increases, the kinetic energy of the molecules of water will increase, and when the relative humidity increases, the concentration of water vapor in the ambient environment will increase which can restrain the water molecules evaporate

Under various temperature and constant relative humidity, the evaporation rate varies. When the temperature is increasing, the evaporation rate will increase, and contrarily, the evaporation rate will decrease. On the other hand, under constant temperature and various relative humidity, the 
evaporation rate also varies. When the relative humidity of the ambient environment is increasing, the evaporation rate will decrease, and when it is decreasing, the evaporation rate will increase.

When the salinity increases, the evaporation rate will decrease, that is to say the pure water droplet has the largest evaporation rate among these kinds of droplets: $0.3 \% \mathrm{NaCl}$ water solution droplet, $0.6 \% \mathrm{NaCl}$ water solution droplet, $0.9 \% \mathrm{NaCl}$ water solution, $1.2 \% \mathrm{NaCl}$ water solution droplet, and $1.2 \% \mathrm{NaCl}$ water solution droplet has the slowest evaporation rate.

In order to make artificial human saliva, numerical solution is used and environmental conditions are: temperature $=23^{\circ} \mathrm{C}$; relative humidity $=38 \%$. The components of the artificial human saliva are shown in Table 6.1. It has the same evaporation time as human saliva droplet.

Table 6. 1 The concentration of components of artificial human saliva

\begin{tabular}{|c|c|}
\hline & Concentration $[\mathrm{mg} / \mathrm{mL}]$ \\
\hline Salt & 9 \\
\hline Protein & 30 \\
\hline Carbohydrate & 35 \\
\hline Lipid & 0 \\
\hline DNA & 0 \\
\hline
\end{tabular}




\section{References}

(CDC), C.f.D.C.a.P., 2009. CDC-Key Facts About Avian Influenza (Bird Flu) and Avian Influenza A (H5NI) Virus. [Online] Available at: http://www.cdc.gov/flu/avian/geninfo/facts.htm [Accessed 17 Nov 2010].

Andreas, E.L., 2005. Hndbook of Physical Constants and FUnctions for Use in Atmospheric Boundary Layer Studies. ENGINEER RESEARCH AND DEVELOPMENT CENTER HANOVER NH COLD REGIONS RESEARCH AND ENGINEERING LAB.

Batchelor, G.K., 2000. An Introduction to Fluid Dynamics. Cambridge University Press.

Boretti, A., 2010. Comparative Emissions from Diesel and Biodiesel Fueled Buses from 2002 to 2008 Model Years. SAE International, 1683(01).

Bull, H.B., 1941. Osmotic pressure of egg albumin solutions. 137, pp.143-51.

CDC, 2010. H1N1 Flu | Interim Guidance on Infection Control Measures for 2009 H1N1 Influenza in Healthcare Settings, Including Protection of Healthcare Personnel. [Online] Available at: http://www.cdc.gov/h1n1flu/guidelines_infection_control.htm [Accessed 17 Nov 2010].

Chiappin, S., Antonelli, G., Gatti, R. \& Palo, E.F.D., 2007. Saliva specimen: A new laboratory tool for diagnostic and basic investigation. 383(1-2), pp.30-40.

Clark, N. et al., 2010. Improvements of Vehicle Fuel Economy Using Mechanical Regenerative Braking. SAE International, 1967(01).

Crowe, C.T., Sommerfeld, M. \& Tsuji, Y., 1997. Multiphase flows with droplets and particles. CRC Press.

Duguid, J.P., 1946. The size and duration of air-carriage of respiratory droplets and droplet nuclei. 44(6), pp.471-79. 
Efunda, 2011. Properties of Distilled Water. [Online] Available at: http://www.efunda.com/materials/common_matl/show liquid.cfm?matlname=waterdistilled $4 \mathrm{c}$ [Accessed 2011].

EngineeringToolBox, n.d. Sodium Chloride - Water. [Online] Available at: http://www.engineeringtoolbox.com/sodium-chloride-water-d 1187.html [Accessed 17 Nov 2010].

Esser, A.F., Bartholomew, R.M., Jensen, F.C. \& Muller-Eberhard, H.J., 1979. Disassembly of viral membranes by complement independent of channel formation. Proc. Natl. Acad. Sci. USA, 76(11), pp.5843-47.

Fuks, N.A., 1959. Evaporation and droplet growth in gaseous media. London: Pergamon Press.

Gururaja, T.L. \& Levine, M.J., 1996. Solid-phase synthesis and characterization of human salivary statherin: a tyrosine-rich phosphoprotein inhibitor of calcium phosphate precipitation. 9(6), pp.283-89.

Hegde, R., Mastrianni, J. \& Scott, M., 2010. A transmembrane form of the prion protein in neurodegenerative disease. Science, 279(5352), pp.827-34.

Hinds, W.C., 1999. Aerosol technology: properties, behavior, and measurement of airborne particles. Wiley-Interscience.

Jones, A.N., 2002. Density of Milk. [Online] Available at: http://hypertextbook.com/facts/2002/AliciaNoelleJones.shtml [Accessed 17 Nov 2010].

Lindfore, K.R., 1924. Surface Tension of Sugar Factory Products. 16(8).

Makkar, H.P.S., Siddhuraju, P. \& Becker, K., 2007. Plant Secondary Metabolites. Methods in Molecular Biology.

Moyle, A.M., Smidansky, P.M. \& Lamb, D., 2006. Laboratory studies of water droplet evaporation kinetics. In 12th Conference on Cloud Physics. Madison, 2006. American Meteorological Society. 
Muson, B.R., Young, D.F. \& Okiishi, T.H., 1994. Fundamentals of Fluid Mechanics. John Wiley \& Sons, Inc.

Nicas, M., Nazaroff, W. \& A, H., 2005. Toward understanding the risk of secondary airborne infection: emission of respirable pathogens. Journal of Occupational and Environmental Hygiene, 2, pp.143-54. [Accessed 1 March 2011].

NOAA, 2010. Water Density Calculator. [Online] Available at: http://www.csgnetwork.com/h2odenscalc.html [Accessed 17 Nov 2010].

Pierre, P., 1998. A to Z of Thermodynamics. Oxford University Press.

Pruppacher, H.R. \& Klett, J.D., 1978. Microphysics of Clouds and Precipitations. London: D. Reidel Publishing Company.

Racaniello, V., 2009. Influenza virus transmission. [Online] Available at: http://www.virology.ws/2009/04/29/influenza-virus-transmission/ [Accessed 27 Feb 2011].

Ranz, W.E. \& Marchall, W.R., 1952a. Evaporation From Drops Part 1. 48(3), pp.141-46.

Ranz, W.E. \& Marshall, W.R., 1952b. Evaporation from drops part 2. Chemical Engineering Progress, 48(4), pp.173-80.

Redmond, N.E., 2007. MET4 and MET4A Calculation of Dew Point. Paroscientific, Inc.

Redrow, J.B., 2009. An investigation into the theoretical and analytical basis for the spread of airborne influenza. Morgantown: West Virginia University.

Roberts, R.C., Makey, D.G. \& Seal, U.S., 1966. Human Transferrin MOLECULAR WEIGHT AND SEDIMENTATION PROPERTIES. The Journal of Biological Chemistry, 24, pp.4907-13.

Roger, R.R. \& Yau, M.K., 1989. A Short Course in Cloud Physics. Butterworth-Heinemann.

Ro, P.S., Hahlen, T.S. \& Bryant, H.C., 1968. Precision Measurements of Water Droplet Evaporation Rates. 7(5).

Rxlist, 2008. nystop (nystatin topical) drug. [Online] Available at: http://www.rxlist.com/nystopdrug.htm [Accessed 17 Nov 2010]. 
Schipper, R.G., Silletti, E. \& Vingerhoeds, M.H., 2007. Saliva as research material: Biochemical, physicochemical and practical aspects. 52(12).

SImetric, 2010. Summary: Mass, Weight, Density or Specific Gravity of water at various temperatures $C$ and thermal coefficient of expansion of water. [Online] Available at: http://www.simetric.co.uk/si water.htm [Accessed 2010].

Smolik, J., Dzumbova, L., Schwarz, J. \& Kulmala, M., 2001. Evaporation of ventilated water droplet: connection between heat and mass transfer. Aerosol Science, 32, pp.739-48.

Spicer, S.S. \& Martinez, J.R., 1984. Mucin Biosynthesis and Secretion in the Respiratory Tract. Env. Health Perspectives, 55, pp.193-204.

Tartakoff, A.M., 1982. The Role of Subcompartments of the Golgi Complex in Protein Intracellular Transport. 300(1099), pp.173-84.

Trefethen, L., 1969. Film Notes for Surface Tension in Fluid Mechanics. Tufts University.

WBC, 2010. Amylase, Alpha. [Online] Available at: http://www.worthingtonbiochem.com/aa/default.html [Accessed 17 Nov 2010].

Weast, R.C., 1990. CRC handbook of chemistry and physics. 70th ed. Boca Raton: CRC Press.

Weber, T. \& Stilianakis, N., 2008. Inactivation of influenza A viruses in the environment and modes of transmission: a critical review. J. Infect, 57(5), pp.361-73.

Weissenborn, P.K., 2006. Surface Tension of Aqueous Electrolytes. Encyclopedia of Surface and Colloid Science. 


\section{Appendix I}

This appendix shows the calculation of how long the tap water takes to obtain the same temperature with the environment. The initial temperature is not a factor that can influence the result. The solution is contained in a beaker and the shape of water can be considered as a cylinder, which has a volume of $1 \times 10^{-5} \mathrm{~m}^{3}$; the height and the diameter of the section of the cylinder are $0.08 \mathrm{~m}$. There is no obvious convection factor.

Characteristic Length: $L_{c}=\frac{V}{A_{s}}=\frac{1 \times 10^{-5} \mathrm{~m}^{3}}{\pi\left[(0.08 \mathrm{~m})^{2} \times 2+0.08 \times 2 \times 10^{-3}\right]}=2.5 \times 10^{-4} \mathrm{~m}$

Biot number: $B i=\frac{h L_{c}}{K}=\frac{15 \mathrm{~W} / \mathrm{m}^{2} \mathrm{~K} \times 2.5 \times 10^{-4}}{0.58 \mathrm{~W} / \mathrm{mK}}=6.45 \times 10^{-3}<0.1$

Lumped system analysis is valid to solve this problem:

$$
\begin{aligned}
& b=\frac{h A_{s}}{\rho V c_{p}}=\frac{15 \times 0.041}{1000 \times 10^{-5} \times 4200}=0.0146 \mathrm{~s}^{-1} \\
& 0.00001=e^{-b t}=e^{-0.0146 t} \\
& t=13.14 \mathrm{~min}
\end{aligned}
$$




\section{Appendix II}

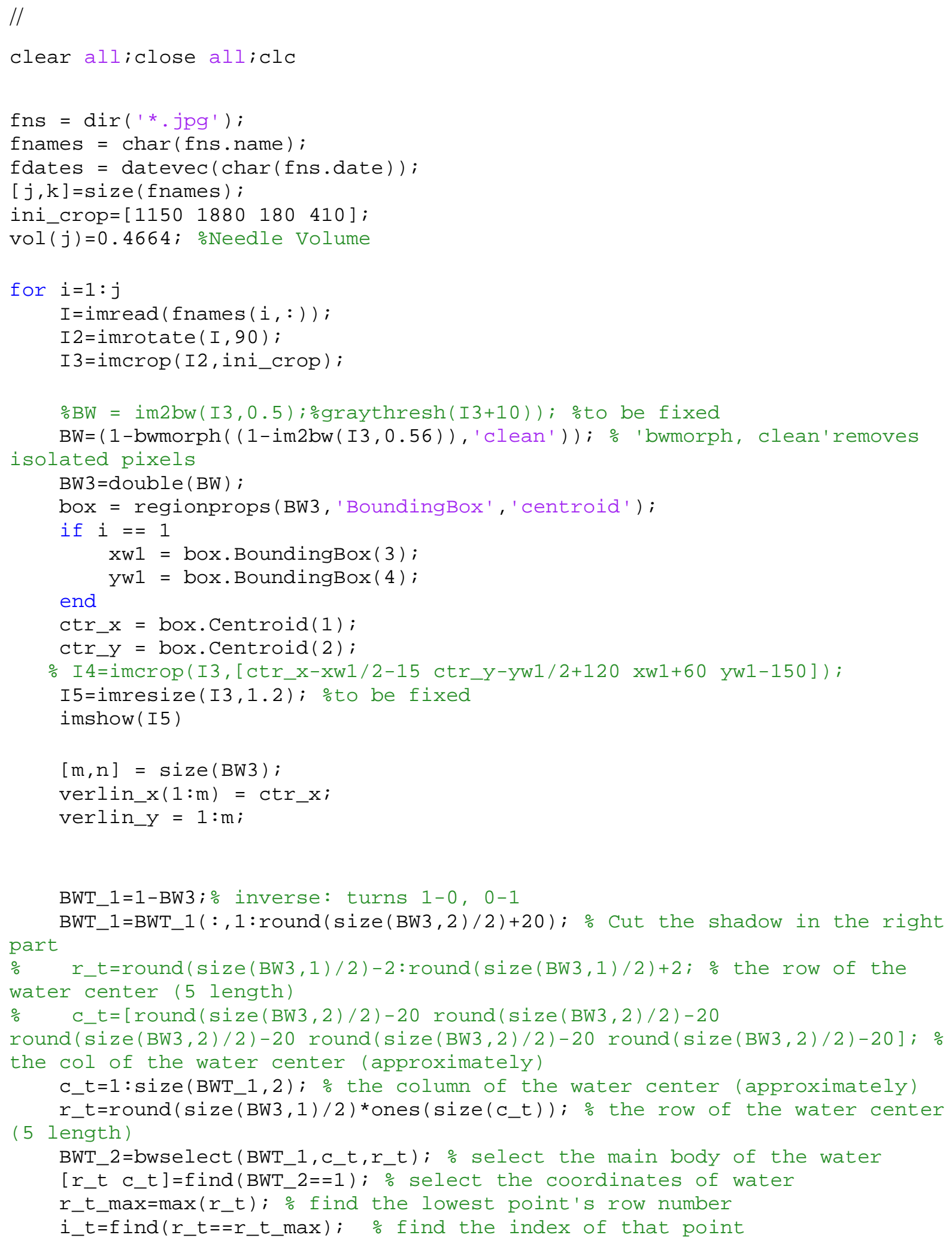




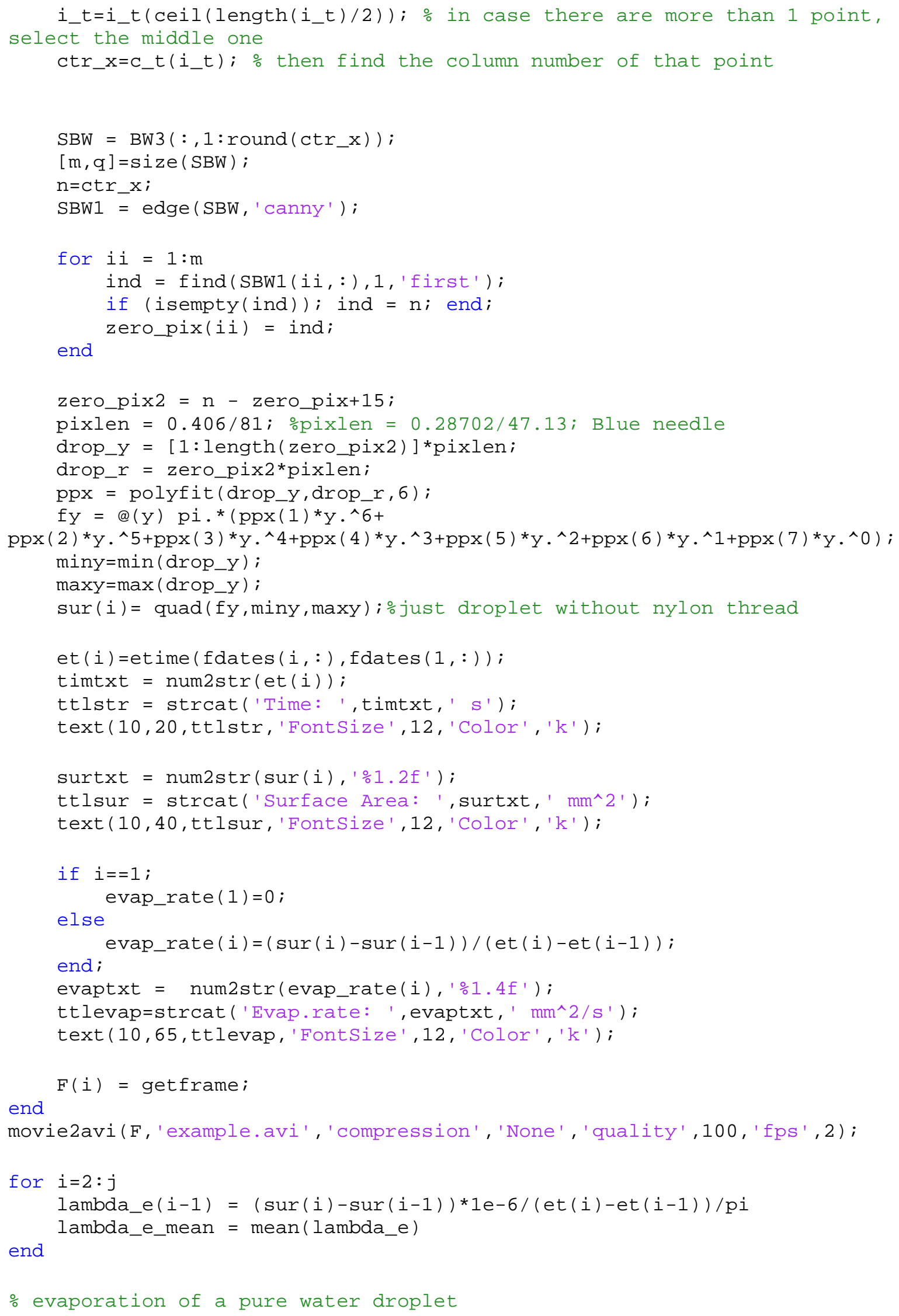




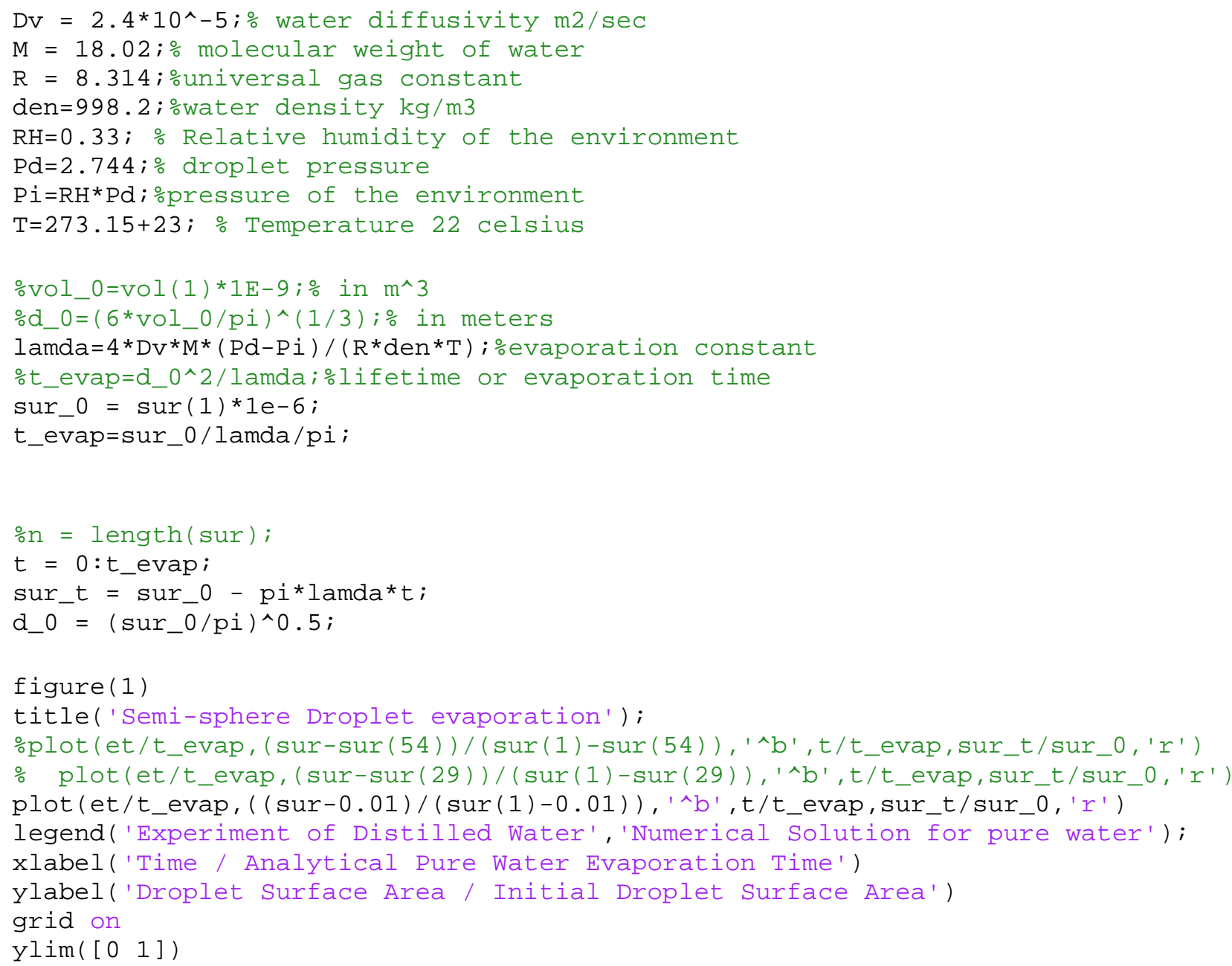




\section{Appendix III}

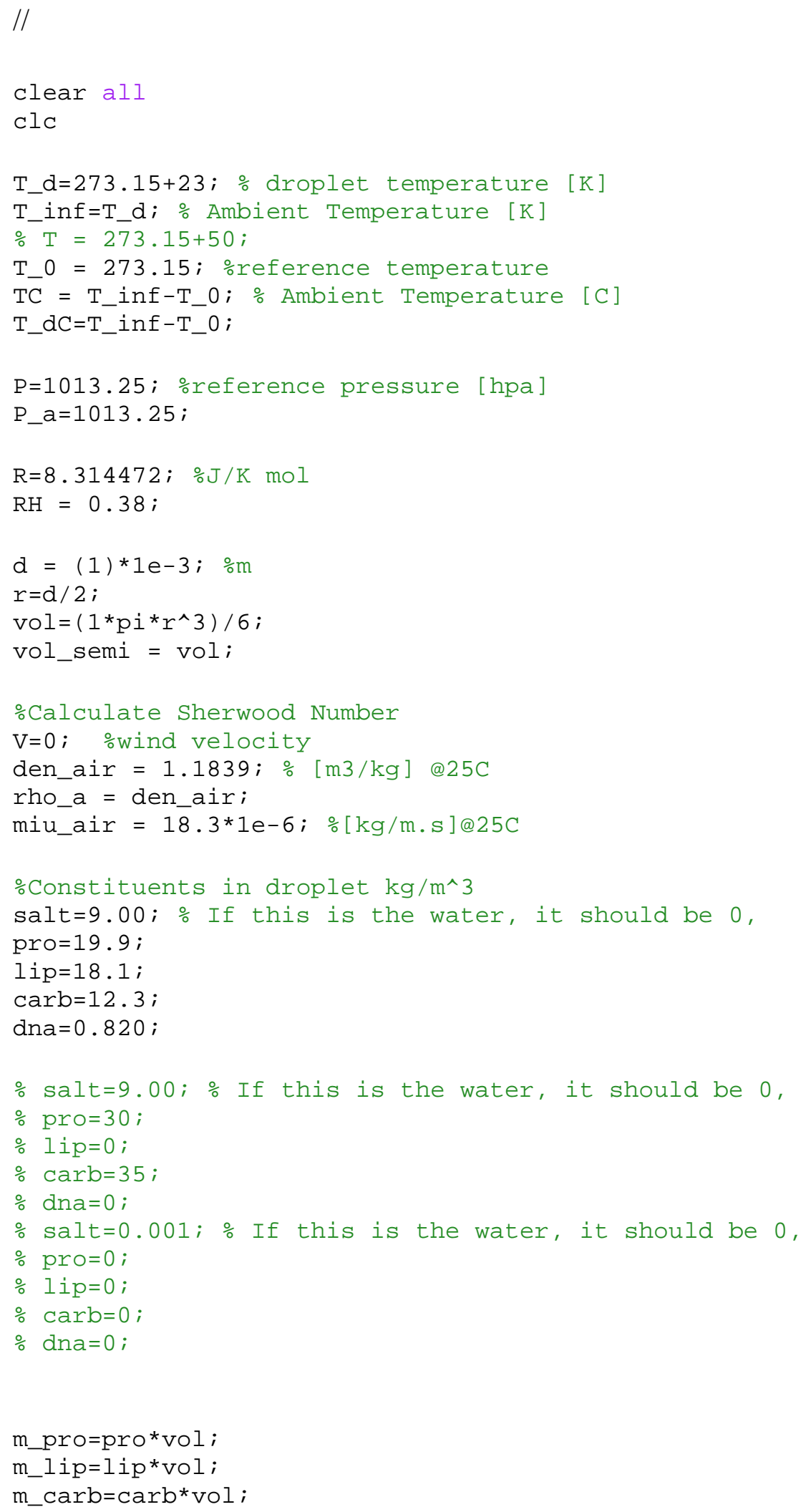




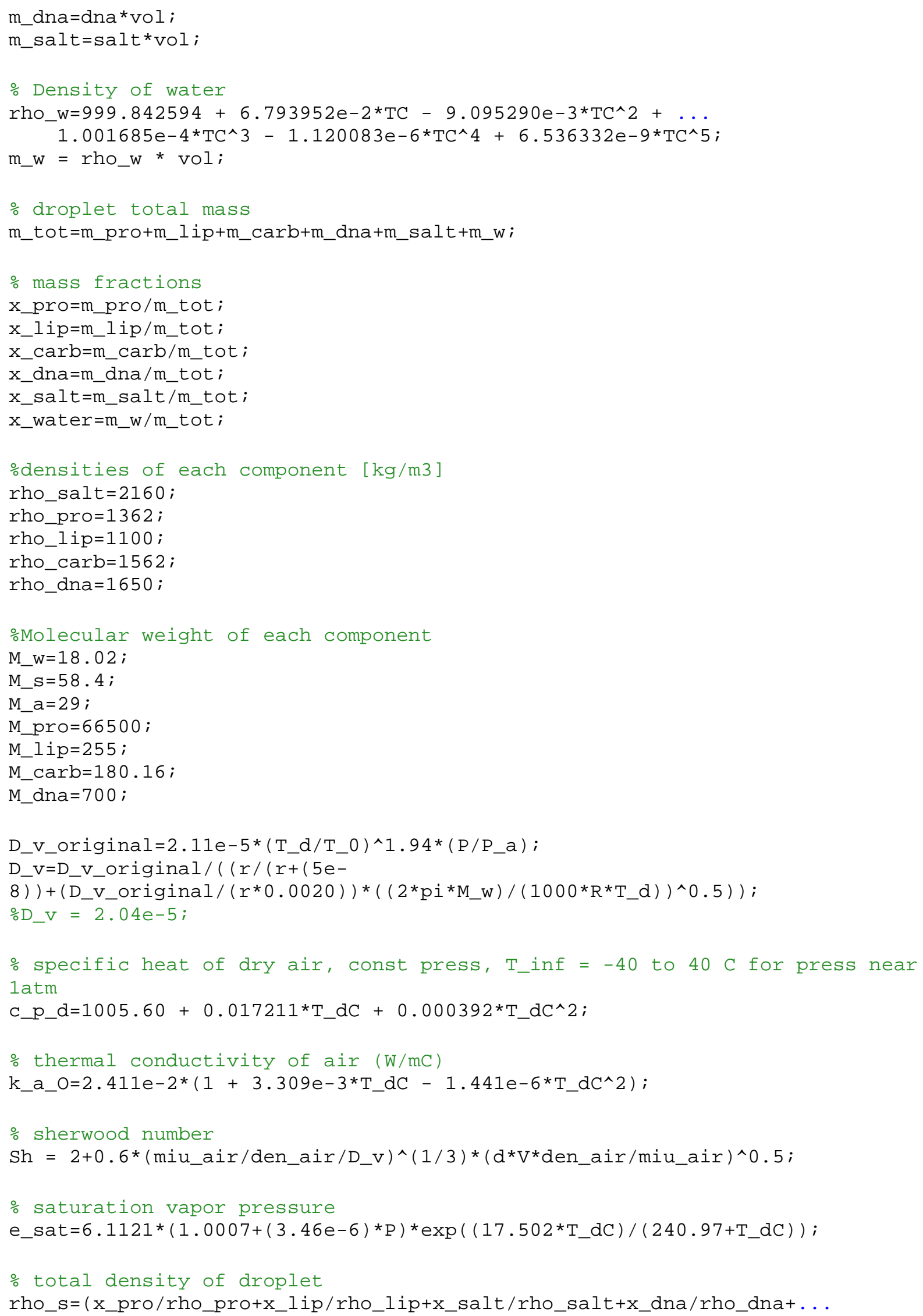




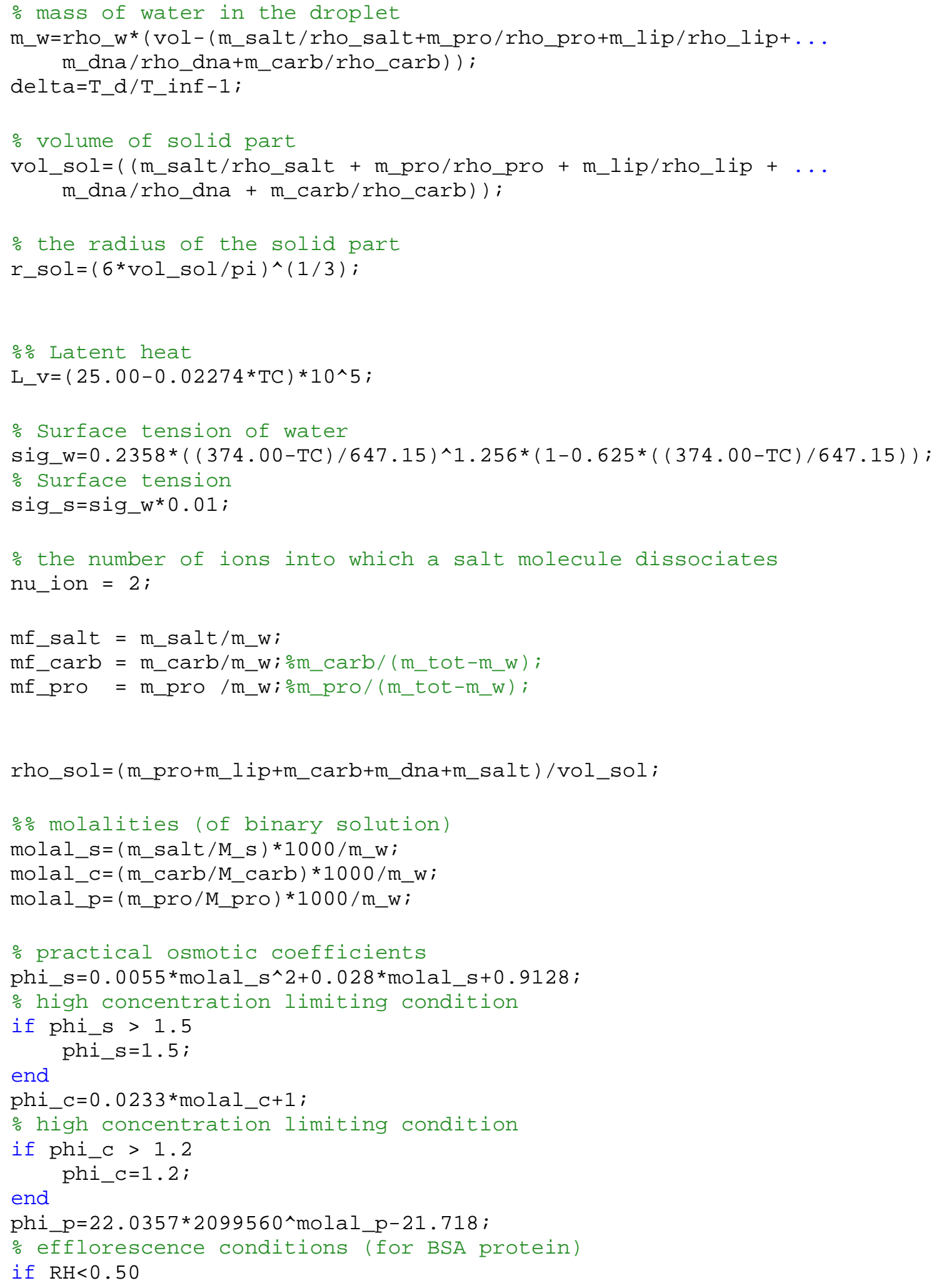




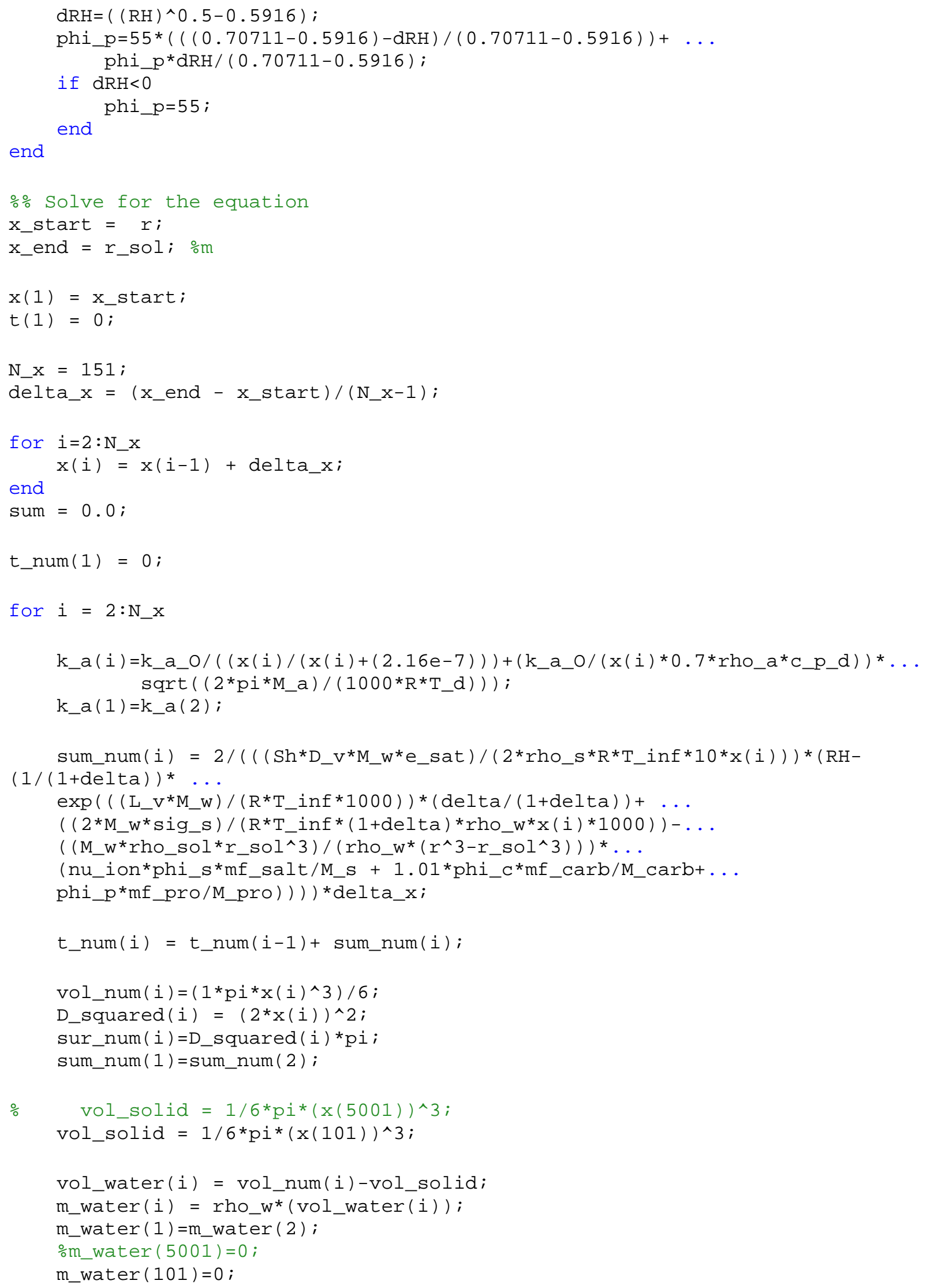




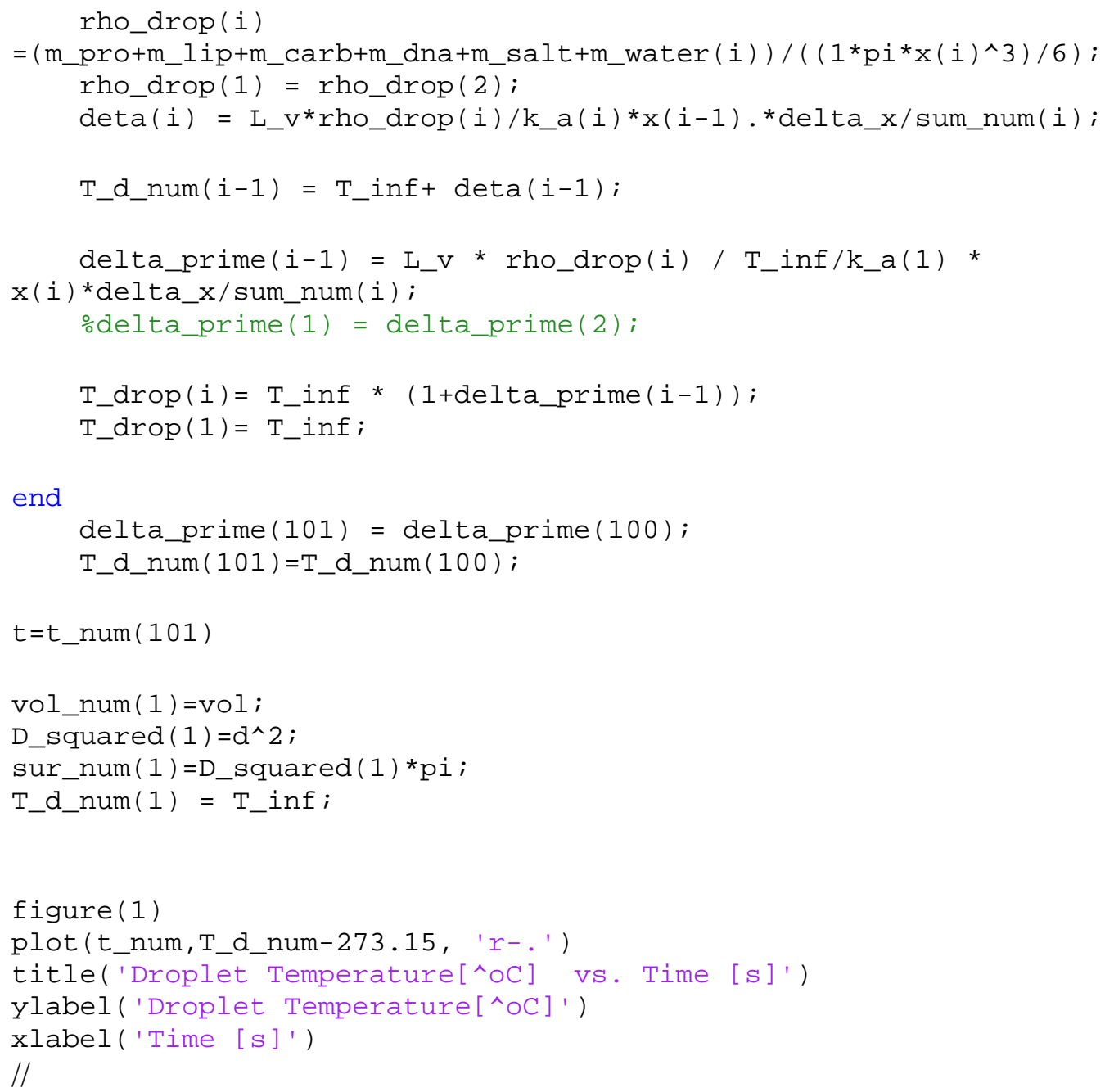

